\title{
${ }^{238} \mathrm{PU}$ FUEL-FORM PROCESSES QUARTERLY REPORT
}

\section{OCTOBER - DECEMBER 1981}
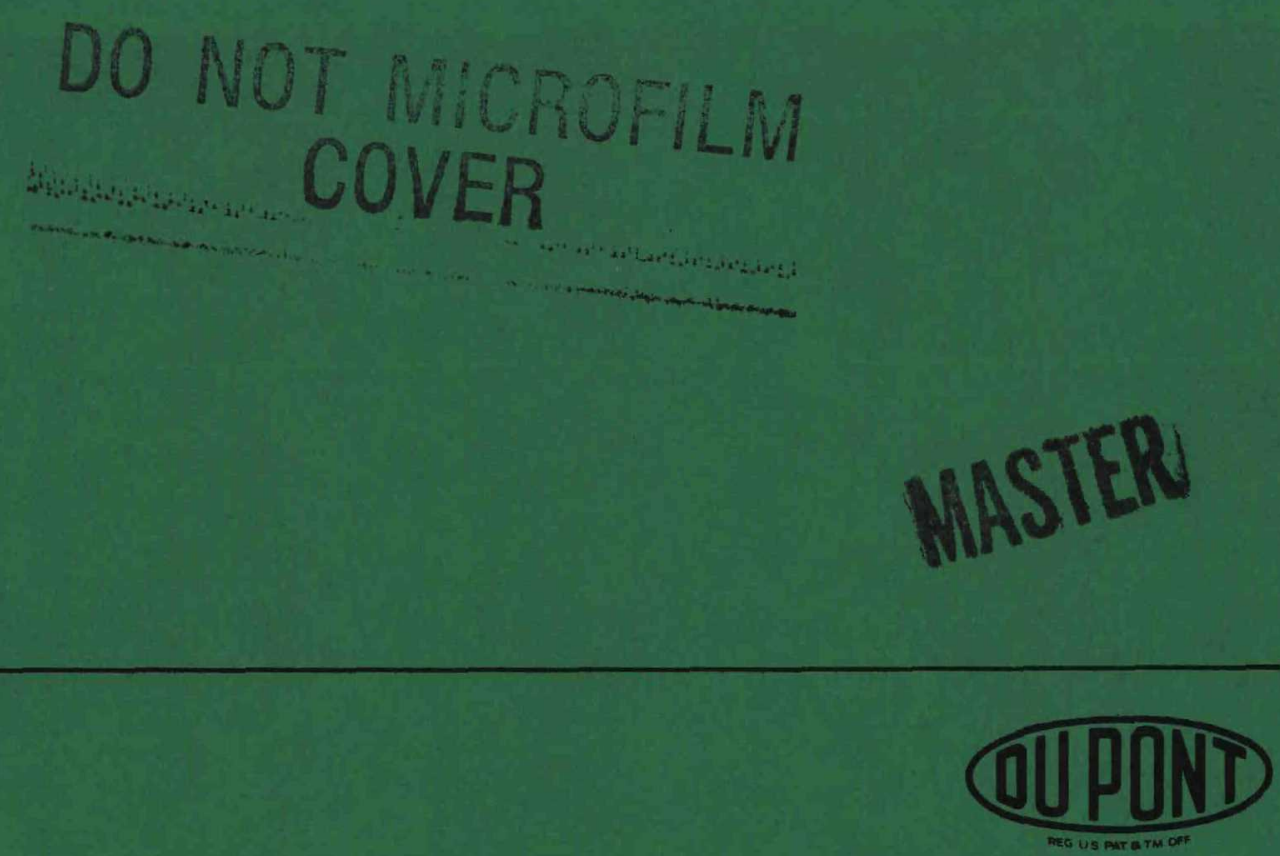

E. I. du Pont de Nemours \& Co. Savannah River Laboratory

Aiken, SC 29808 


\section{DISCLAIMER}

This report was prepared as an account of work sponsored by an agency of the United States Government. Neither the United States Government nor any agency Thereof, nor any of their employees, makes any warranty, express or implied, or assumes any legal liability or responsibility for the accuracy, completeness, or usefulness of any information, apparatus, product, or process disclosed, or represents that its use would not infringe privately owned rights. Reference herein to any specific commercial product, process, or service by trade name, trademark, manufacturer, or otherwise does not necessarily constitute or imply its endorsement, recommendation, or favoring by the United States Government or any agency thereof. The views and opinions of authors expressed herein do not necessarily state or reflect those of the United States Government or any agency thereof. 


\section{DISCLAIMER}

Portions of this document may be illegible in electronic image products. Images are produced from the best available original document. 


\section{DISCLAIMER}

This report was prepared by E. I. du Pont de Nemours and Company (Du Pont) for the United States Department of Energy under Contract DE-AC09-76SR00001 and is an account of work performed under that Contract. Neither the United States, the United States Department of Energy nor Du Pont, nor any of their employees, makes any warranty, express or implied, or assumes any legal liability or responsibility for the accuracy, completeness, or usefulness of any information, apparatus, product, or process disclosed herein, or represents that its use will not infringe privately owned rights. Reference herein to any specific commerical product, process, or service by trade name, mark, manufacturer, or otherwise does not necessarily constitute or imply endorsement, recommendation, or favoring of same by Du Pont or by the United States Government or any agency thereof. The views and opinions of authors expressed herein do not necessarily state or reflect those of the United States Government or any agency thereof. 
DPST- $-81-128-4$

DE82 018587

\section{${ }^{238} \mathrm{PU}$ FUEL-FORM PROCESSES \\ QUARTERLY REPORT}

\section{OCTOBER - DECEMBER 1981}

Approved by:

R. L. Folger, Research Manager

Hydrogen and Ceramic Technology Division

Publication Date: May 1982

\section{Issued by E. I. du Pont de Nemours 8 Co. Savannah River Laboratory Aiken, SC 29808}

PREPARED FOR THE U. S. DEPARTMENT OF ENERGY UNDER CONTRACT DE-AC09-76SR00001
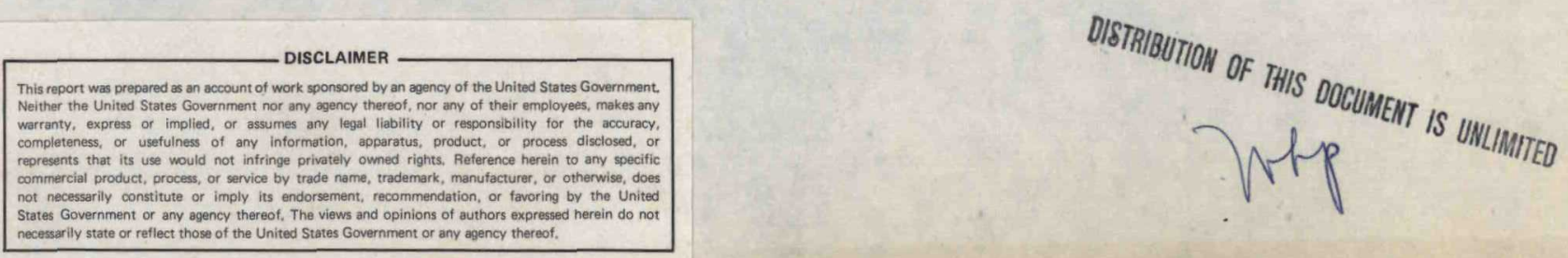
page blank 
Foreword 5

Genera1-Purpose Heat Source (GPHS) Process Demonstration

Introduction and Summary 6

Extensive cracking of the ${ }^{238} \mathrm{PuO}_{2}$ fuel form prior to encapsulation in the iridium containment shell for heat sources results in increased recycle cost and decreased production efficiency. To better understand this cracking, Savannah River Laboratory (SRL) has made an extensive review of the development of ${ }^{38} \mathrm{PuO}_{2}$ fuel forms from small-scale Multihundred Watt (MHW) pellets through the current GPHS full-scale pellet production.

Background 6

During the early startup of production of the GPHS pellets at the Savannah River $\mathrm{Pl}$ ant (SRP), cracking of the ${ }^{238} \mathrm{PuO}_{2}$ fuel pellet prior to encapsulation was excessive. Severe cracking of the oxide fuel pellet renders pellet encapsulation impossible, and thus lowers production yields.

Cracking of ${ }^{238} \mathrm{PuO}_{2} \quad 7$

Historically, ${ }^{238} \mathrm{PuO}_{2}$ fuel has almost always been uncracked after hot pressing in a graphite die, but has emerged cracked and fragile from the final heat-treatment furnace.

Effects of Process Variables on Fuel Microstructure and Cracking

Cracking tendency depends on the microstructure of the fuel form and on the hot pressing conditions used to fabricate it. In general, a microstructure of large intershard porosity is more desirable because it allows internal gas to escape more readily and it can absorb more reoxidation strain.

\section{Duplication of LANL GPHS Microstructure 23}

The internal structures of typical GPHS Pellets fabricated at LANL and in the PEF differed significantly. The LANL pellets had severe density gradients and were extensively cracked. 


\section{Conclusion 27}

Cracking in $\mathrm{PuO}_{2}$ fuel hot pressed in graphite dies can be caused by the combined action of $\mathrm{CO} / \mathrm{CO}_{2}$ gas pressure generated and trapped within the fuel and by the tensile stresses in the pellet caused by reoxidation of the fuel.

References 84 
This report is one of a series to summarize progress in the Savannah River Laboratory ${ }^{238} \mathrm{Pu}$ Fuel Form Program. This program is supported primarily by the DOE Advanced Nuclear Systems and Projects Division (ANSPD).

Goals of the Savannah River Laboratory (SRL) program include providing technical support for the production of ${ }^{238} \mathrm{PuO}_{2}$ fuel forms in the Savannah River Plant's (SRP) Plutonium Fuel Form (PuFF) Facility. This part of the program includes:

Demonstration of processes and techniques developed by the Los Alamos National Laboratory (LANL) for production at SRP. Information from the demonstration will provide the technical data for technical standards and operating procedures.

Technical Support to assist plant startup and to ensure continuation of safe and efficient production of high-quality heat-source fuel.

Technical Assistance after startup to accommodate changes in product and product specifications, to assist user agencies in improving product performance, to assist SRP in making process improvements that increase efficiency and product reliability, and to adapt plant facilities for new products. 


\section{INTRODUCTION AND SUMMARY}

Extensive cracking of the ${ }^{238} \mathrm{PuO}_{2}$ fuel form prior to encapsulation in the iridium containment shell for heat sources results in increased recycle cost and decreased production efficiency. To better understand this cracking phenomena, Savannah River Laboratory (SRL) has made an extensive review of the development of $238 \mathrm{PuO}_{2}$ fuel forms from small-scale Multi-hundred Watt (MHW) pellets through the current GPHS full-scale pellet production. From this fabrication data, the effect of a variation of pellet processing parameters on pellet microstructure and cracking is analyzed and correlated. All available evidence suggests strongly that cracking is caused by the combined action of (1) the pressure of $\mathrm{CO} / \mathrm{CO}_{2}$ gas generated during the hot pressing in graphite dies and trapped within the fuel and (2) the tensile stresses in the pellet caused by reoxidation of the fuel.

The key process variables which affect microstructure and cracking appear to be hot pressing temperature, shard sintering temperature and atmosphere, hot press pressure, and rate at which the pressure is applied. The hot press temperature appears to play a major role in controlling gas pressure.

Porosity is the key microstructural characteristic controlling the internal gas pressure, and therefore the cracking, as proposed by this theory. Ideally, for minimum cracking, large intershard pores are required. However, careful selection and control of the hot pressing parameters can often offset the effects of fine porosity.

\section{BACKGROUND}

During the early startup of production of GPHS pellets at the Savannah River Plant (SRP), cracking of the ${ }^{23}{ }^{8} \mathrm{PuO}_{2}$ fuel pellet prior to encapsulation into the iridium containment capsule was excessive. Severe cracking of the oxide fuel pellet renders pellet encapsulation impossible and thus lowers production yields. Before corrective steps were taken to control pellet cracking in the Plutonium Fuel Form (PuFF) Facility at SRP, yield of usable integral pellets was only about $50 \%$. The high cost associated with recycle of each fractured pellet (approximately $\$ 50,000$ ) makes understanding of the cracking mechanisms necessary so that cracking can 
be controlled. The control of cracking in the PuFF has improved to the extent that recent yields are exceeding $90 \%$.

To understand cracking in $238 \mathrm{PuO}_{2}$, SRL has made an extensive review of previous ${ }^{238} \mathrm{PuO}_{2}$ fuel form fabrication data in an attempt to correlate the effect of pellet processing parameters on pellet microstructure and cracking. This report presents data that have been obtained from the development and production of the Multihundred Watt (MHW) fuel form as well as from GPHS development and production through early 1981. These data are interpreted in terms of a cracking theory that emphasizes the role of gas pressure effects. The effects of critical process variables on gas generation are discussed.

\section{CRACKING OF ${ }^{238} \mathrm{PuO}_{2}$}

Historically, ${ }^{238} \mathrm{PuO}_{2}$ fuel has almost always been uncracked after hot pressing in a graphite die, but has emerged cracked and fragile from the final heat-treatment furnace. During 1977, in early MHW development work, extensive cracking was observed in small-scale $18 \mathrm{~g} 238 \mathrm{PuO}_{2}$ pellets. The ceramographic results obtained from these $18-\mathrm{g}$ pellets strongly suggested that cracks resulted from the reduction of $\mathrm{PuO}_{2}$ to $\mathrm{PuO}_{2-\mathrm{x}}$ by reaction of the oxide with the graphite die during hot pressing. The two cracking mechanisms arising from this reduction are (1) $\mathrm{co} / \mathrm{CO}_{2}$ gas formation during hot pressing and (2) tensile stresses caused by a disparity in densities arising from a phase change when the $\mathrm{PuO}_{2-x}$ is reoxidized to stoichiometric $\mathrm{PuO}_{2}$ during final heat treatment after hot pressing. The effects of these two mechanisms on cracking depend fundamentally upon the amount of reduction (and thus amount of gas generated) and the size and distribution of the pores within the fuel. Since oxide reduction and pellet porosity are controlled by a few critical process variables, the key to eliminating or controlling pellet cracking is proper setting and control of these variables.

The proposed mechanisms for fuel cracking can be briefly explained as follows. $\mathrm{CO} / \mathrm{CO}_{2}$ gas is generated during hot pressing by the carbothermic reduction of $\mathrm{PuO}_{2}$. This gas leads to internal pressure within the ceramic and causes cracking of the as-pressed fuel as the pressing pressure is reduced. The magnitude of this internal pressure depends on (1) hot pressing conditions, which control gas generation, and (2) pellet porosity, which controls gas escape. Some of the gas is trapped within the fuel as the fuel is cooled. During cooling, the internal pressure is reduced because of lower temperatures and thermodynamic reduction of $\mathrm{CO} / \mathrm{CO}_{2}{ }^{\mathrm{l}}$ according to the reactions: 


$$
\begin{aligned}
& \mathrm{PuO}_{2-\mathrm{x}}+\mathrm{xCO}=\mathrm{xC}+\mathrm{PuO}_{2} \\
& \mathrm{PuO}_{2-\mathrm{x}}+\frac{\mathrm{x}}{2} \mathrm{CO}_{2}=\frac{\mathrm{x}}{2} \mathrm{C}+\mathrm{PuO}_{2}
\end{aligned}
$$

On reheating during final heat treatment, the internal pressure again builds as the trapped gas expands and the carbon reduces the $\mathrm{PuO}_{2}$ to form $\mathrm{CO}_{2} \cdot{ }^{1}$ The internal pressure places the surface in tension. This tension, combined with the tensile stresses from fuel reoxidation that proceeds from the pellet surface inward, causes surface or "mudflat" cracking. When these surface cracks meet internal cracks, the fuel fractures.

Thermal tensile stresses also act on the fuel. However, experience shows that these are probably not one of the primary sources of surface cracking. PEF GPHS pellet No. 7 was subjected to thermal stresses from 10 to 12 thermal cycles between about $800^{\circ} \mathrm{C}$ and $400^{\circ} \mathrm{C}$ over twenty-minute intervals. Pellet No. 7 was also thermally stressed by being exposed to flowing helium for 12 hr at an ambient pellet temperature of $150-200^{\circ} \mathrm{C}$. Following thermal tests, the pellet was sectioned and examined metallographically. No surface cracks or microcracks were found as a result of the thermal stress tests. ${ }^{2}$ Thermal stress on the pellet in the final heat treatment furnace is expected to be much less than that experienced by Pellet No. 7 during the above thermal tests. Therefore, since most pellets crack during final heat treatment, cracking from reoxidation stresses seems more likely than cracking from thermal stress.

\section{Example of Cracking Mechanism}

An example of this cracking mechanism is shown in Figure 1. Two fuel spheres were made: one (Sphere 28) generated more gas than the other (Sphere 26). Sphere 26 (on the left) had a slow release of hot-pressing pressure so that it remained uncracked on the surface in the as-pressed condition. On the other hand, the pressure was instantaneously removed from Sphere 28 at high temperature. This allowed rapid expansion of the internal gas and resulted in at least one large crack visible at the surface (Figure 2).

After reoxidizing at $1380^{\circ} \mathrm{C}$, Sphere 26 was crazed but integral. Sphere 28 had no crazing but had fractured into four pieces (Figure 1). According to the proposed mechanism, Sphere 26 pressurized internally as it heated up at the beginning of the reoxidation heat treatment, putting the surface in tension. That tension, combined with the tensile stresses from the phase change arising 
from reoxidation near the surface, led to the cracking observed. On the other hand, the as-pressed cracks in Sphere 28 were extended by repressurization during reheating until fracture occurred. The fractured surface was stress relieved so that reoxidation stresses did not cause surface cracking. Sphere 28 suggests that reoxidation stresses alone are not sufficient to cause surface cracking. This suggestion has been substantiated by several fuel pellets which have not cracked even after reoxidation (e.g. Pellets 7 and 8 ).

Cross sections of Spheres 26 and 28 show further evidence of the proposed gas-induced cracking mechanism. Figure 3 shows the density variations and internal crack pattern of Sphere 28. Density variations with the low-density core, higher density inner band, and low-density outer band are shown. Also, the cracks start from the core and proceed toward the surface. Both of these effects are consistent with the gas-cracking mechanism.

Figure 4 shows typical microstructures from each of the areas of different density. The micrograph on the right is from the core and shows the large grain growth and pore coalescence typical of sintering with a trapped gas. ${ }^{3}$ In this case, the gas is hindered from getting out of the fuel because of its depth within the fuel and the general difficulty of its escaping from a die. Larger porosity in the middle picture shows the microstructure of the higher density inner band. Gas is expected to escape relatively easily from this band because the permeation distance is shorter and because the band is close to the low-density outer band. Pores did not coalesce in the inner band. The entire center of the sphere probably looked similar to the inner band initially, but at high temperatures, pores coalesced to an increasing extent with depth into the sphere. The outer band (left band) was next to the inductively heated die wall and would have been at higher temperatures during heat up than the inner regions of the pellet. The outer band probably had low density because the gas pressure was present early in the sintering, keeping the pores 1 arge with respect to the grains. Under these conditions, grain growth and pore coalescence did not occur as they did in the core where the grain size was large with respect to the pore size (as in the highdensity inner band). The pores in the outer band remained large with respect to the grains so that pore and grain growth did not occur even after the pressure had subsided.

Sphere 28 cracked when the hot-pressing pressure was released suddenly, and the internal gas tried to escape down the pressure gradient (Figures 3, 5, and 6). Near the core, the large pores probably permitted gas to funnel into a few large escape cracks. These large cracks then split into many smaller gas escape cracks to maintain the flow of the ever increasing gas volume through the dense middle band (Figures 3 and 5 ). As the crack entered the lowdensity outer band, the gas dissipated in the pores (Figures 5 
and 6 ). When the crack tip reached the low-density outer band, the crack propagation velocity was probably high enough (relative to the rate of dissipation of gas in the pores) for the crack to propagate to the surface before dissipation of the gas in the pores reduced the stress intensity at the crack tip sufficiently to blunt the crack.

In contrast to Sphere 28 , Sphere 26 had no visible surface aspressed cracks (although it likely had some internal cracks), but the sphere developed numerous surface cracks during reheating in oxygen (Figure 1). A cross section shows that these surface cracks (Figure 7) started from the outside and progressed inward. This type of crack would be expected from reoxidation cracking, beginning with reoxidation and tensile stress at the surface and working inward with the oxidation front. When the reoxidation surface crack links up with a pre-existing gas crack, fracture can occur.

\section{Evidence of As-Pressed Cracks}

The present cracking mechanism proposes that (1) ${ }^{238} \mathrm{PuO}_{2}$ fuel has internal as-pressed cracks, and (2) sufficient gas can be trapped in porous microstructures to repressurize the fuel during reheating. Figure 8 shows cross sections of twin $18 \mathrm{~g}$ MHW parametric ${ }^{238} \mathrm{PuO}_{2}$ pellets hot pressed simultaneously in different holes of the same die. The pellet on the left shows that the large cracks seen in the heat-treated pellets (right side) were present in the as-pressed condition. In some cases for the small-scale MHW pellets, excessive shard separation was found as pressed (Figure 9), but this separation seemed to heal during heat treatment of the sister pellet (Figure 10). Since the large shard separations do not exist normally in other hot-pressed ceramics, they are presumably caused by trapped gas. By comparison, many GPHS pellets made in PEF had few cracks after heat treatment. Presumably, these pellets were crack free in the as-pressed condition. However, many GPHS pellets made in PuFF were cracked or broken in the as-pressed condition.

\section{Evidence of Trapped Gas}

SRL demonstrated trapping of gas in a $\mathrm{PuO}_{2}$ matrix; ${ }^{1}$ gas formed and trapped during hot pressing of $89 \%$ theoretical density pellets was not removed after reoxidizing for 12 hours at $1370^{\circ} \mathrm{C}$. During this reoxidation, cracks did not develop (Figure 11 , top) even though the fuel was reoxidized to full stoichiometry. However, during reheating the sample to $1550^{\circ} \mathrm{C}$, extensive internal cracking occurred (Figure 11, bottom). During reheating in oxygen, the carbon formed by the reduction of $\mathrm{CO}$ and $\mathrm{CO}_{2}$ by $\mathrm{PuO}_{2-\mathrm{x}}$ during cooling of the pellet after hot pressing is postulated to reoxidize 
in the pores and grain boundaries. This carbon then combines with the residual gas already in the pores to pressurize the pellet. At $1370^{\circ} \mathrm{C}$, the pressure did not exceed the tensile strength of the pellet, but at $1530^{\circ} \mathrm{C}$, it apparently did.

To test the hypothesis of trapped carbon within the fuel, $\mathrm{CeO}_{2}$ - a chemical analog of $\mathrm{PuO}_{2}$ - was pressed into small 1/4-inchdiameter pellets, heated, and then examined for carbon on an internal fracture surface with Auger spectroscopy. The $\mathrm{CeO}_{2}$ standin was necessary because the Auger system was not equipped to handle radioactive materials. One set of pellets was cold pressed in a graphite die and heated to $1550^{\circ} \mathrm{C}$ in vacuum without removing the pellets from the die. A second set was cold pressed in steel dies and heated in air to $1550^{\circ} \mathrm{C}$. The carbon-to-cerium ratio $(\mathrm{C} / \mathrm{Ce})$ on the fracture surface at the center of the pellets for those pellets heated in graphite was 0.22 . The $\mathrm{C} / \mathrm{Ce}$ ratio for pellets heated in air was 0.03. Although the Auger analyses could not distinguish whether the carbon was elemental carbon or adsorbed $\mathrm{CO}_{2}$, the analyses clearly showed that heating the $\mathrm{CeO}_{2}$ in contact with graphite resulted in an enhanced concentration of carbon in some form within the pellet.

The carbon is expected to be transported by permeation of co and $\mathrm{CO}_{2}$ gases rather than by diffusion of elemental carbon. Diffusion of carbon into the core of the full-sized fuel pellets where gas effects have been observed would require a diffusion coefficient as high as $10^{-4} \mathrm{~cm}^{2} / \mathrm{sec}$. Such a high diffusion coefficient seems unlikely, especially in a system where the carbon will react to form $\mathrm{CO} / \mathrm{CO}_{2}$ gases. Data on carbon diffusion in oxides are rare in the 1 iterature. One source ${ }^{4}$ reported carbon diffusion in $\mathrm{BeO}$ to have a diffusion coefficient of $\sim 10^{-10} \mathrm{~cm}^{2} / \mathrm{sec}$. However, carbon diffusion coefficients in oxides having cations with additional, lower oxidation states would be expected to be different from oxides having cations with single oxidation states.

In the following sections, the cracking theory is used to explain cracking and microstructure effects observed in (1) MHW parametric and production spheres, 5,6 (2) 18-g MHW parametric study pellets, ${ }^{7}$ (3) small-scale development pellet's, 1 (4) GPHS process development pellets made in the Plutonium Experimental Facility (PEF), $2,8-11$ and (5) GPHS pellets produced in the PuFF facility for production. Observations on each of the above fuel types suggest that the same mechanism caused the cracking observed in both the MHW and GPHS production fuel forms. The principal guide to understanding the cracking mechanism has been the parametrically produced $18-\mathrm{g}$ MHW pellets. The statistically designed nature of the fabrication schedule of these pellets allowed assessment of effects of individual variables (main effects) or of combinations of variables (interactions). 


\section{EFFECTS OF PROCESS VARIABLES ON FUEL MICROSTRUCTURE CRACKING}

Cracking tendency depends on gas generation and porosity (size and distribution). The key process variables that appear to control gas generation and porosity are believed to be hot press temperature, shard sintering temperature, hot press pressure, and pressure ramp. The effects of these four variables were obtained from the parametric evaluation tests conducted in the PuFF facility. -7 $^{-7}$ The conditions for the experimental statistical study of the $18 \mathrm{~g}$ pellets are given in Tables 1 and 2. A discussion of the key process variables is presented in the following sections.

\section{Effect of Hot Press Temperature}

Statistical evaluation of the $0 / M$ ratio for the twelve MHW parametric pellets showed that of the four process variables being evaluated, only hot press temperature had a significant effect ( $>90 \%$ confidence leve 1 ) on the $0 / M$ ratio. Therefore, the amount of gas generated is determined primarily by the hot press temperature.

Trapped gas affects porosity, hence the effects of process variables on gas generation and trapping $c$ an be assessed from examination of the fuel microstructure. Conditions that promote gas generation are high temperature for hot pressing and, to a lesser extent, low shard sintering temperature. Conditions that promote gas trapping are low shard sintering temperature, high hot pressing pressure, and rapid pressure ramp. Low shard sintering temperature and high hot pressing load lead to smaller pores and capture of more of the released gas.

The effects of high and low hot pressing temperature (HPT) on pore size are compared in Figure 12 for different combinations of equivalent settings of shard sintering temperature (SST), hot press pressure (HPP) and pressure ramp (RAMP). For low shard sintering temperature, high hot press pressure and fast pressure ramp (i.e., conditions that promote and trap gas, Figure 12a), high hot press temperature appears to produce larger intershard pores than does low hot press temperature. This result is pore coursening caused by gas pressure. Fuel produced by this combination of variables usually cracks severely. For high shard sintering temperature, high hot press pressure and slow pressure ramp [conditions for low gas generation and moderate trapping (Figure 12b)], high hot pressing temperature appears to produce finer porosity. This result indicates a lack of trapped gas.

For low shard sintering temperature, low hot press pressure, and slow pressure ramp [conditions for high gas generation and low 
TABLE 1

Settings of Process Variables for Fabrication of MHW Fuel Pellets According to the Statistically Designed Experiment ${ }^{7}$

Process Variable

Experimental Level

$+\stackrel{-*}{\text { Exper }}$

Shard Sintering Temperature (SST), ${ }^{\circ} \mathrm{C} \quad 1300 \quad 1150$

Hot Press Pressure (HPP), psi $2950 \quad 875$

Pressure Ramp (Ramp), sec** $10 \quad 180$

Hot Press Temperature (HPT), ${ }^{\circ} \mathrm{C} \quad 1550 \quad 1450$

* The "+" or "-" code will be used throughout this report to refer to the high or low setting of the process variable.

** Time from initiation of pressing load ramp to final load or pressure.

TABLE 2

Permutation of Settings of Process Variables for Statistically Designed Experiment (MHW 18-g pellets) ${ }^{7}$

MHW Pellet Permutation of Variable*

Run No.

SST HPP Ramp HPT

1

2

3

4

5

6

7

8

9

10

11

12

$\begin{array}{llll}- & - & + & - \\ - & + & - & + \\ + & - & + & + \\ - & + & + & - \\ + & + & - & + \\ + & - & + & + \\ - & + & + & + \\ + & + & + & - \\ + & + & - & - \\ + & - & - & - \\ - & - & - & + \\ - & - & - & -\end{array}$

SST = Shard Sintering Temperature

HPP $=$ Hot Press Pressure

Ramp = Pressure Ramp

HPT $=$ Hot Press Temperature 
trapping capability (Figure 12c)], high hot press temperature again produces finer porosity than at low temperatures. In this case, even with high gas generation, the microstructure is too open to retain the gas. These different conditions serve to illustrate the interactive nature of the four key parameters.

\section{Bffect of Shard Sintering Temperature}

Although shard sintering temperature cannot affect the thermodynamics of fuel reduction (theoretical $0 / \mathrm{M}$ ratio) it is expected to affect the kinetics of reduction to give a similar effect as hot pressing temperature as shown by the following example.

The effects of high and low shard sintering temperature on fuel porosity are compared for different combinations of equivalent settings of hot press pressure and temperature in Figure 13. Combinations in which pressure ramp was also constant were not available. However, porosity is not a strong function of ramp as will be shown later, therefore, the effect of nonconstant ramp should be small. For low hot press temperatures, increasing the shard sintering temperature results in increasing the intershard pore size at either high or low settings of hot press pressure (Figure 13a and 13b). However, for high hot press temperatures, the intershard porosity is coarser for shards fired at low temperature (Figure 13c and 13d). One possible explanation for this is that pore coarsening may result if more gas is formed and trapped in the fuel during pressing at the higher temperature. This coarsening effect appears to have a temperature threshold that is a function of the amount of gas generated. The more gas that is generated, the lower the threshold hot press temperature required to see the effect of low shard sintering temperature leading to pore coarsening. On the average, the oxygen-to-metal (O/M) ratio of MHW fuel hot pressed at $1530^{\circ} \mathrm{C}$ is 1.84 compared to 1.93 for GPHS. More reduction implies that gas evolution from MHW shards is a kinetic rather than a thermodynamic effect. Hence, pore coarsening occurs in low-fired MHW shards hot pressed at $1530^{\circ} \mathrm{C}$ as seen in the MHW pellets. In contrast, pore coarsening does not seem to occur in SRL GPHS pellets (made with grog feed sintered in argon) below a hot press temperature of about $1575^{\circ} \mathrm{C}$.

\section{Effect of Hot Press Pressure}

No statistically significant effect of pressure on $0 / M$ was found. The effects of high and low hot press pressure on fuel porosity are compared for different combinations of equivalent settings of shard sintering temperature, pressure ramp, and hot press temperature in Figure 14. As shown in the figure, porosity becomes finer as hot press pressure increases. This was true for 
all combinations of shard sintering temperature and hot press temperature tested. However, for high-fired shards, combined with low hot press temperature and pressure ramp, changing the hot press pressure had only a small effect on porosity.

\section{Effect of Pressure Ramp}

Faster ramp pressure increases the internal volume of cracks. Statistical evaluation of the parametric MHW pellets reveals that the volume of internal cracks within each pellet is a moderately strong function of the pressure ramp. The statistical experiment tested a 10-sec and 3-min ramp. In comparison, GPHS Pellets 30 and 33, which were fabricated in the Plutonium Experimental Facility (PEF), tested a 5-min and a 1-min ramp, respectively. Surface cracks on Pellet 33 were more numerous that were those on centerline pellets. Metallographic cross sections (Figures 15a and 15b) reveal that PEF GPHS Pellet 33 had more internal cracks than did Pellet 30 , but Pellet 33 cracking was not extensive. Microstructurally, both pellets were nearly the same (Figures 16a and 16b). From these examples, the inference on effect of pressure ramp is that more gas is trapped with faster ramps. However, pore coarsening as a function of pressure ramp was not observed with the MHW statistical pellets. Instead, nonuniformity in density was seen. This nonuniformity is shown in Figure 17 where the effect of fast and slow pressure ramp on fuel porosity are compared for different combinations of equivalent settings of shard sintering temperature, hot press pressure, and hot press temperature. As shown in Figure 17, very rapid pressure ramps applied in conjunction with high hot press pressure have the effect of disturbing the uniformity of the pore size distribution leaving both high- and low-density regions. However, no noticeable pore coarsening is observed. Differences of pore size within each pellet of the comparison pe1lets are greater than are differences between the pellets (cf Figures 18 and $17 \mathrm{~b}$ ).

\section{Effects of Interactions Among Process Variables}

Two process variables are said to interact when the effect of one variable on a process depends on the setting of the other variable. The interactive nature of the shard sintering temperature and the three major hot press variables (hot press pressure, pressure ramp, hot press temperature) has already been indicated. This section deals with specific interactions between sets of variables. 


\section{Interaction Between Shard Sintering Temperature and Hot Pressure Temperature}

Previous sections have shown that the effect of hot press temperature on fuel porosity depended on the shard sintering temperature. For low hot press temperature, increasing the shard sintering temperature caused coarser porosity because of reduced shard sinterability. However, at high hot pressing temperature, under conditions where $\mathrm{CO} / \mathrm{CO}_{2}$ gas could be trapped within the fuel, low shard sintering temperature could actually increase the porosity over that obtained by high shard sintering temprature. The mechanism believed to be responsible for this increased porosity is that of gas-induced pore coalescence (Figures 12 and 13). This pore coalescence provides evidence that the kinetics of reduction of low-fired shards is faster than for high-fired shards. In general, the pore size from combinations of high shard sintering temperature and low hot press temperature are larger than those pores produced by pore coarsening due to low-fired shards and high hot press temperatures. Large pores are desirable because they control gas transport within the fuel, blunt crack tips and accommodate reoxidation strains. However, causing large pores by gas-induced coarsening is evidently self-defeating, because the adverse effects of the gas appears to be greater than the beneficial effects of larger pores.

\section{Interaction of Hot Press Pressure and Pressure Ramp}

The effects of different combinations of hot press pressure and pressure ramp are illustrated in Figure 19. High values of both variables lead to high-density clumps in the microstructure (Figure 19a) which may be caused by internal gas pressure leading to pockets of fuel which are hydrostatically pressed. Lowering the hot press pressure or the ramp reduces the clumping effect. The effect of high hot press pressure and slow pressure ramp is compared to the effect of low hot press pressure and fast pressure ramp in Figures $19 b$ and $19 c$, respectively. The density gradient from the outer band to the inner pellet shown in Figure 19b (but absent in Figure 19c) indicates that high hot press pressure may be a stronger contributor to the clumping than is high pressure ramp.

\section{Interaction Among Hot Press Pressure, Shard Sintering} Temperature and Hot Press Temperature

Since higher pressure leads to smaller pores, high pressure can promote cracking if gas generating conditions are present, 
vis., low shard sintering temperature and high hot pressing temperature. In cases where the gas generation rate has been minimized by using high fired shards and low hot pressing temperature, increasing the hot press pressure may be necessary to close the die to achieve the desired density. Under the above conditions, the net effect is to reduce the cracking tendency. The interaction of the above variables is treated in more detail in Reference 6 .

As shown above, a microstructure of large intershard porosity is, in general, more desirable because it allows internal gas to escape more rapidly and it can absorb more reoxidation strain. However, it is possible to have poor microstructure with unfavorable pore size and distribution and still have few, if any, cracks provided that hot pressing conditions are properly chosen. If pressing conditions which reduce gas generation are chosen, then cracking will not be observed, even in pellets with small porosity. An example of this is shown in Figure 20, PEF GPHS Pellet 24 which had relatively fine porosity compared to ideal centerline porosity. Because of well-chosen hot pressing conditions, only a few minor cracks were observed. In contrast, MHW Sphere 28 had regions of coarse porosity; but because of poorly chosen hot pressing conditions, it was extensively cracked. (This sphere was a parametric sphere and had cracked during hot pressing prior to final heat treatment.) The key fabrication condition for each fuel form are given in Table 3 .

\section{TABLE 3}

Key Fabrication Conditions for PEF GPHS Pellet 24 and Parametric MHW Sphere 28

\section{Fabrication Condition}

Shard sintering

Temperature, ${ }^{\circ} \mathrm{C}$

Shard Sintering Atmosphere

Hot Press Pressure, psi

Ramp, min.

Hot Press

Temperature, ${ }^{\circ} \mathrm{C}$

Hold after Die Closure, min

Pressure Release mode
PEF GPHS

Pellet 24

$60 \% \quad 1100$

$40 \% 1600$

Ar

2800

5

1530

5

Slow during

cool-down

( $\sim 5$ minutes)
MHW Sphere 28

$100 \% \quad 1440$

$\mathrm{Ar} / 5 \% \mathrm{O}_{2}$

3000

$10 \mathrm{sec}$ to $600 \mathrm{psi}$

$1.5 \mathrm{~min} 600$ to

3000 psi

1440

Die did not close

Sudden 
The fabrication conditions for GPHS Pellet 24 that tended to minimize gas formation and gas pressure gradient within the fuel are believed to be the slow release of hot press pressure during cooling. In contrast, MHW Sphere 28 was made using conditions of sudden release of hot pressing pressure (which would tend to create a pressure gradient within the fuel) and high hot press pressure and rapid pressure ramp (which favored gas entrapment).

Hot pressing conditions can be used not only to eliminate pellet cracking, but also to deliberately enhance cracking for a given porosity if engineered cracks are desirable. An example of this is PEF GPHS Pellet 41 which will be discussed later.

\section{Effects of Process Variables During GPHS Development in PEF}

The effects of the key process variables already described and of some additional process variables are used in this section to explain the results obtained on GPHS pellets made in PEF during early development. Although GPHS and MHW processes are different, cracking mechanisms appear to be the same. In general, GPHS pellets are believed to be more crack-free than are MHW fuel spheres for the following reasons.

1. Gas generation is less because of grog feed ( $40 \%$ addition of high fired, dense shards). The high density shards are believed to reduce the kinetics of fuel reduction rather than the thermodynamic potential for reduction. Gas generation is also less because the GPHS centerline hot pressing temperature is $\sim 1525^{\circ} \mathrm{C}$ for GPHS vs. a $1560^{\circ} \mathrm{C}$ for MHW.

2. Intershard pores remain large. This is due in part to use of grog feed. Gas escape will be easier through these large pores than through a maze of smaller pores of equivalent total volume because the path will be less tortuous.

3. Hot press pressure is reduced at a slower rate during cooling than in the MHW process. This cycle avoids the catastrophic failure seen in MHW Spheres 28 to 30 . The MHW process was later operated on a similar cycle, which was effective in reducing cracking.

4. Shorter residence time at maximum hot press temperature, less reduction occurs.

5. Thermal stresses are less severe on cooling. 
In the examples that follow, the effect of test changes in several process variables will be explained, using the proposed gas cracking theory.

\section{Effects of Using Low-Fired MHW Shards and High Hot Pressing Temperature}

These conditions lead to low $0 / M$ ratio and a low density outer band. PEF GPHS Pellet 6 was fabricated using $86 \%$ shards sintered at the MHW shard sintering temperature $\left(1300^{\circ} \mathrm{C}\right)$ and $14 \%$ shards sintered at $1450^{\circ} \mathrm{C} .{ }^{2}$ The pellet was hot pressed at $1550^{\circ} \mathrm{C}$. Consistent with the lack of high-fired shards, the final $O / M$ was 1 ow, 1.905. A low-density outer band was formed (Figure 21a) in this pellet similar to MHW Pellet 2, (Figure 21b) which had a similar combination of low shard sintering temperature ( $100 \%$ of shards sintered at $\left.1150^{\circ} \mathrm{C}\right)^{7}$ and high hot pressing temperature $\left(1550^{\circ} \mathrm{C}\right) .^{7}$ Hot pressing pressure and pressure ramp for GPHS Pellet 6 and MHW Pellet 2 were so similar that significant differences from these variables are not expected (2950 psi and 5 minutes for GPHS $6 ; 2800$ psi and 3 minutes for MHW 2).

\section{Effects of Low Shard Sintering Temperature and Low Hot Pressing Temperature}

GPHS Pellet 16 was made using $60 \%$ low-temperature shards $\left(1050^{\circ} \mathrm{C}\right.$ ) hot pressed at $1475^{\circ} \mathrm{C} .9^{9}$ This is compared (Figure 22) to centerline $\mathrm{Pellet} 17\left(1150^{\circ} \mathrm{C}\right.$ shards; $1525^{\circ} \mathrm{C}$ hot pressing temperature). 10 The very fine porosity of Pellet 16 probably results from the low shard sintering temperature. The intershard porosity around the shards was preserved without pore coarsening because of the low hot pressing temperature. However, even though the extent of reduction was relatively small $(0 / M=1.96$ for Pellet 16 versus 1.94 for Pellet 17), the fine porosity prevented escape of the gas generated and promoted cracking. The small amount of reduction of Pellet 16 is consistent with the MHW parametric experiments which indicated that hot pressing temperature plays a more dominant role than does shard sintering temperature in determining $\mathrm{O} / \mathrm{M}$ ratio. For Pellet 16, the low shard sintering temperature should tend to generate more gas than normal, but its effect is believed to be dominated by the effect of low hot pressing temperature.

\section{Effect of Load Initiation Temperature}

This effect is small for initiation temperatures either less than or greater than centerline. The fabrication conditions of GPHS Pellets 12,13 , and 17 are given in Table $4 .^{8,10}$ The pressure 
ramp was begun for GPHS Pellet 12 at $1100^{\circ} \mathrm{C}$, for GPHS Pellet 17 at $1350^{\circ}$ (centerline), and for GPHS Pellet 13 at $1500^{\circ} \mathrm{C}$ (MHW conditions). Pictures of these heat-treated pellets (Figure 23) show that GPHS Pellet 12 had slightly more-pronounced cracks than GPHS Pellet 13 had. The micrograph of Pellet 17 is not clear but does reveal that large cracks are not present. Close examination of polished sections of these pellets (Figure 24) reveals that GPHS Pellet 12 has more internal cracking than the other two. Pellet 13 appears to have about the same cracking as Pellet 17. Figure 24 also shows that GPHS Pellet 12 has a higher density outer band, which is not present in the other two pellets. It is possible that this denser band leads to more gas trapping in GPHS Pellet 12, which may be responsible for the increased cracking. The internal microstructure for these three pellets is similar (Figure 25), GPHS Pellets 12 and 13 being nearly indistinguishable from each other. GPHS Pellet 17 shows signs of pore coarsening as judged by the larger size of the fine intershard porosity although there is no obvious reason for this and this type phenomena should not occur below $\sim 1575^{\circ} \mathrm{C}$. The similarity of cracking and microstructure as well as $0 / \mathrm{M}$ ratio and bulk density (Table 5) suggest that the effect of load initiation temperature is small for temperatures less than centerline and probably smaller still for temperatures greater than centerline.

TABLE 4

Key Fabrication Conditions for PEF GPHS Pellets 12, 13, and 17

PEF GPHS Pellet No.

GPHS 12 GPHS 13 GPHS 17

Shard Sintering Temperature, ${ }^{\circ} \mathrm{C}$

Low-fired Shards $\quad 1100 \quad 1100 \quad 1100$

High-fired Shards $1600 \quad 1600 \quad 1600$

Shard Sintering Atmosphere

Argon Argon Argon

Hot press pressure, psi $\quad 2800 \quad 2800 \quad 2800$

Temperature of load initiation, ${ }^{\circ} \mathrm{C} \quad 1100 \quad 1500 \quad 1350$

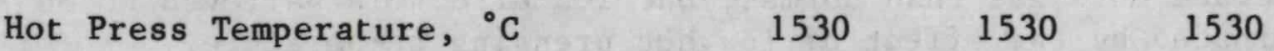

Pressure Release Mode Slow during cooling 
TABLE 5

Oxygen to Metal (O/M) Ratio and Bulk Density for

PEF GPHS Pellets 12, 13, and 17

PEF GPHS Pellet No.

\begin{tabular}{llll}
\hline GPHS 12 & GPHS 13 & GPHS 17 \\
\hline
\end{tabular}

$\begin{array}{llll}0 / M & 1.93 & 1.92 & 1.93\end{array}$

Bulk Density, \% TD $85.1 \quad 84.5 \quad 84.4$

\section{Effect of $2 \%$ Increase in Die Charge}

Increased die charge led to greater internal cracking. Except for an extra $\sim 3 \mathrm{~g}(2 \%)$ of $\mathrm{PuO}_{2}$ charged to the die, Pellet 20 was fabricated under centerline conditions. 10 External cracking after heat treatment was slight (Figure 26a), but internally the microstructure had numerous fine cracks (Figure 26b). Although the extent of intershard porosity was reduced, some large intershard pores remained (Figure 26c). The observed internal cracking suggests that the porosity was too fine to prevent cracking even though the amount of gas generated in this sample was slightly less than the average for GPHS pellets $(0 / M=1.938$ vs. 1.928 for average GPHS pellet).

\section{Effect of Tight Die Punches}

Where the annulus between the punch and die wall is small, as for PEF GPHS Pellet 23,10 gas entrapment occurs leading to considerable internal cracking (Figure 27). Clearance between the punch and die wall for PEF GPHS Pellet 23 was $<0.0005$ inch. Normally it is 0.002 inch. Pore coarsening in some areas of Pellet 23 were similar to MHW Sphere 28 (Figures $28 \mathrm{a}$ and 28b). In other areas, although pore coalescence occurred, the resultant pore size was not large (Figure 28c). $\mathrm{O} / \mathrm{M}$ for Pellet 23 was 1.92, typical for GPHS.

\section{Effect of Shard Sintering Atmosphere}

Shards sintered in argon/water at Los Alamos National Laboratory (LANL), or argon/oxygen in the PuFF facility appear to be less dense and more reactive during hot pressing than are shards sintered in pure argon in the PEF. 12 The shards fired in argon/water or argon/oxygen behave in an analogous manner to shards fired at too low a temperature and lead to considerable cracking as shown (Figure 29) for PEF GPHS Pellet 39. This pellet was made with shards sintered in argon/oxygen in PuFF. At present, data are insufficient for determining whether shard sintering atmosphere 
affects the $0 / M$ ratio during hot pressing, although some observations point in that direction. (For example, LANL pellets have typical $0 / \mathrm{M} \sim 1.88-1.90$. However, there is also some evidence to suggest that LANL pellets have been hot pressed at a higher hot press temperature.)

\section{Effect of Combination of Gas-Producing Fabrication Conditions}

As shown in Table 6 , several fabrication conditions for PEF GPHS Pellet 37 were set to maximize gas generation and entrapment and reduction: oxidizing shard sintering atmosphere, high hot press pressure $(5400 \mathrm{psi})$, fast pressure ramp (10 sec), long soak at maximum hot press temperature $(15 \mathrm{~min})$. Hot press temperature and shard sintering temperature were centerline, but as shown above, sintering in $\mathrm{Ar} / \mathrm{O}_{2}$ has a similar effect as low sintering temperature. These conditions led to substantial pore coarsening (Figure 30 ). The large grains are mostly clear of small pores, indicating that pore growth occurred by pore coalescense.

\section{TABLE 6}

Fabrication Conditions for PEF GPHS 37

\begin{tabular}{|c|c|c|}
\hline & GPHS 37 & $\begin{array}{l}\text { PEF } \\
\text { Centerline }\end{array}$ \\
\hline Shard Sintering Temperatures, ${ }^{\circ} \mathrm{C}$ & $\begin{array}{l}1100 \\
1600\end{array}$ & $\begin{array}{l}1100 \\
1600\end{array}$ \\
\hline Shard Sintering Atmosphere & $\mathrm{Ar} / 5 \% \mathrm{O}_{2}$ & Ar \\
\hline Preload, lbs & 0 & 200 \\
\hline Hot Press Pressure, psi & 5400 & 2800 \\
\hline Pressure Ramp & $10 \mathrm{sec}$ & $5 \mathrm{~min}$ \\
\hline Hot Press Temperature & 1525 & 1525 \\
\hline Time of Temperature after Die Closure, min & 15 & \\
\hline Pressure Release Mode & slow, dur & ig cool down \\
\hline
\end{tabular}

Microstructures similar to that of Pellet 37 are typical for entrapped gas. In fact, gas pressure was high enough to cause grainboundary separation, giving the appearance of etching to the aspolished section shown in Figure $30 \mathrm{a}$. At higher magnification on an etched specimen (Figure $30 \mathrm{~b}$ ), grain-boundary separations are easily distinguished from etched grain boundaries by the low dihedral angle (rounding of grains at 3 -grain intersections). High gas pressure is also confirmed by the low $\mathrm{O} / \mathrm{M}$ ratio of this pellet $(0 / \mathrm{M}-1.80)$. Comparing the microstructure of Pellet 37 to that of a more normal pellet at low magnification (Figure 31 ), it is clear that the large 
pores could act as crack initiators. The relative lack of cracking (Figure 32) may be due to the slow pressure release and the high hot pressing pressure, which may have exceeded the highest gas pressure.

Further examination of Pellet 37 reveals that the large pores were probably formed before die closure. The vertically elongated shape of the pores near the pellet surface were probably caused by shear of the region next to the die wall over the inner portion of the pellet (Figure 33).

\section{DUPLICATION OF LANL GPHS MICROSTRUCTURE}

\section{Pellet Cracking}

The internal structures of GPHS pellets fabricated at LANL and in the PEF ostensibly using LANL hot pressing conditions differed significantly. The LANL pellet had severe density gradients and was extensively cracked. ${ }^{8}$ The SRL pellet (No. 32) had almost no density gradients and only a few cracks. The difference was surprising (Figure 34) since SRL was attempting to duplicate the LANL conditions. Perhaps more surprising is the similarity of the LANL pellet microstructure to that of MHW Sphere 28 (Figure 35), which suggests that the same mechanism caused the cracking and density gradients in both fuel forms. A series of pellets were made in the PEF in an effort to duplicate the cracked LANL microstructure. The fabrication conditions for these pellets and the LANL pellet are given in Table 7 . A description of these pellet fabrication tests follows.

PEF GPHS Pellet 34 was fabricated in an $\mathrm{Ar} / \mathrm{H}_{2} \mathrm{O}$ sintering atmosphere, using shards that were prepared and sintered at LANL. The pellet was hot pressed in an SRL die under LANL hot press conditions. Metallographic examination showed GPHS Pellet 34 had several large internal cracks (Figure 36a) and numerous very small cracks (Figure 36b), but did not duplicate the LANL pellet in cracking or in density gradients. Higher magnification micrographs (Figure 37) of the core of Pellet 34 showed that the pore distribution was similar to that of the LANL pellet but the LANL pore size was larger. The implication from the larger LANL pores that the LANL pellet had higher internal gas pressure during fabrication is supported by the relative $0 / M$ ratio of these two pellets: $O / M=1.93$ for SRL GPHS 34 and $1.88-1.90$ for the LANL pellet. The numerous small cracks of Pellet 34 suggest that this pellet was on the verge of extensive cracking similar to the LANL pellet. Had the gas pressure been higher, as from higher hot press temperature, an extensive crack network might have occurred as in Pellet 41 (Figure 38), which shows the result of a combination of the most likely process deviations expected in the PuFF facility. 
PEF GPHS Pellet 41 had extensive internal cracks similar to the LANL pellet. It also had a density gradient although it was less pronounced than in the LANL pellet. The fabrication parameters for Pellet 41 are given in Table 7 , but the key features of these conditions are (1) low-fired shards and (2) high hot pressing temperature. This pellet was intended to test the result of combining the most likely deviations from centerline hot pressing conditions expected in PuFF. To duplicate the PuFF shard sintering furnace, the shards for Pellet 41 were fired in $\mathrm{Ar} / 5 \% \mathrm{O}_{2}$ with a temperature gradient ranging from $1000^{\circ} \mathrm{C}$ to $1100^{\circ} \mathrm{C}$ for the lowfired shards and a gradient of $1540^{\circ} \mathrm{C}$ to $1600^{\circ} \mathrm{C}$ for the high-fired shards. The maximum hot pressing temperature was $1610^{\circ} \mathrm{C}$. Other process deviations probably had a negligible effect. The fact that this combination of low-fired shards and high hot pressing temperature led to more gas formation than for Pellet 34 is shown by the $0 / \mathrm{M}$ ratio of 1.89 (which is the same as for the LANL pellet). The pore size of Pellet 41 tends to preserve the outline of the original shards, whereas most traces of the original shards have been

\section{TABLE 7}

Fabrication Conditions for SRL Pellets Made to Duplicate Microstructures of LANL GPHS Pellets

\begin{tabular}{|c|c|c|c|c|}
\hline & $\begin{array}{l}\text { GPHS } 34 \\
\text { LANL Shards } \\
\text { and HP } \\
\text { Conditions } \\
\end{array}$ & $\begin{array}{l}\text { GPHS } 35 \\
\text { SRL Shards } \\
\text { and LANL HP } \\
\text { Conditions } \\
\end{array}$ & $\begin{array}{l}\text { GPHS } 36 \\
\text { LANL Shards } \\
\text { and SRL HP } \\
\text { Conditions } \\
\end{array}$ & GPHS 41 \\
\hline Source of Shards & LANL & PEF & LANL & PEF \\
\hline Shard Sintering Temperature & $1100 / 1600$ & Same & Same & $\begin{array}{l}1000-1100 \\
1540-1600\end{array}$ \\
\hline Shard Sintering Atmosphere & $\mathrm{Ar} / \mathrm{H}_{2} \mathrm{O}$ & Ar & $\mathrm{Ar} / \mathrm{H}_{2} \mathrm{O}$ & $\mathrm{Ar} / 5 \% \quad \mathrm{O}_{2}$ \\
\hline Hot Pressing Pressure, psi & 2830 & 2800 & 2800 & 2840 \\
\hline $\begin{array}{l}\text { Temperature of Load } \\
\text { Initiation, }{ }^{\circ} \mathrm{C}\end{array}$ & 1300 & 1350 & 1350 & 1410 \\
\hline Hot Press Temperature, ${ }^{\circ} \mathrm{C}$ & 1530 & 1530 & 1530 & 1610 \\
\hline $\begin{array}{l}\text { ime at Temperature } \\
\text { Die Closure, min }\end{array}$ & 15 & 15 & 5 & 5 \\
\hline
\end{tabular}

obliterated in the LANL pellet (Figure 39). This is thought to be evidence that LANL shards are more easily crushed during pressing than SRL shards. In view of the small pore sizes in both pellets, effects of their respective pore structures on pellet cracking would not be expected to differ significantly. 
PEF GPHS Pellet 35 was produced using SRL shards and LANL hot pressing conditions. Cracking of Pellet 35 (Figure 40a) was less than that of Pellet 34 although still more than for a PEF centerline pellet. Evidence of microcracking is shown in Figure $40 \mathrm{~b}$. Some large intershard porosity is present (Figure $40 \mathrm{c}$ ) but is not as extensive as in PEF centerline pellets (Figure 40d). A comparison of the O/M ratio of Pellet 35 (1.95) and Pellet 34 (1.93) provides some additional evidence that LANL shards are more easily reduced than SRL shards.

PEF GPHS Pellet 36 was made using LANL shards and SRL hot pressing conditions. This pellet showed the least tendency to crack of any of the attempts to reproduce the LANL microstructure (Figure $41 \mathrm{a})$. No tendency for the microcracking seen in Pellets 34 and 35 was apparent (Figure 4lb). The porosity is finer than for centerline SRL pellets (Figures 4lc and 4ld), indicating that the LANL shards are more reactive or more easily crushed than SRL shards. The $0 / \mathrm{M}$ ratio of Pellet 36 was 1.91 , slightly below the average for SRL shards (1.93), which may indicate again more rapid reduction by the LANL shards.

In comparing SRL and the LANL hot pressing conditions, a significant difference is the length of hold at high temperature after die closure ( 15 minutes for LANL versus 5 minutes for SRL). During this temperature hold the possibility exists for additional reduction to occur. The extra gas and resultant reoxidation stresses that attend reduction would lead to the observed cracking.

The progressive effects on cracking of the different combinations of shards and hot pressing conditions used in GPHS Pellets 34 to 36 to simulate the LANL cracking can be seen in Figure 42 . In order of least cracking the combinations run as follows: LANL shards/SRL hot pressing conditions (Figure 42a), SRL shards/LANL hot pressing conditions (Figure 42b), LANL shards/LANL hot pressing conditions (Figure 42c). Since none of these attempts to reproduce LANL microstructure gave pellets as crack free as centerline SRL pellets, it is clear that the combination of SRL shards and hot pressing conditions offers the best crack resistance. Also, since Pellet 35 (SRL shards/LANL hot pressing conditions) had more cracks than Pellet 36 LANL shards (SRL hot pressing conditions), it is possible that the LANL hot pressing conditions contribute more to cracking than the LANL shards. However, the author feels the weight of evidence shows shard sintering conditions to have more affect on cracking than length of time at temperature after die closure (key difference between LANL and SRL hot pressing condition in these tests). 


\section{Pellet Density Gradients}

The low-density outer rind observed on the LANL pellet (Figure 35 ) has also been seen on other GPHS pellets, specifically PEF GPHS Pellets 6 and 41 (Figures 21 and 38). This low-density rind $c$ an be related to low shard sintering temperature and high hot pressing temperature. PEF Pellet 6 had a high percentage of MHW (low-fired) shards and was fabricated above the GPHS centerline temperature. Also, Pellet 41 had deliberately low-fired shards and a very high hot pressing temperature. The available data on the LANL pellet suggest that it too had low temperature shards and also a high hot pressing temperature. As seen above, the LANL shards used to make the LANL pellets behave like low-fired SRL shards (even though they were sintered at centerline temperatures) in that they are more easily reduced and possibly more easily crushed. Although the LANL pellet was reportedly hot pressed at the centerline temperature, there is reason to believe that the temperature was considerbly higher. This belief is based on the following reasons. First, GPHS Pellet 41 was the only pellet showing similar cracking to that of the LANL pellet, and it was heated to $1610^{\circ} \mathrm{C}$. Second, 0/M ratio has been shown to correlate most strongly with hot press temperature. Hence, after being heated to $1610^{\circ} \mathrm{C}$, GPHS Pellet 41 had an $0 / M$ ratio of 1.89 similar to that of the LANL pellet. Also, LANL shards hot pressed at SRL at $1530^{\circ} \mathrm{C}$ were reduced to an $O / M$ of only 1.91 (Pellet 36). Third, the extensive cracking such as that seen in the LANL pellets has only been observed under the dual conditions of low shard sintering temperature and high hot pressing temperature. Since the LANL shards behave like low-fired SRL shards, the hot pressing temperature for the LANL pellet probably was high. Fourth, the larger pore size of the LANL pellet than PEF Pellet 41 suggests that conditions equivalent to low shard sintering temperature and high hot press temperature existed. For these reasons, the possibility exists that the hot pressing temperature used at LANL is at least $50^{\circ} \mathrm{C}$ higher than that used at SRL.

To summarize the work to reproduce the LANL microstructure, LANL shards heated in $\mathrm{Ar} / \mathrm{H}_{2} \mathrm{O}$ give finer porosity in pellets after final heat treatment of the pellet than do SRL shards heated in pure $\mathrm{Ar}$ (Figure 4lc and 4ld). Also, LANL hot pressing conditions lead to finer porosity than SRL hot pressing conditions

(Figures $40 \mathrm{c}$ and $40 \mathrm{~d}$ ) and are more conducive to cracking. The combination of LANL shards and LANL hot pressing conditions should lead to very fine porosity as seen in Pellet 34 (Figure 37a).

The large pores (relative to Pellet 34) and low $0 / \mathrm{M}$ ratio of the LANL pellet examined by SRL support the belief that cracking was due to excess gas pressure. These observations and others suggest that even though the LANL and SRL pellets were supposed to be hot pressed at $1530^{\circ} \mathrm{C}$, the LANL pellet was actually hot pressed 
at a temperature at least $50^{\circ} \mathrm{C}$ higher than that used for the SRL pellets. It is believed that LANL-type microstructures can be produced by using shards fired in $\mathrm{Ar} / \mathrm{O}_{2}$ at temperatues below the $1100^{\circ} \mathrm{C}$ centerline and by hot pressing at temperatures above $1575^{\circ} \mathrm{C}$. The effect might also be enhanced by increasing the relative amount of the low-fired shards above the present $60 \%$ level.

\section{FABRICATION OF PRODUCTION GPHS FUEL IN THE PUFF FACILITY}

\section{Modifications to Reduce Cracking}

Early production pellets fabricated in the PuFF facility were badly cracked. Metallographic examination of these pellets suggested that the cracking was the result of too fine a pore size. In Figure 43 an early PuFF pellet is compared to a PEF centerline pellet and a later PuFF pellet. Of the many process adjustments initiated by the PuFF facility, the following were probably most significant in reducing the cracking: (1) increasing the low-fired shard sintering temperature by $40^{\circ} \mathrm{C}$, and (2) using hydraulic pellet ejector to eject the pellet from the die rather than cutting open the die. This step significantly reduced the mechanical shock of pellet removal, which would have enhanced fracture of internally cracked, as-pressed pellets; (3) Using fresh shards; shards used to fabricate early PuFF pellets had been aged about 2 months. During this time $\mathrm{CO}_{2}$ and $\mathrm{H}_{2} \mathrm{O}$ present in small amounts in the cell atmosphere may have adsorbed on the $\mathrm{PuO}_{2}$ causing additional gas pressure during hot pressing.

As a result of these process adjustments, PuFF GPHS Pellet 54 was considerably less cracked than were previous pellets (Figure 43). Metallographic analysis showed Pellet 54 to have a bimodal pore characteristic with some regions of porosity approaching those of a centerline PEF pellet and other regions with porosity as fine as before (Figure 44). However, the extent of highdensity areas observed in PuFF pellets indicates that cracking tendency will persist.

\section{CONCLUSION}

Cracking in $\mathrm{PuO}_{2}$ fuel hot pressed in graphite dies can be caused by the combined action of $\mathrm{CO} / \mathrm{CO}_{2}$ gas pressure generated and trapped within the fuel and by the tensile stresses in the pellet caused by reoxidation of the fuel. $\mathrm{CO} / \mathrm{CO}_{2}$ gas pressure is believed to be a principal cause of cracking and is controlled by the hot pressing temperature and shard sintering temperature and atmosphere, and to some extent by the hot press pressure, and pressure ramp. Reoxidation tensile stresses initiate at the pellet surface 
during reoxidation and progresses inward. If some internal cracking exists, fracture of the pellet can occur when the reoxidation cracks link with the internal cracks. Porosity is the key microstructural characteristic controlling the internal gas pressure and therefore the cracking. Ideally, for minimum cracking, large intershard pores are required. However, careful selection and control of the hot pressing parameters can often offset the adverse effects of fine porosity.

To minimize cracking at constant hot pressing pressure and pressure ramp, shard sintering temperatures must be at or moderately above centerline $\left(1100^{\circ} \mathrm{C}\right)$, and hot pressing temperatures at or slightly below centerline $\left(1530^{\circ} \mathrm{C}\right)$. Sintering shards in argon only is also helpful. More extensive cracking, similar to that observed in LANL pellets, can be produced by (1) lowering the shard sintering temperature 50 to $100^{\circ} \mathrm{C}$ below centerline and sintering in an oxidizing atmosphere, and (2) by increasing the hot pressing temperature to at least $1575^{\circ} \mathrm{C}$. 


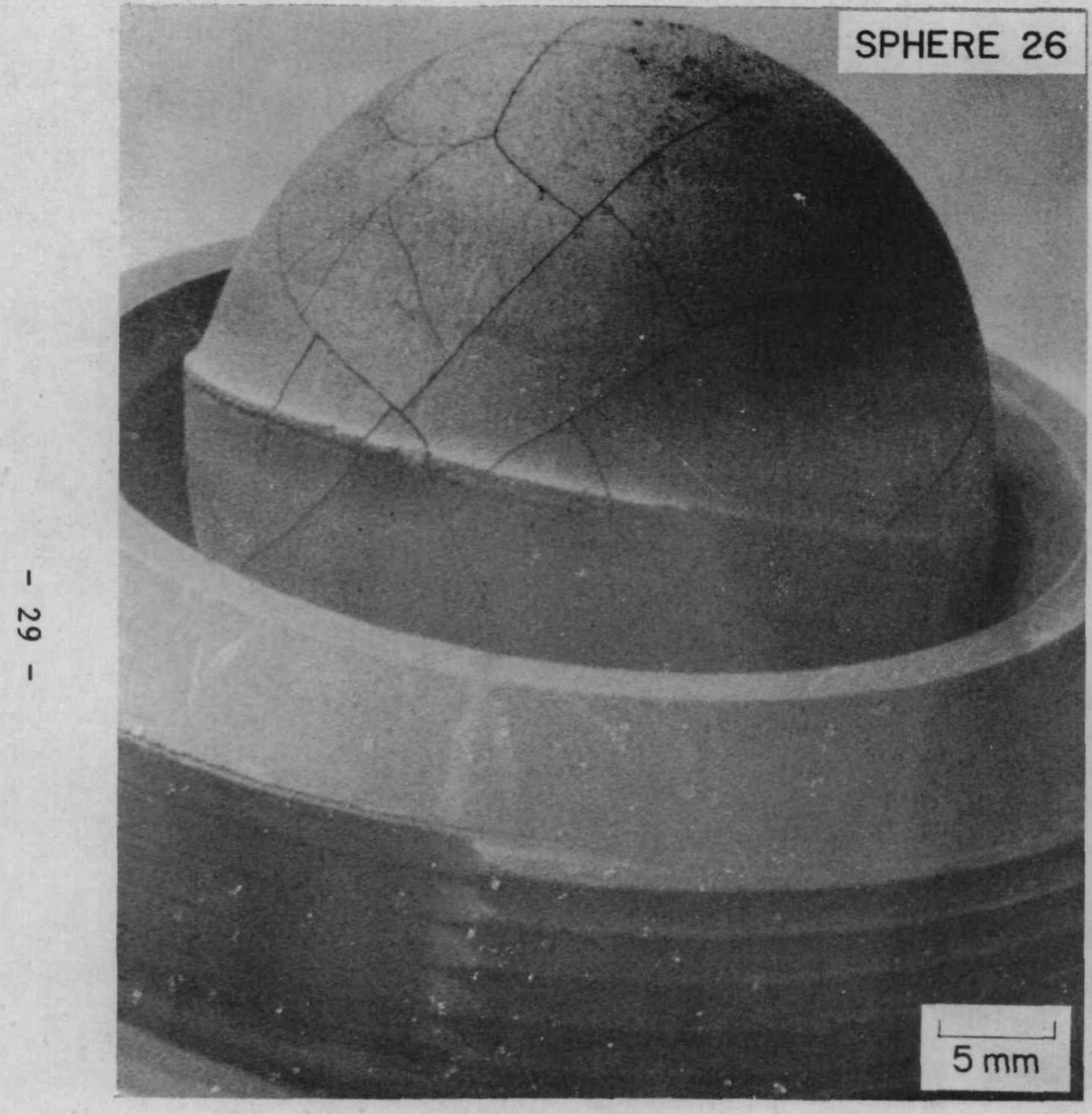

a. Sphere 26 Showing "Mudflat"-Type Cracks

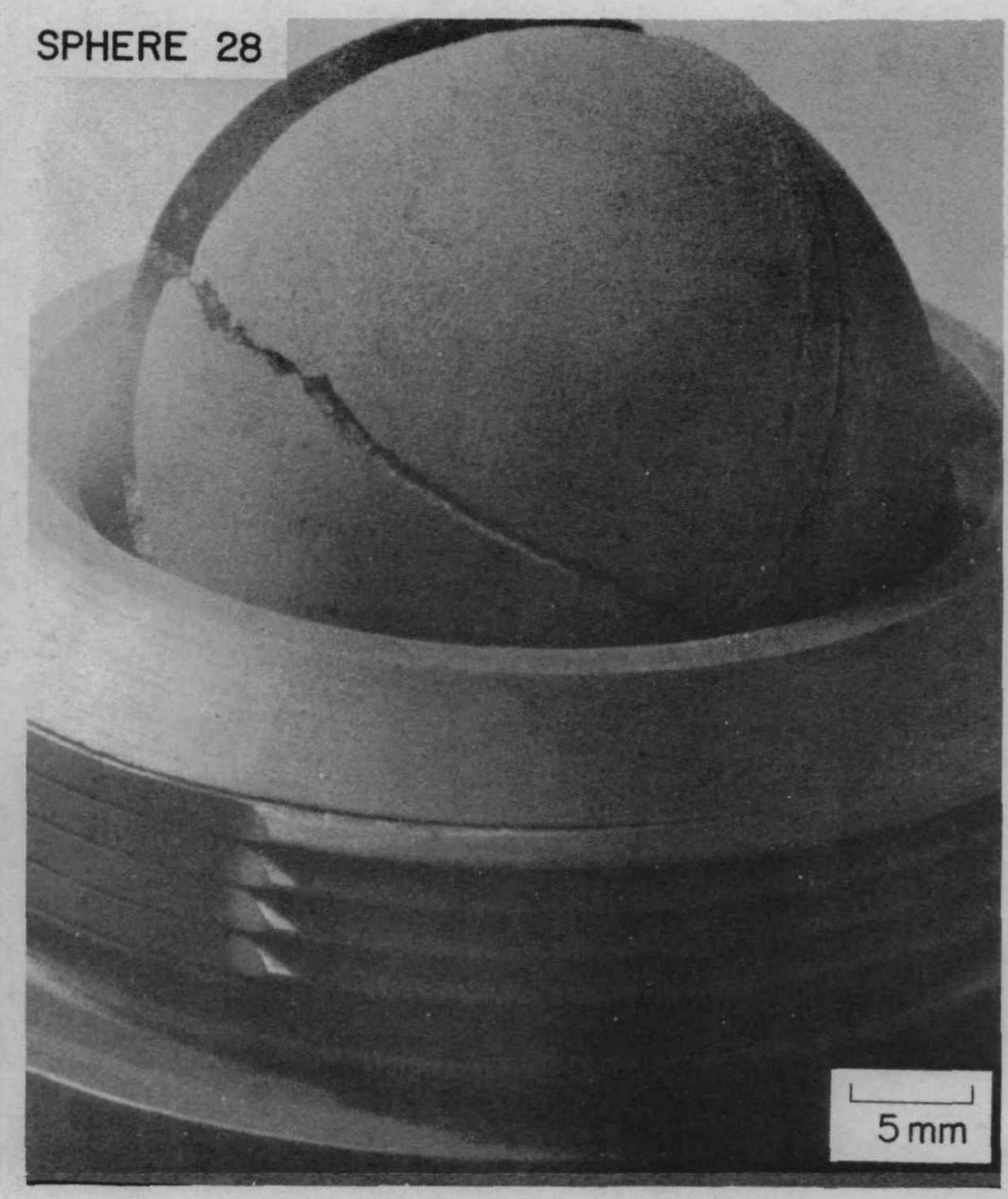

b. Sphere 28 Broken into Large Chunks Without "Mudflat" Cracks

FIGURE 1. Appearance of Heat-Treated Multihundred Watt (MHW) ${ }^{238} \mathrm{PuO}_{2}$ Fuel Spheres 


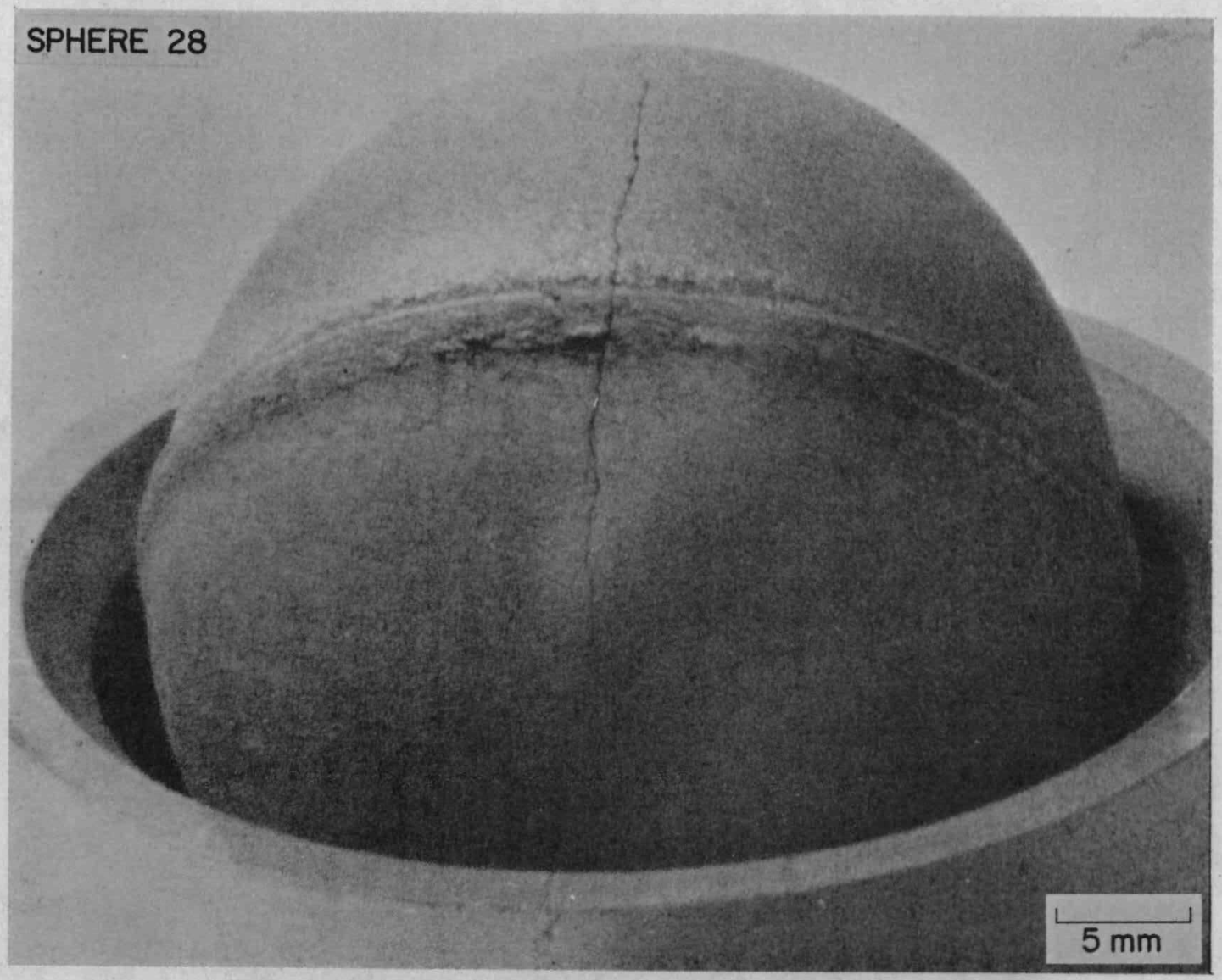

FIGURE 2. As-Pressed Crack in MHW Sphere 28 


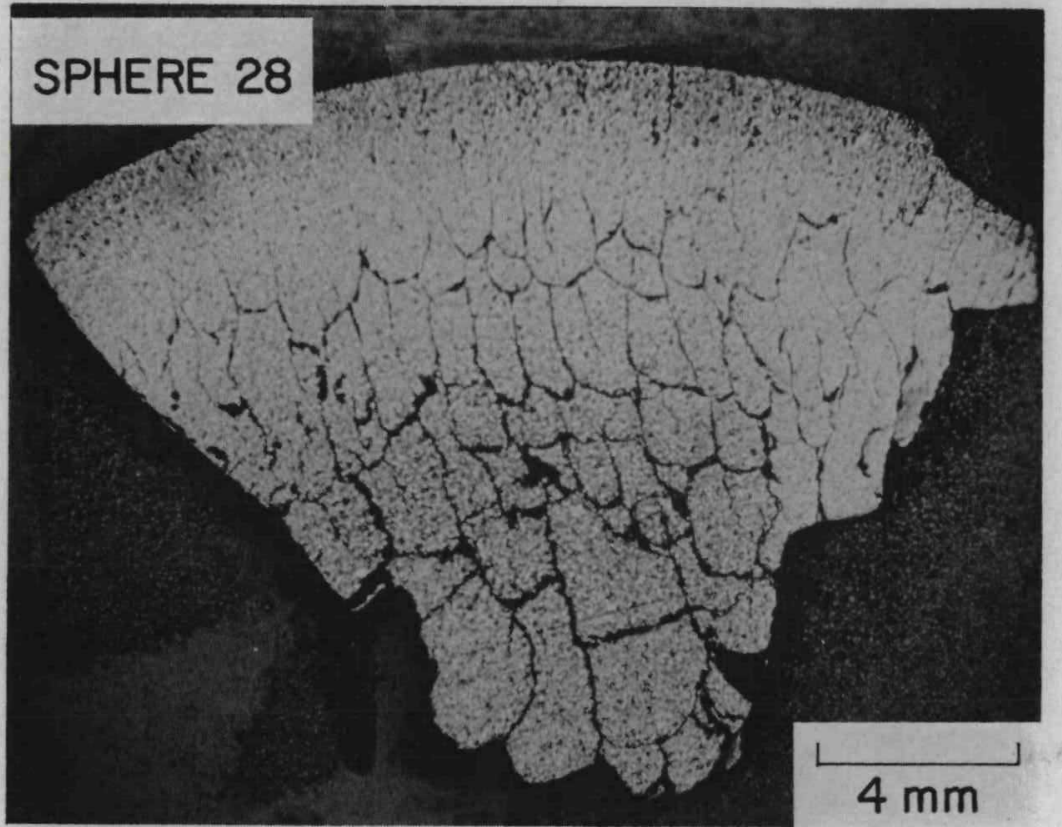

FIGURE 3. Internal Crack Pattern of Sphere 28 


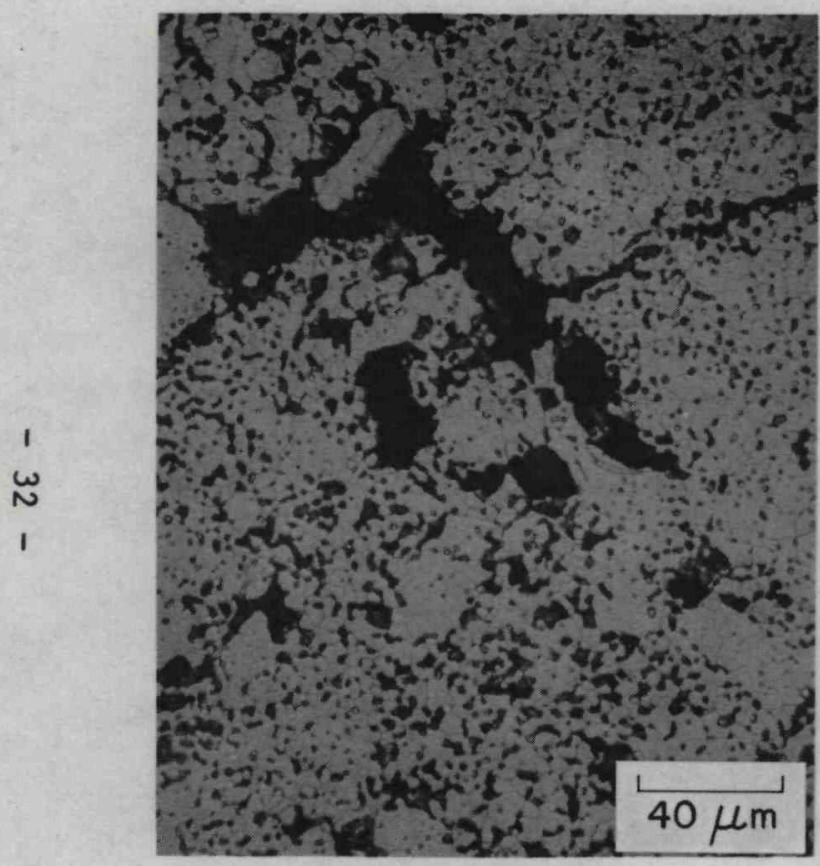

OUTER BAND

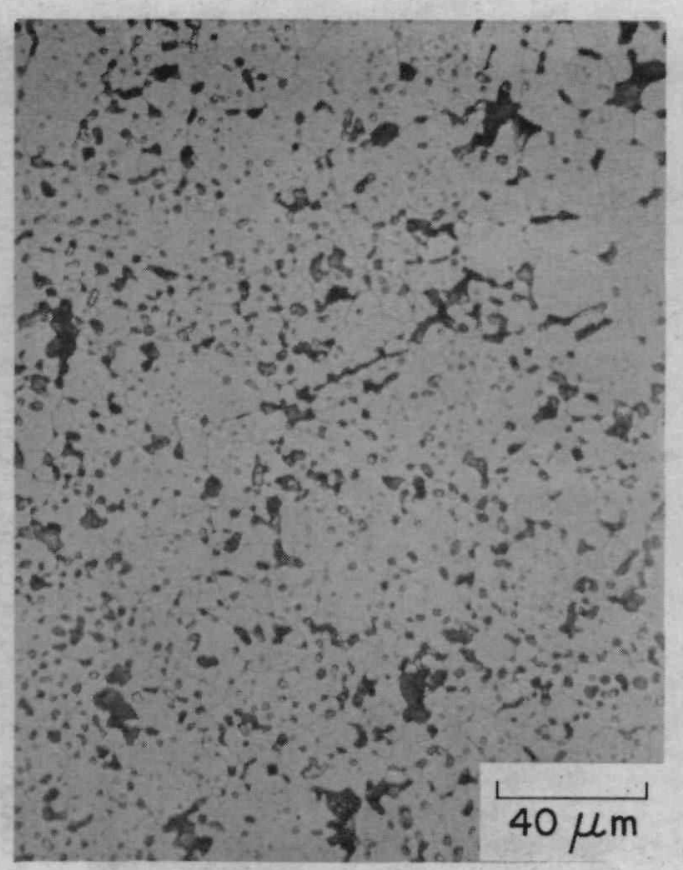

INNER BAND

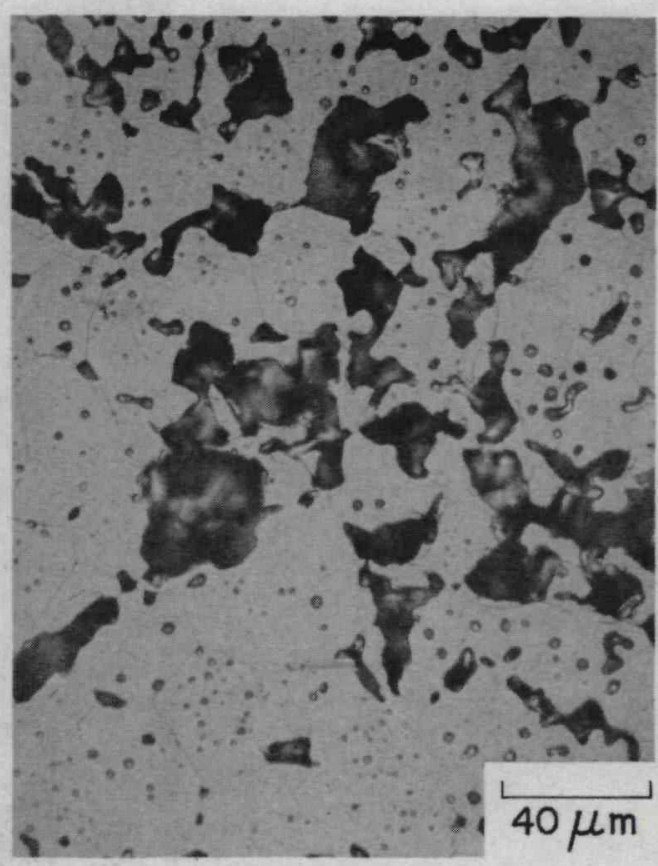

CORE

FIGURE 4. Microstructure of Sphere 28 


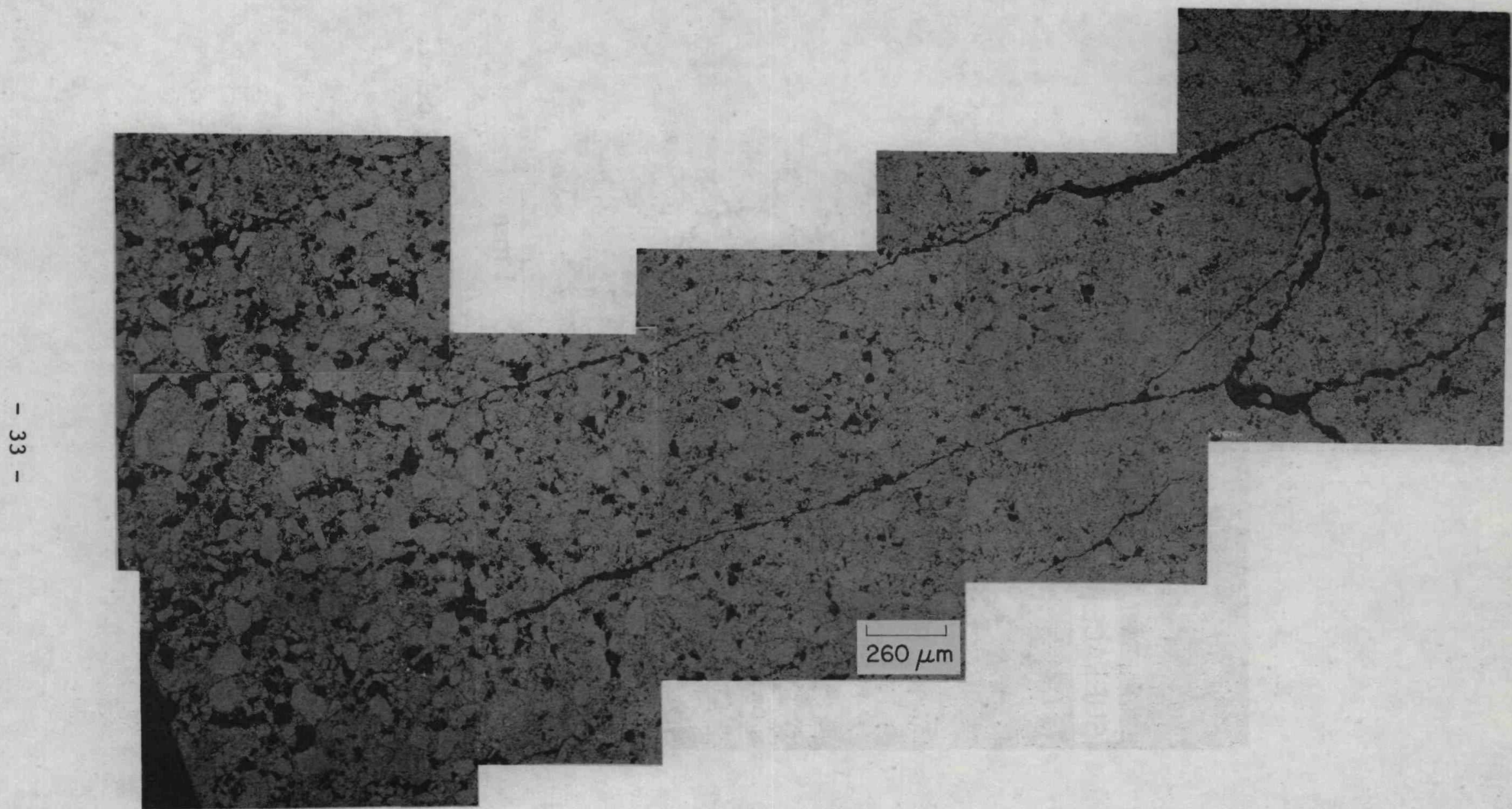

FIGURE 5. Internal Crack Patterns of Sphere 28 Showing Crack Branching from Core to Surface and Dissipation of Crack in Low-Density Outer Band 


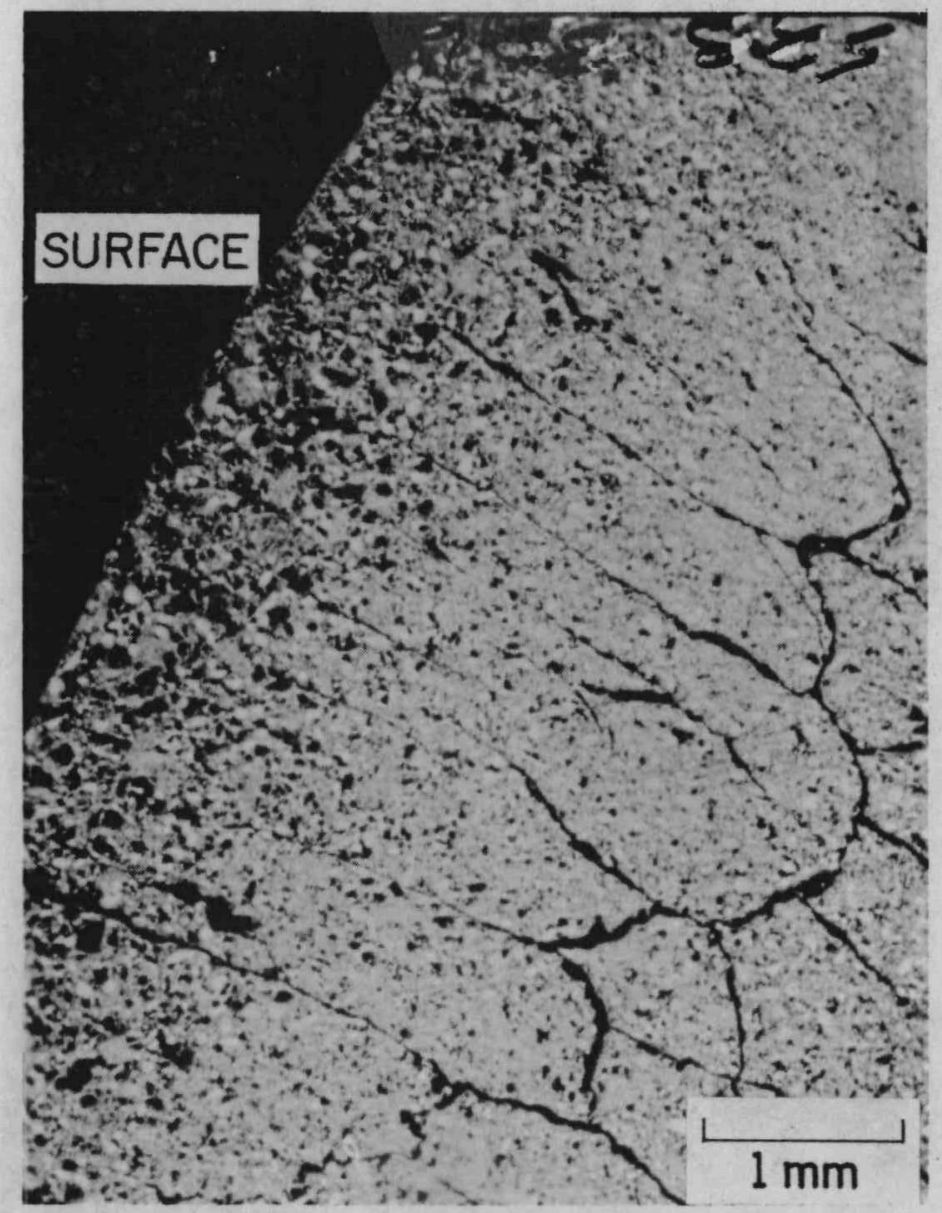

FIGURE 6. Internal Crack Pattern of Sphere 28 Showing Cracks Diminishing as They Approach Outer Surface 


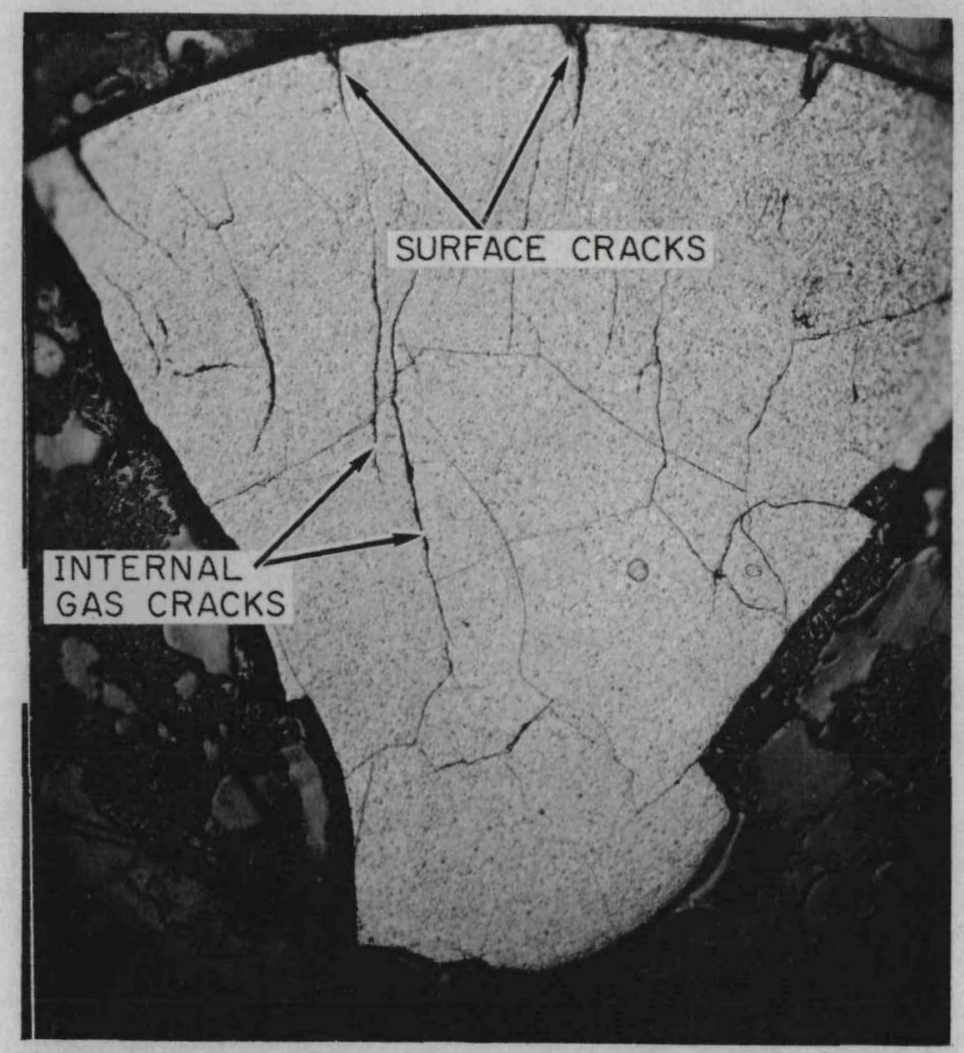

FIGURE 7. Cracks in Sphere 26 


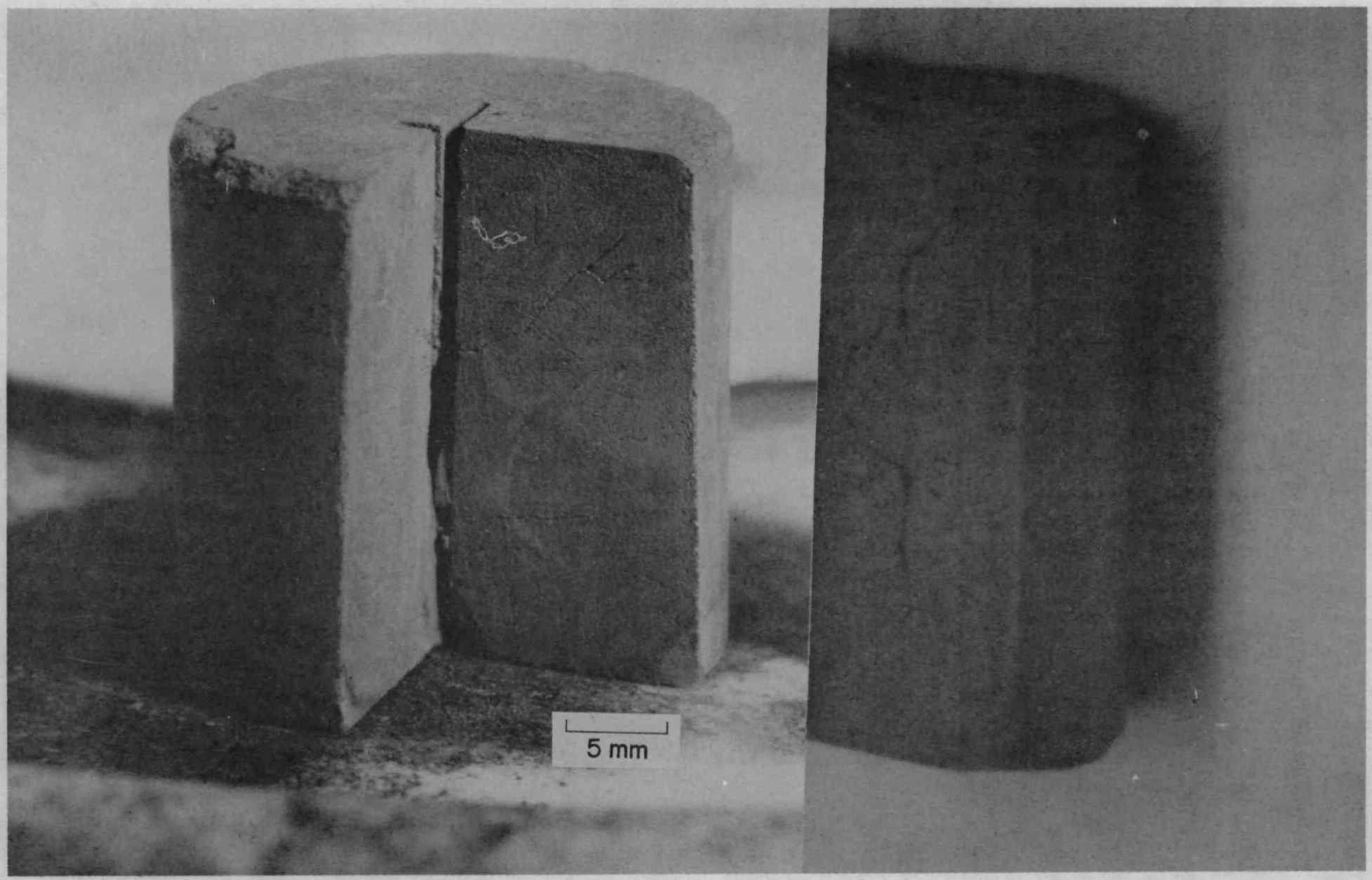

a. Cracks in As-Pressed Pellet

b. Similar Cracks in Heat-Treated Pellet

FIGURE 8. Cracking in MHW 18-g Pellets, Run No. 10 


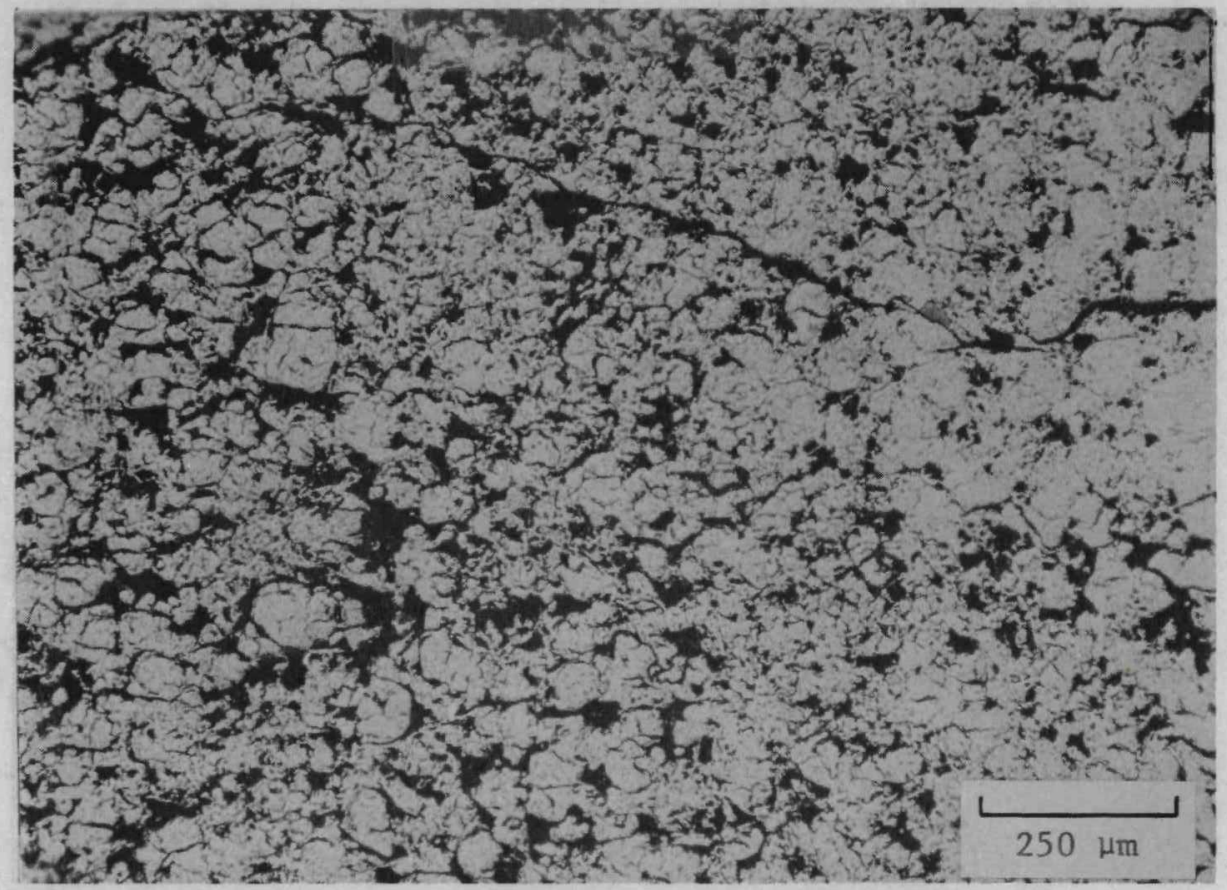

a. Low Magnification

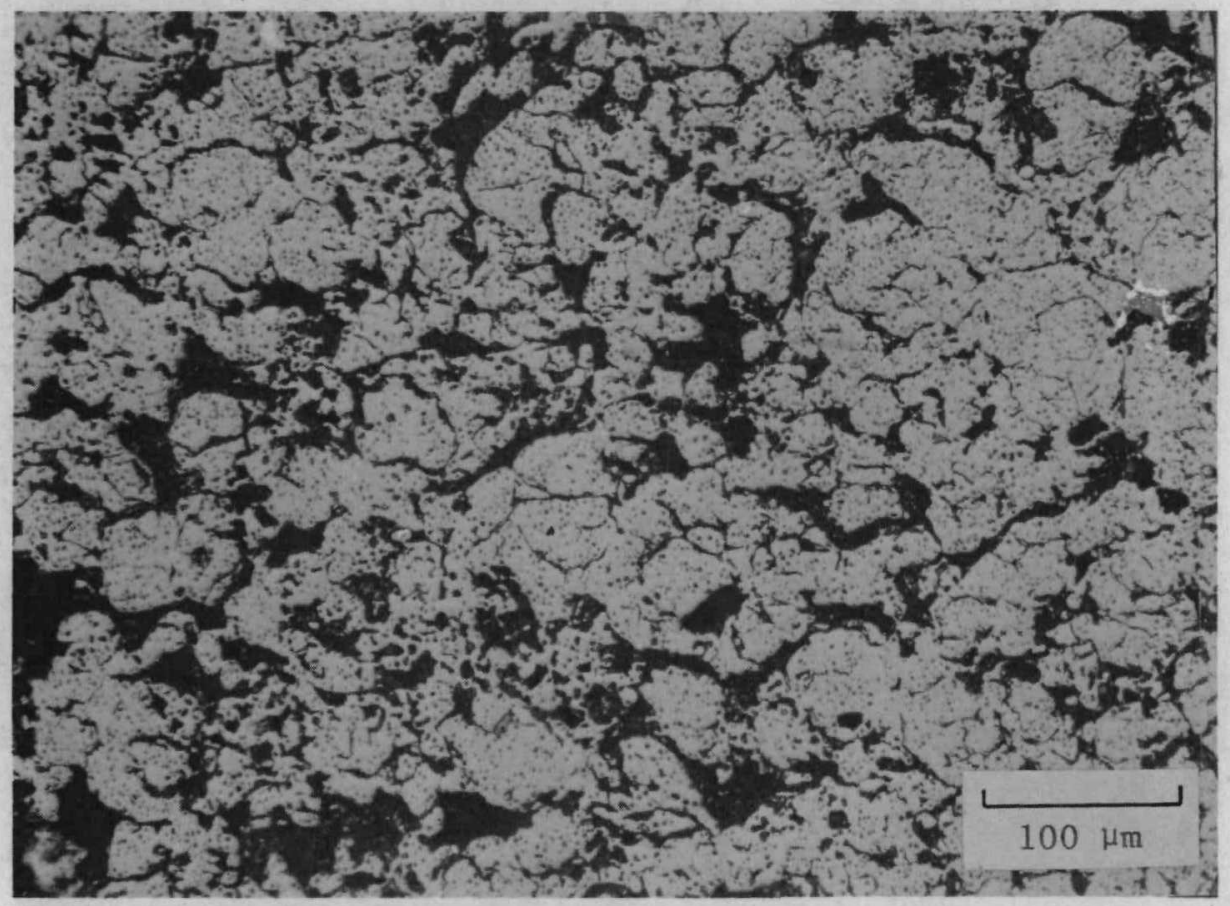

b. High Magnification

FIGURE 9. Shard Separation in As-Pressed MHW 18-g Pellets, Run No. 10 


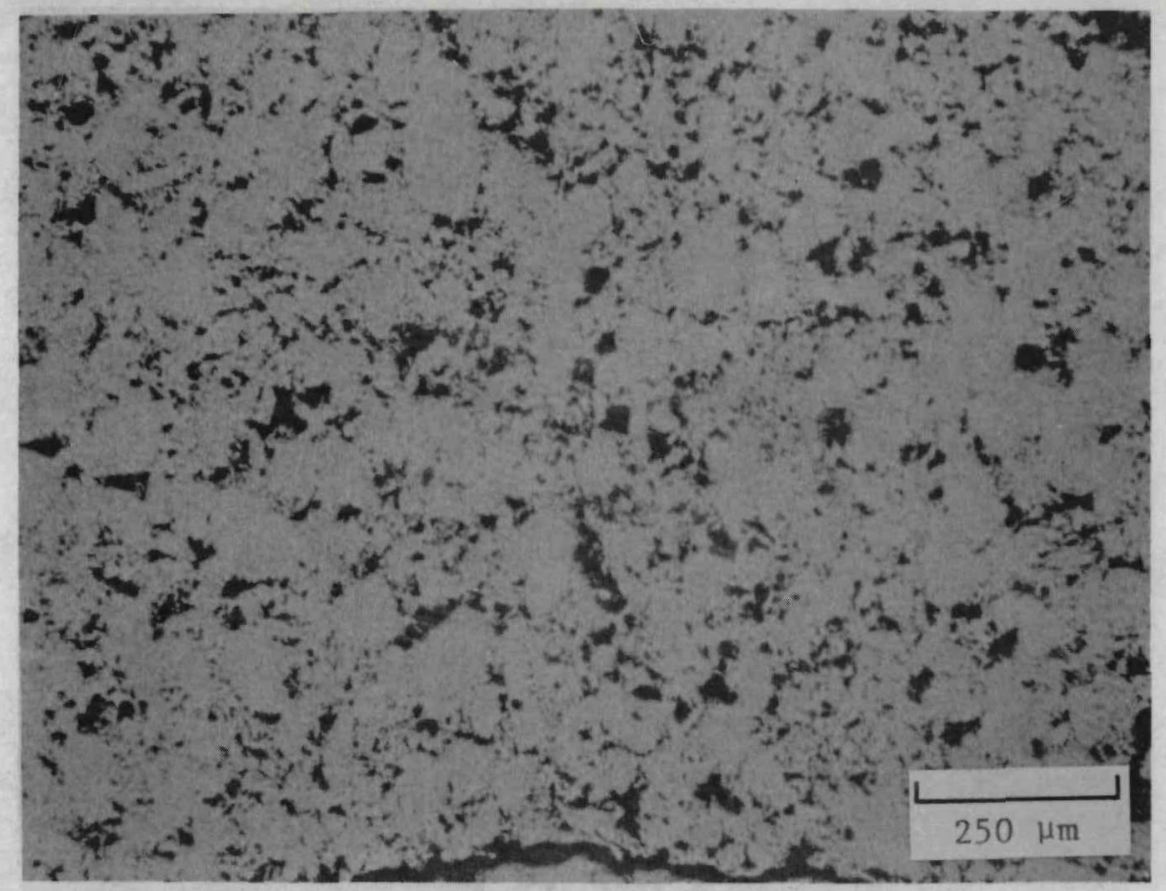

a. Center of pellet

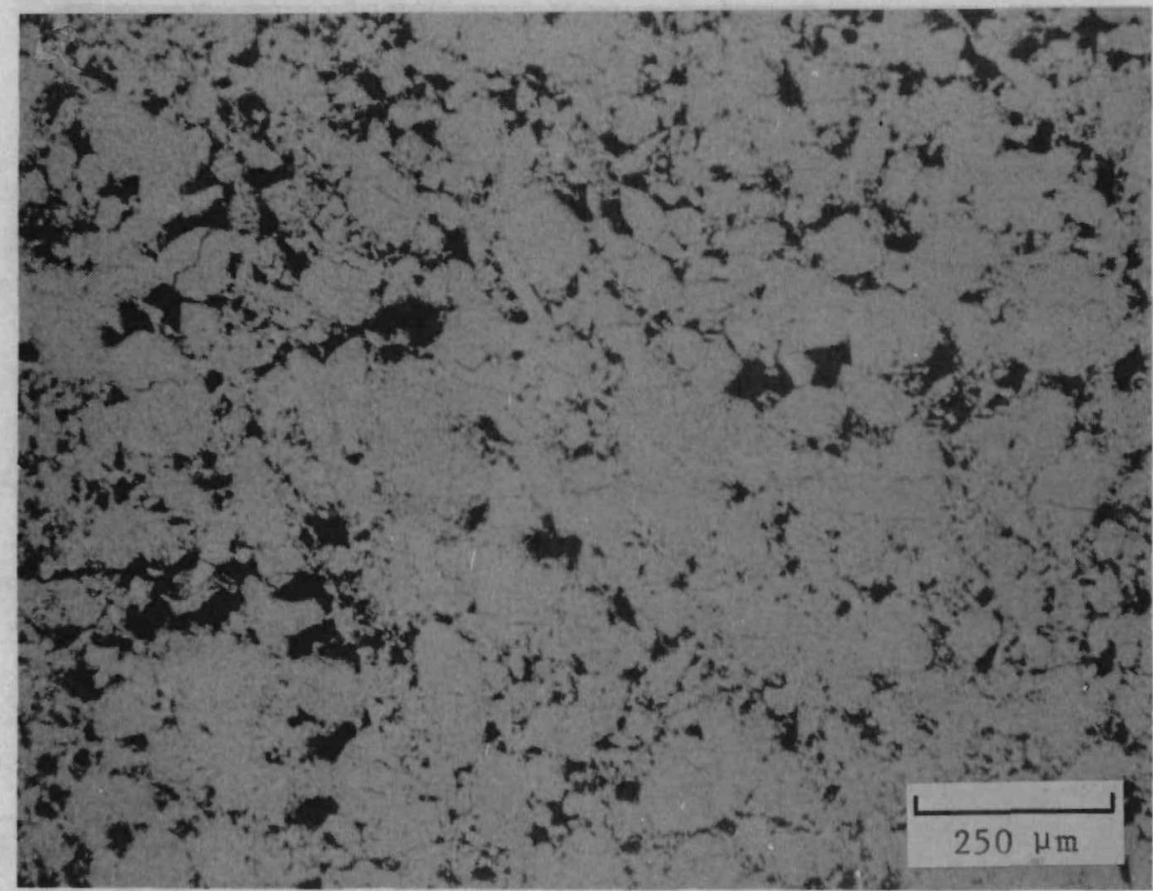

b. Edge of Pellet. Long hairline cracks may be unhealed, but closed separations

FIGURE 10. Healed Shard Separation in Heat-Treated Duplicate of Run No. 10 

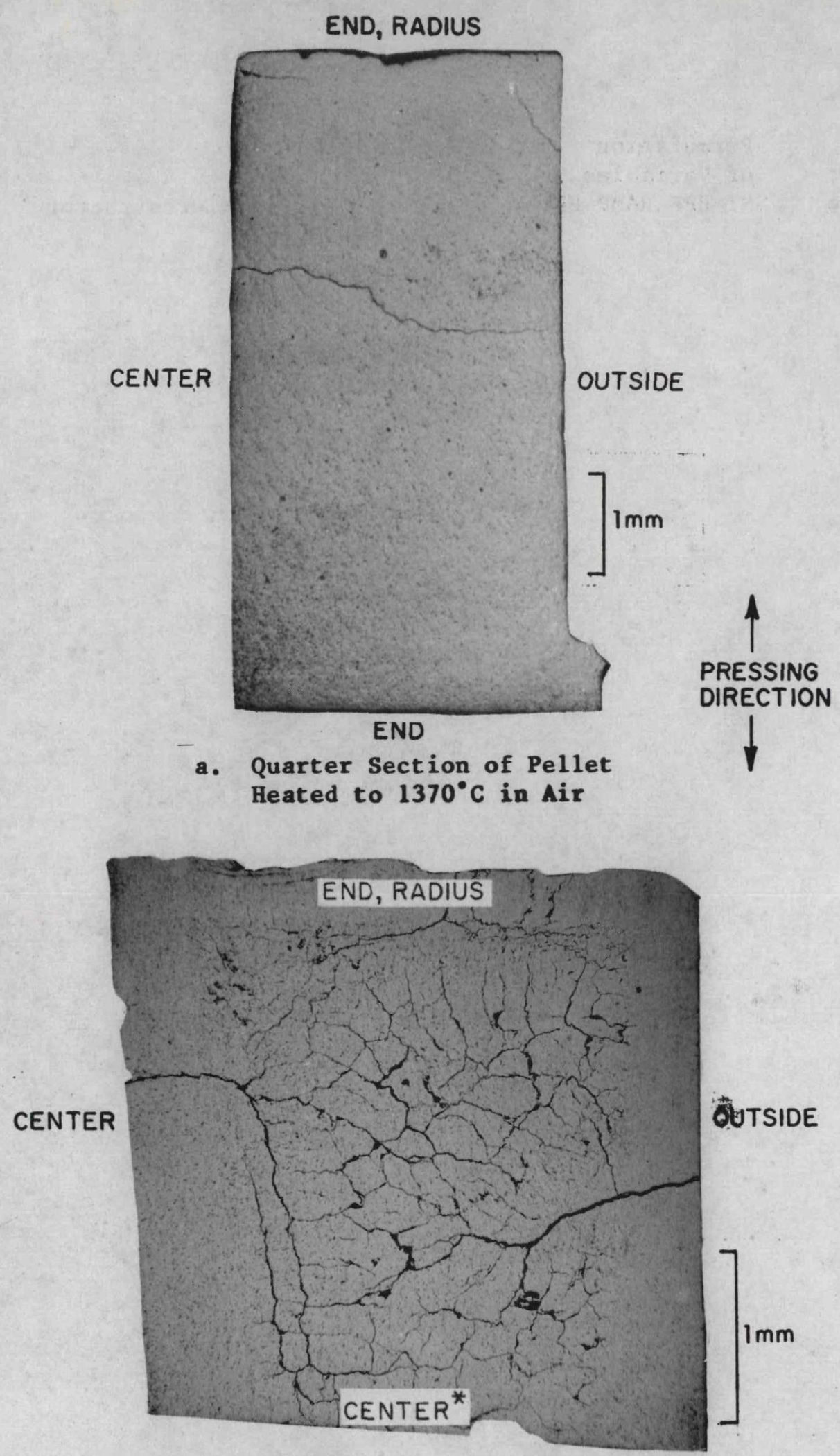

FIGURE 11. Cracks Caused by Expansion of Trapped Gas 


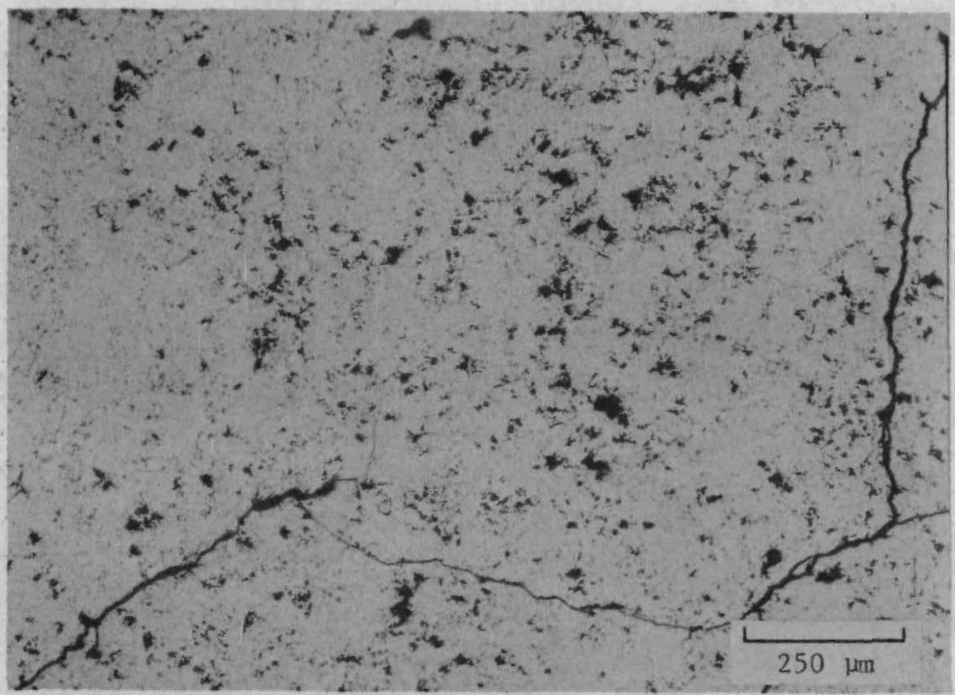

4

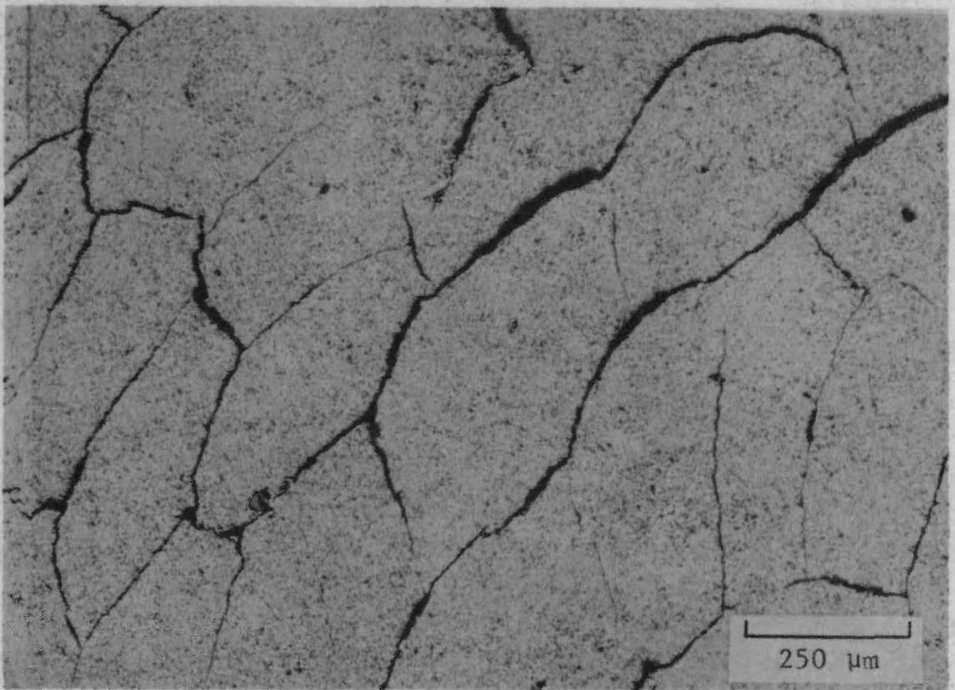

FIGURE 12. Effect of Hot Press Temperature on Microstructure of MHW Pellets. a. Low Shard Sintering Temperature, High Hot Press Pressure, Fast Ramp. 


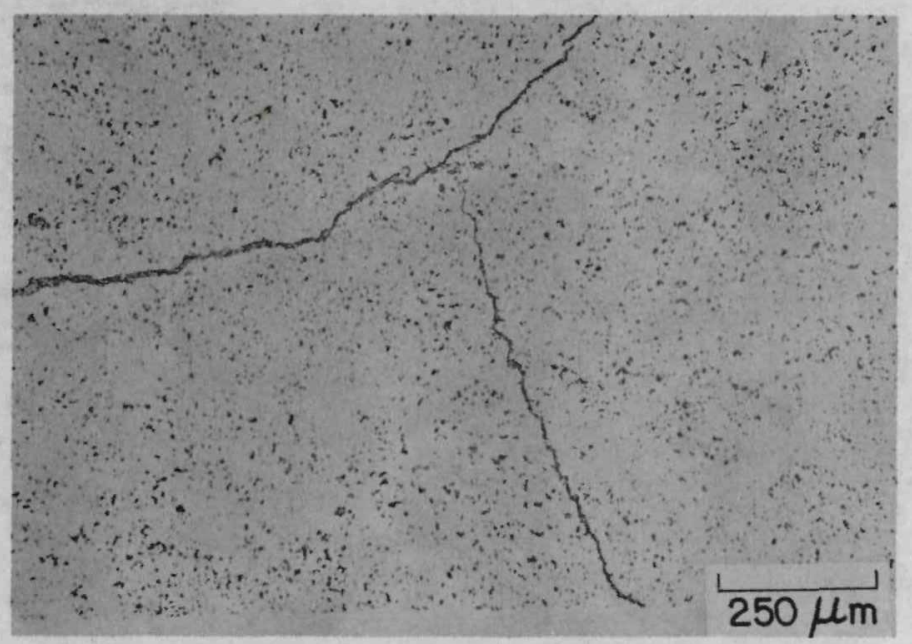

9

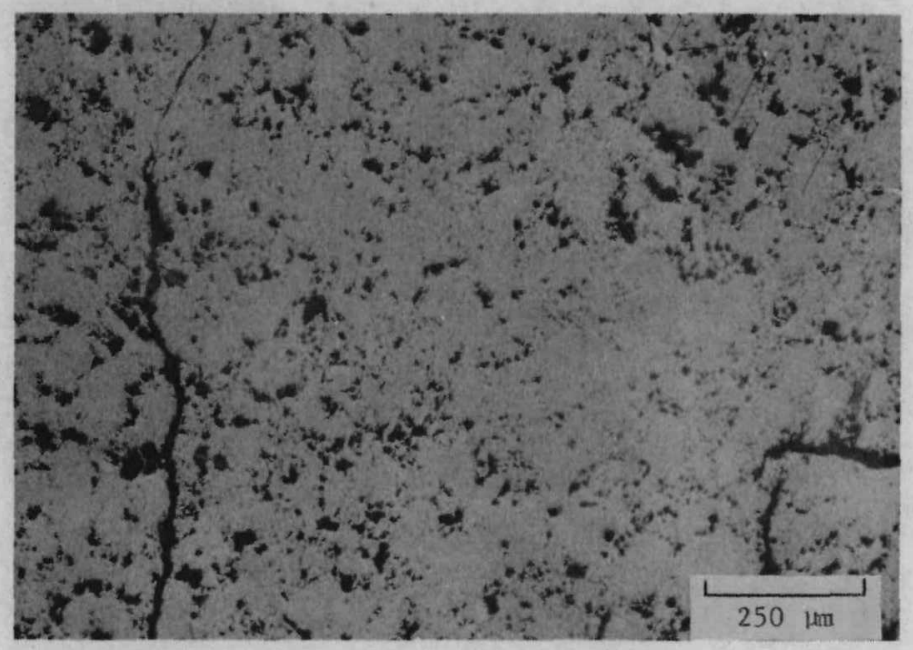

FIGURE 12. Continued, b. High Shard Sintering Temperature, High Hot Press Pressure, Slow Ramp. 


$\begin{array}{ll}\text { MHW } & \text { Permutation } \\ \text { Pellet } & \text { of Variables } \\ \text { Run No. } & \text { SST HPP RAMP HPT }\end{array}$

Microstructure

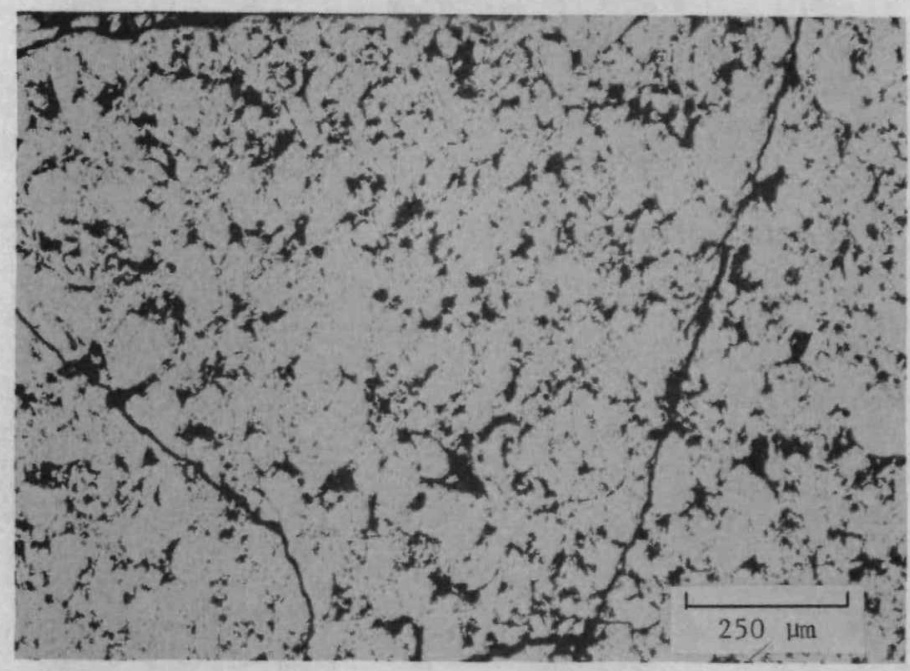

12

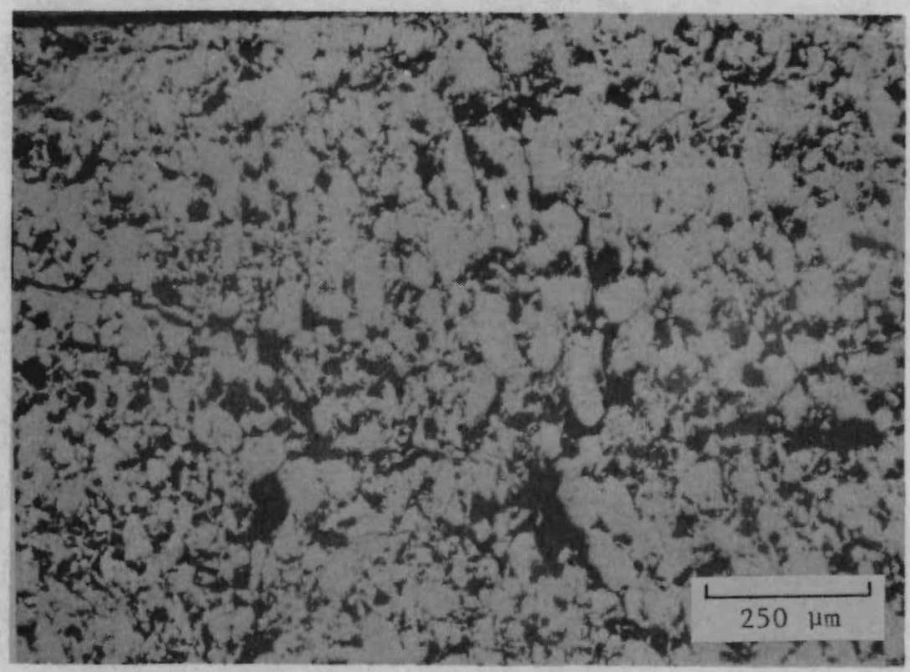

FIGURE 12. Continued. c. Low Shard Sintering Temperature, Low Hot Press Pressure, Slow Ramp. 
MHW Permutation

Pellet of Variables

Run No. SST HPP RAMP HPT

Microstructure

4

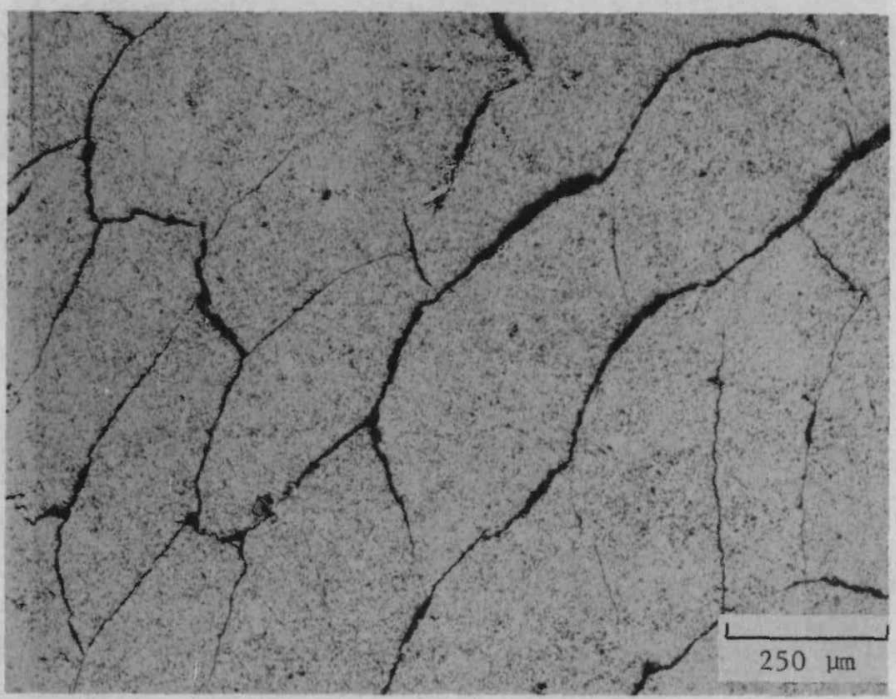

9

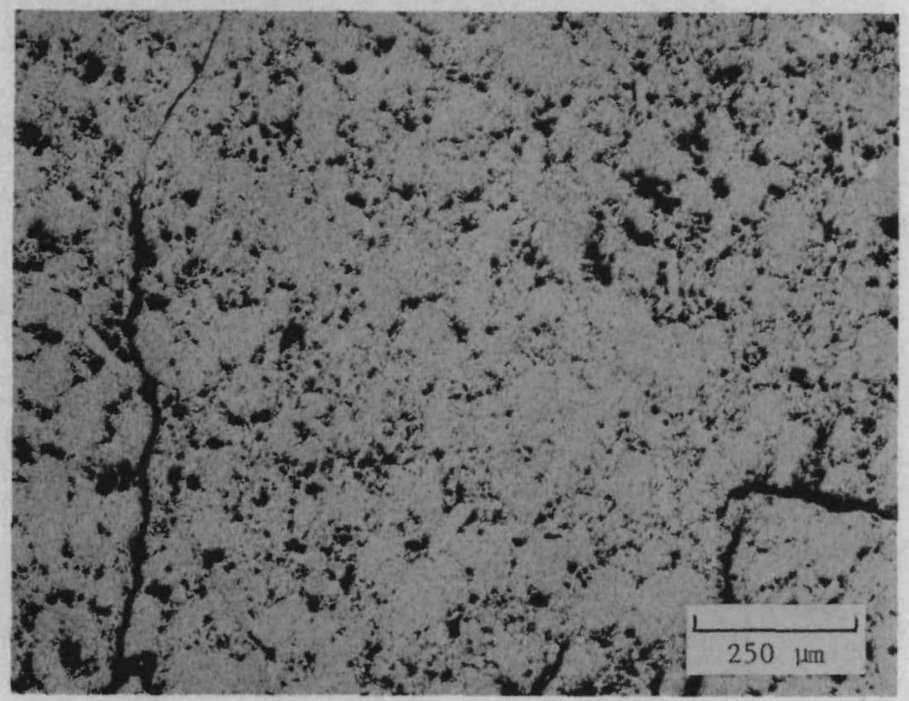

FIGURE 13. Effect of Shard Sintering Temperature on Microstructure of MHW Pellets. a. High Hot Press Pressure, Variable Ramp, Low Hot Press Temperature (See Tables 1 and 2). 
MHW Permutation

Pellet of Variables

Run No. SST HPP RAMP HPT
Microstructure

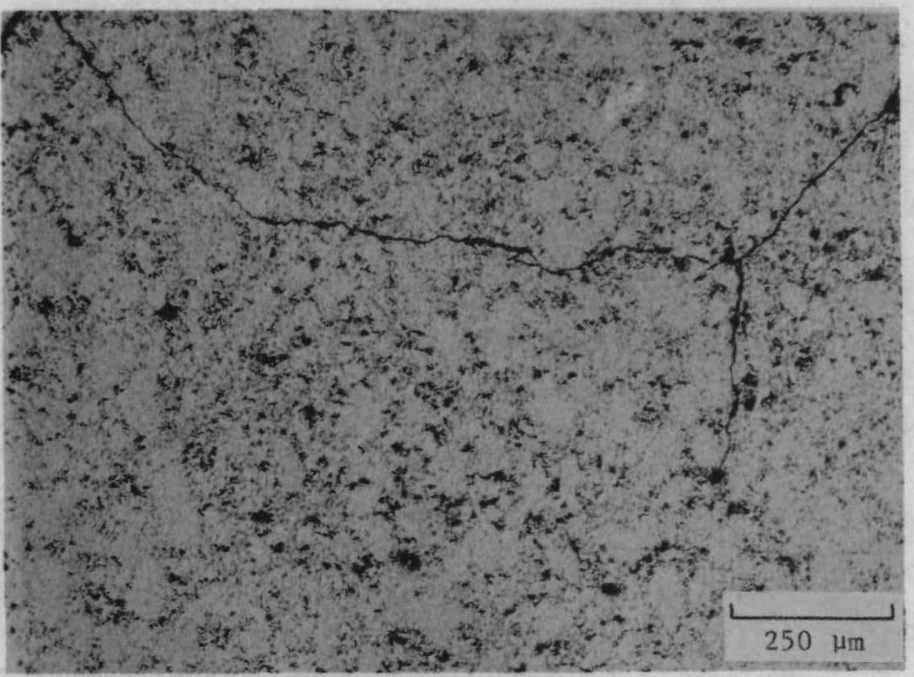

10

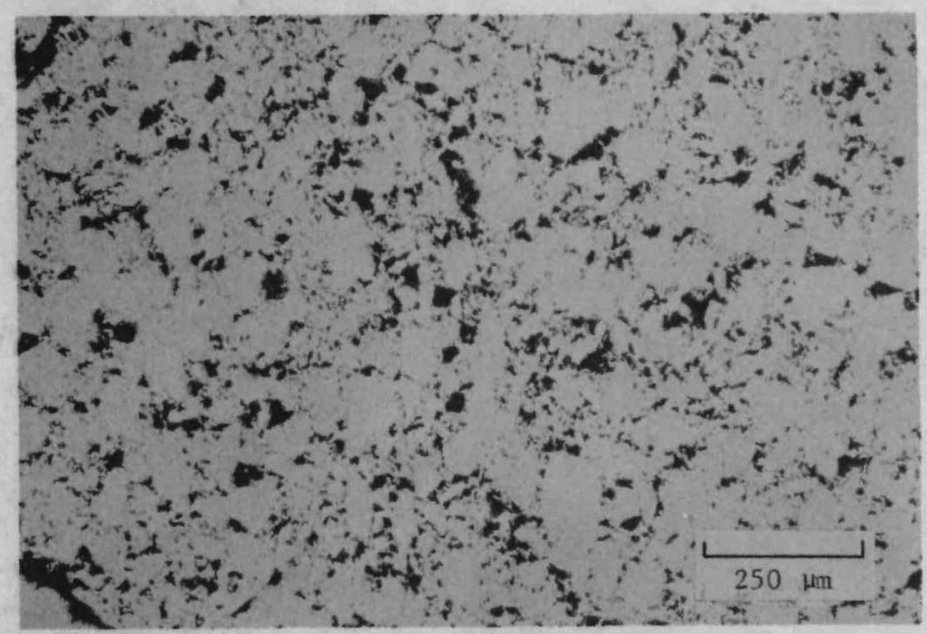

FIGURE 13. Continued. b. Low Hot Press Pressure, Variable Ramp, Low Hot Press Temperature. 
MHW Permutation

Pellet of Variables

Run No. SST HPP RAMP HPT

Microstructure

7

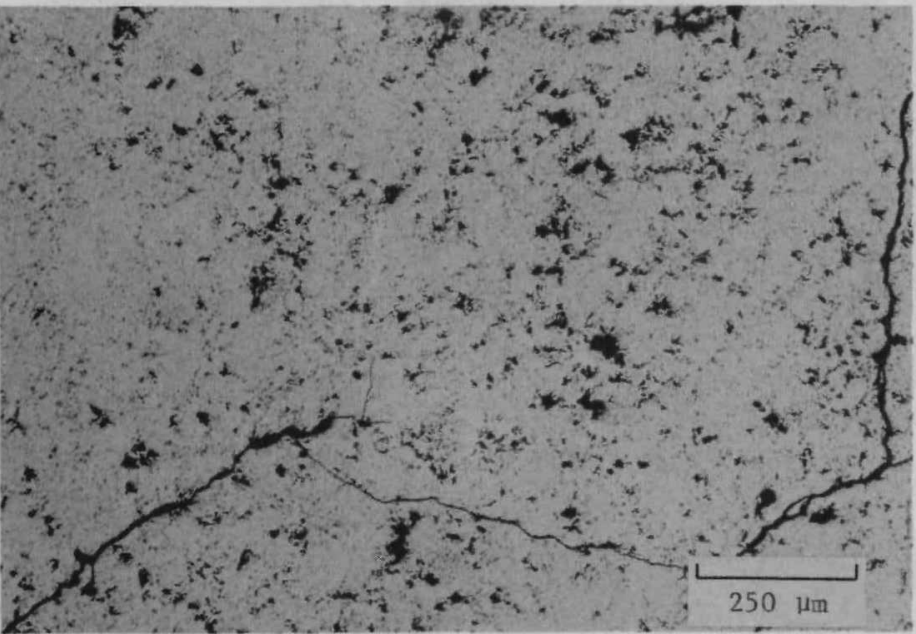

2

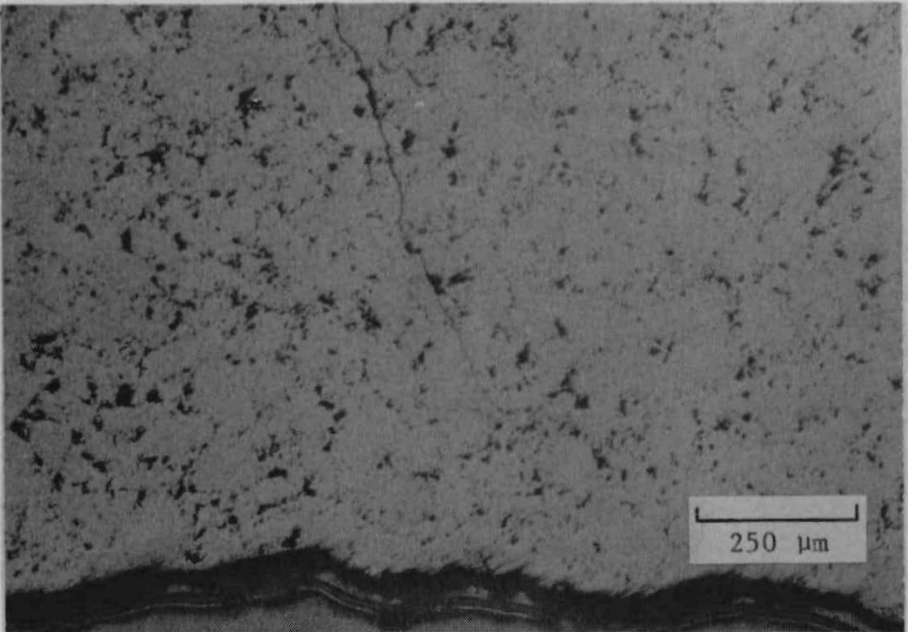

FIGURE 13. Continued. c. High Hot Press Pressure, Variable Ramp, High Hot Press Temperature. 
MHW Permutation

Pellet of Variables

Run No. SST HPP RAMP HPT

5

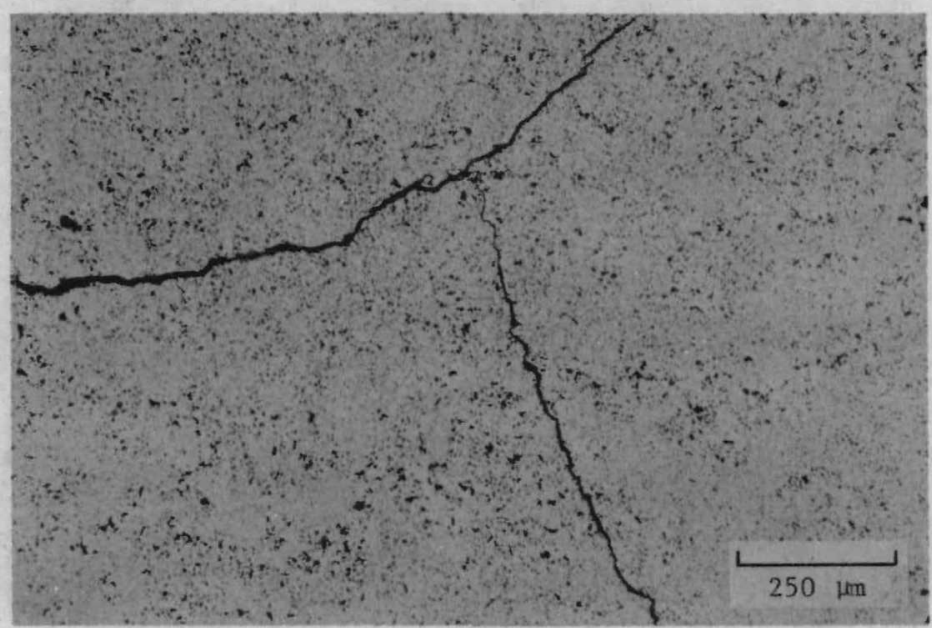

FIGURE 13. Continued. d. For High Hot Pressure, Variable Ramp, High Hot Press Temperature. 
MHW. Permutation

Pellet of Variables

Run No. SST HPP RAMP HPT

Microstructure

2

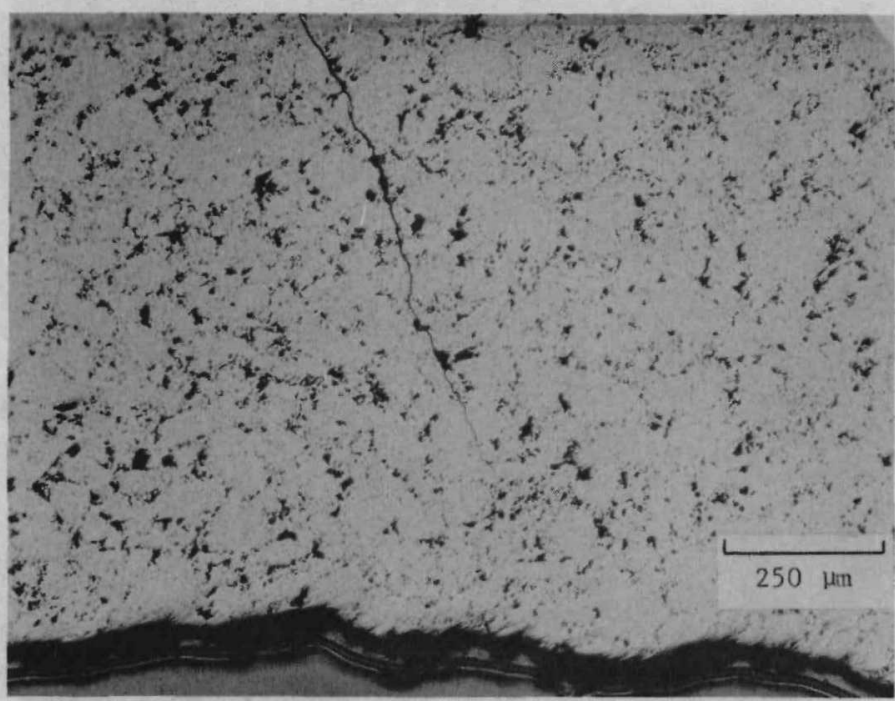

11

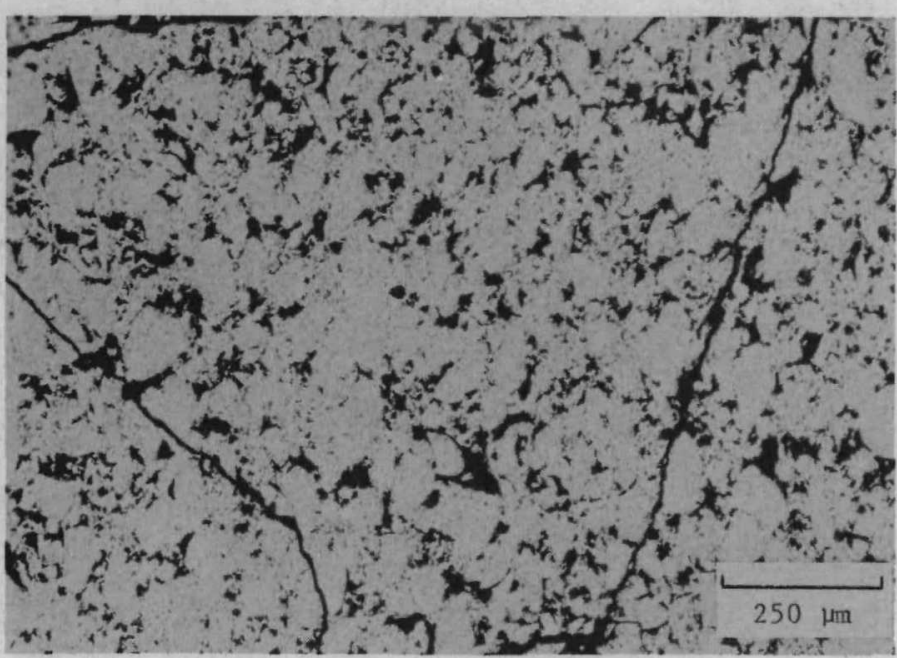

FIGURE 14. Effect of Hot Press Pressure on Microstructure of MHW Pellets. a. Low Shard Sintering Temperature, Slow Ramp, High Hot Press Temperature. 


$\begin{array}{ll}\text { MHW } & \text { Permutation } \\ \text { Pellet } & \text { of Variables } \\ \text { Run No. SST HPP RAMP HPT }\end{array}$

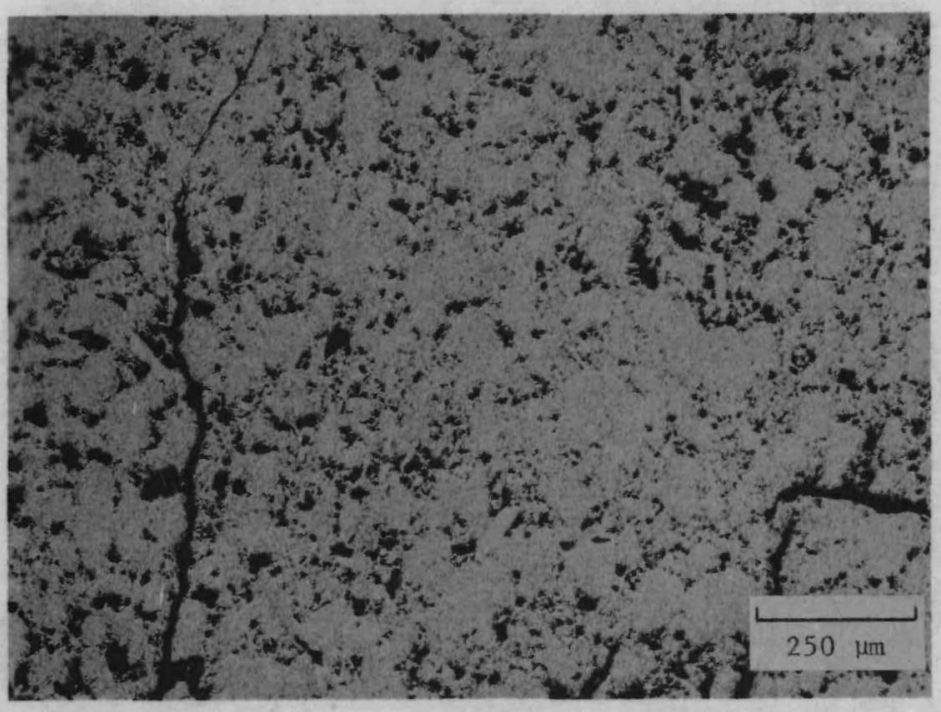

10

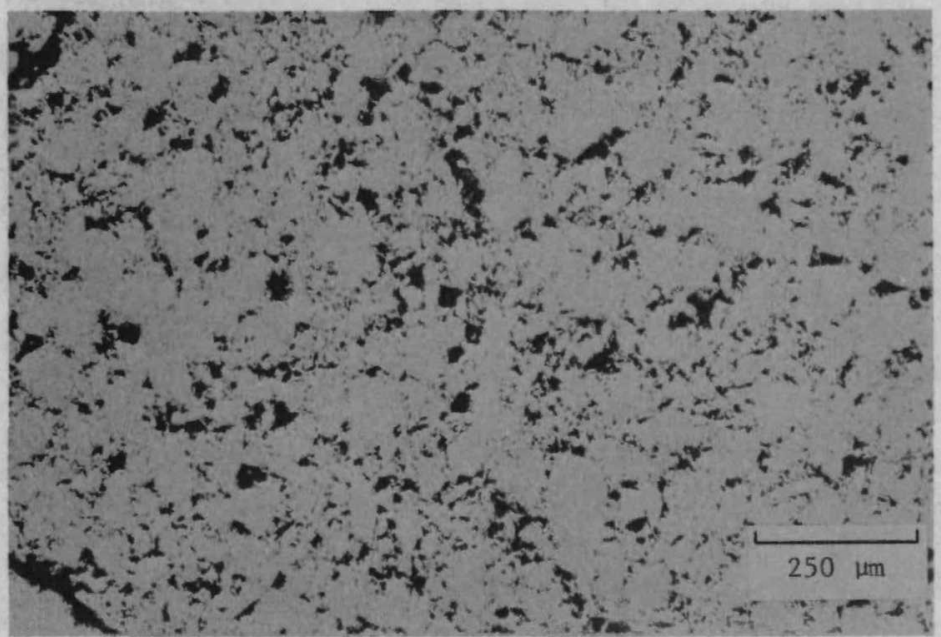

FIGURE 14. Continued. b. High Shard Sintering Temperature, Slow Ramp, Low Hot Press Temperature. 
MHW Permutation

Pellet of Variables

Run No. SST HPP RAMP HPT Microstructure

4

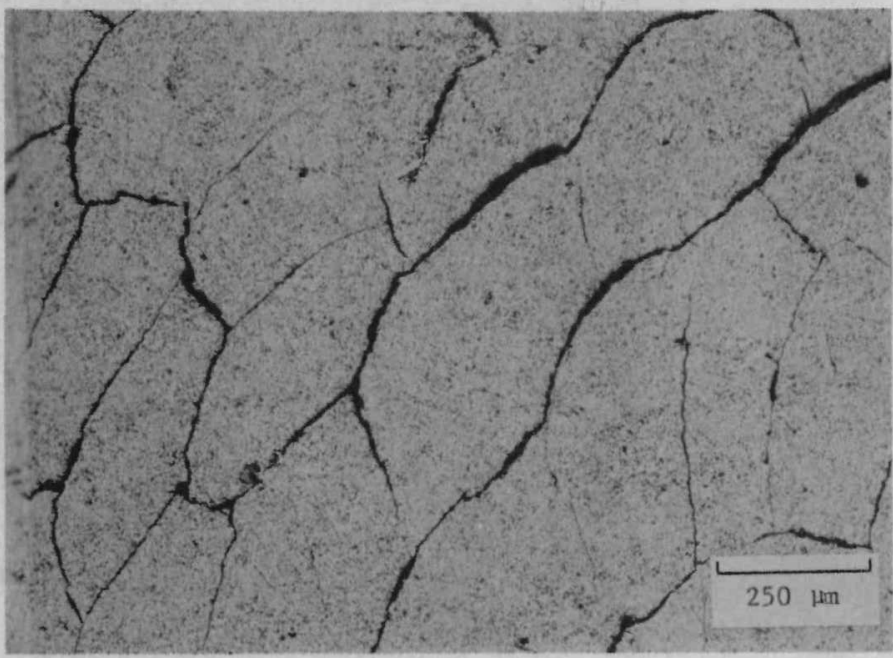

1

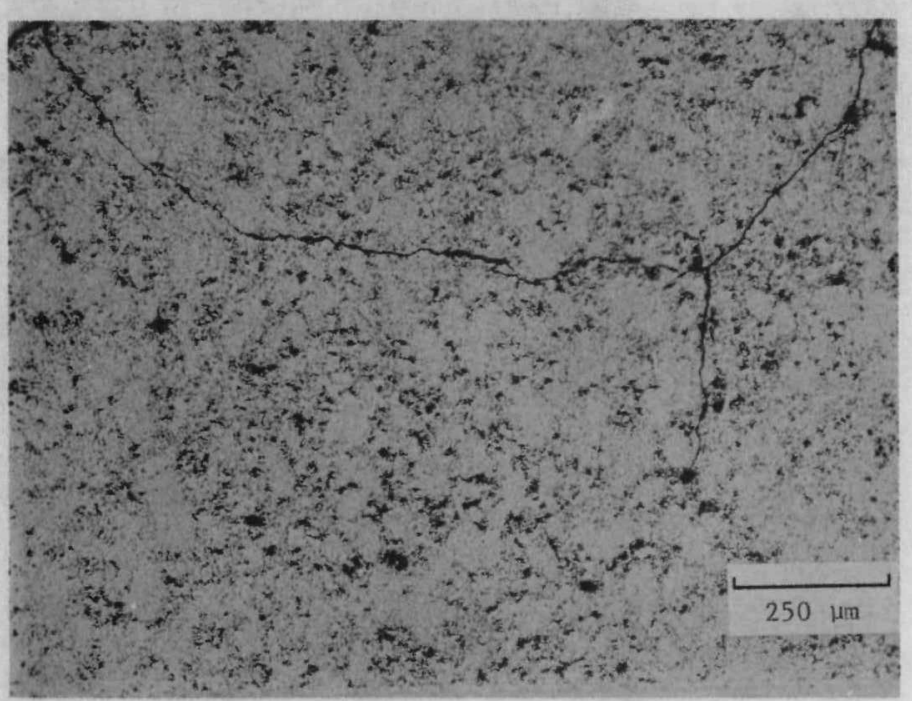

FIGURE 14. Continued. c. Low Shard Sintering Temperature, Fast Ramp, Low Hot Press Temperature. 


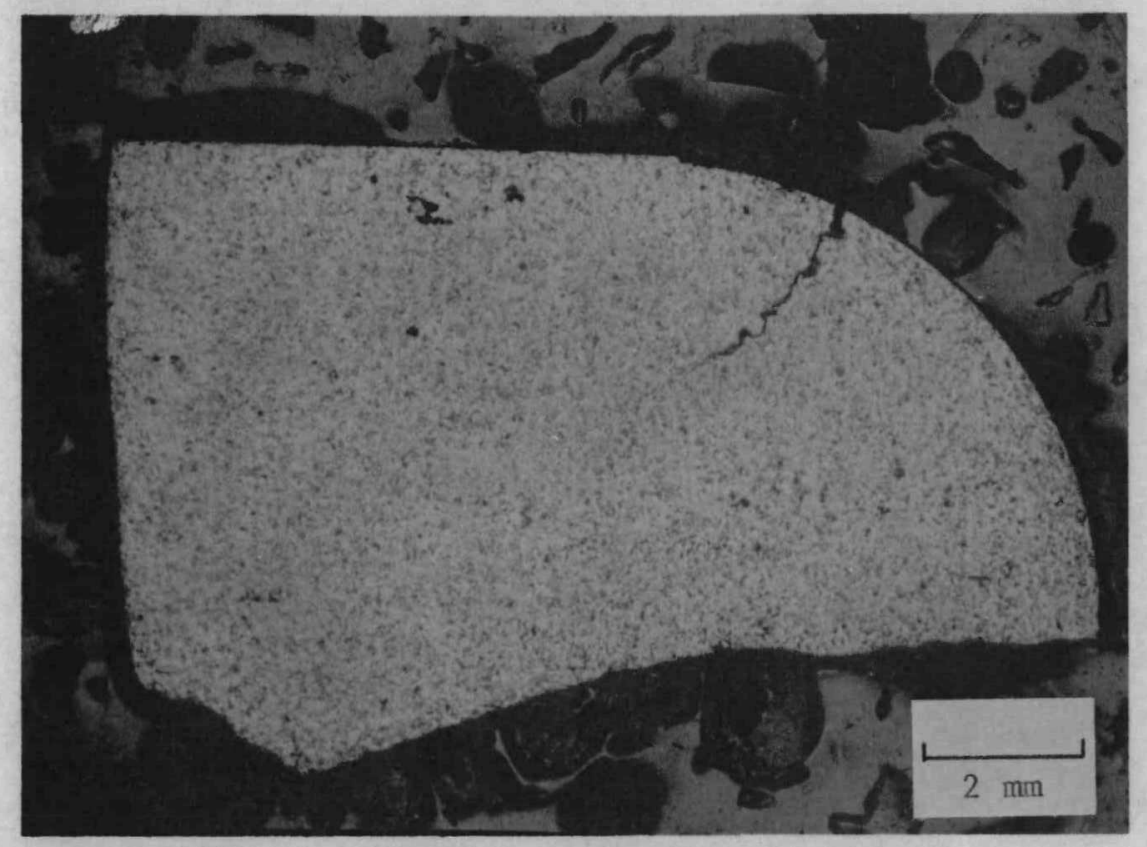

a. GPHS Pellet 30 , 5-min Ramp (Centerline)

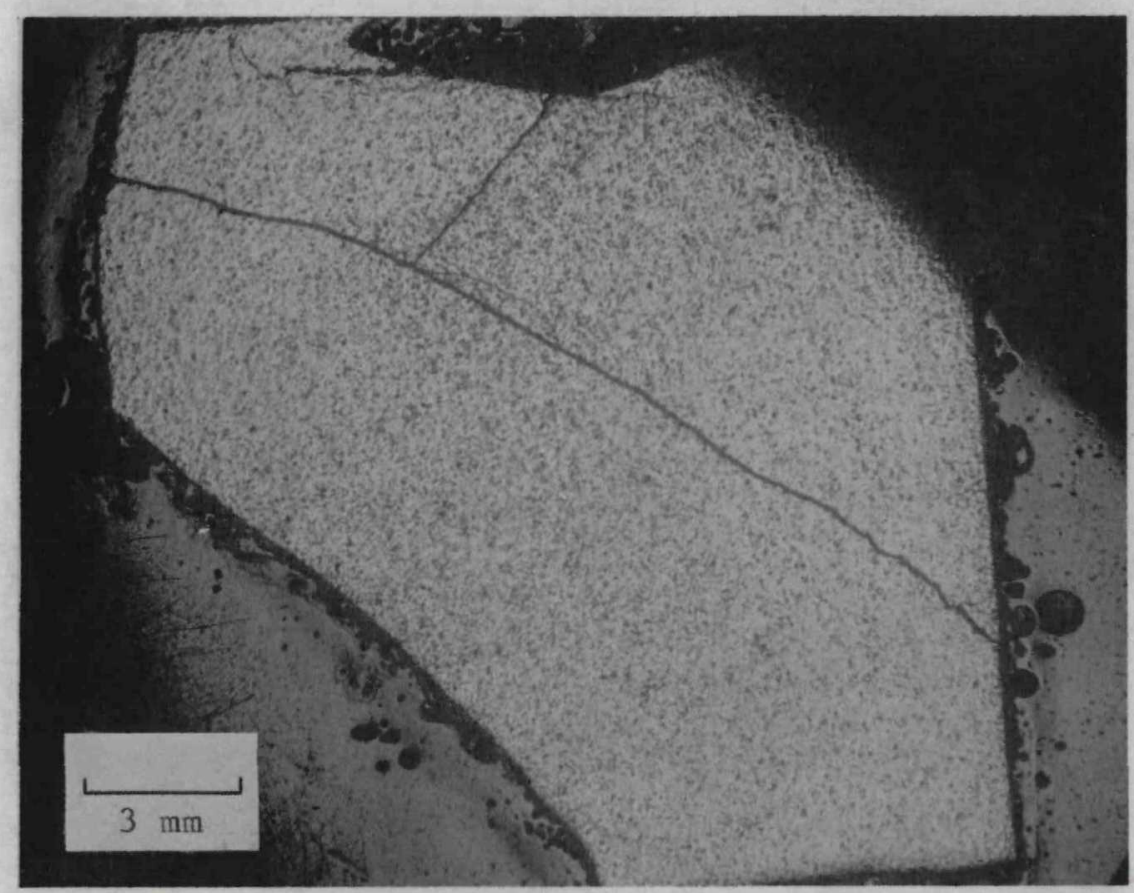

b. GPHS Pellet 33, 1-min Ramp

FIGURE 15. Effect of Pressure Ramp on Cracking in SRL GPHS Pellets 


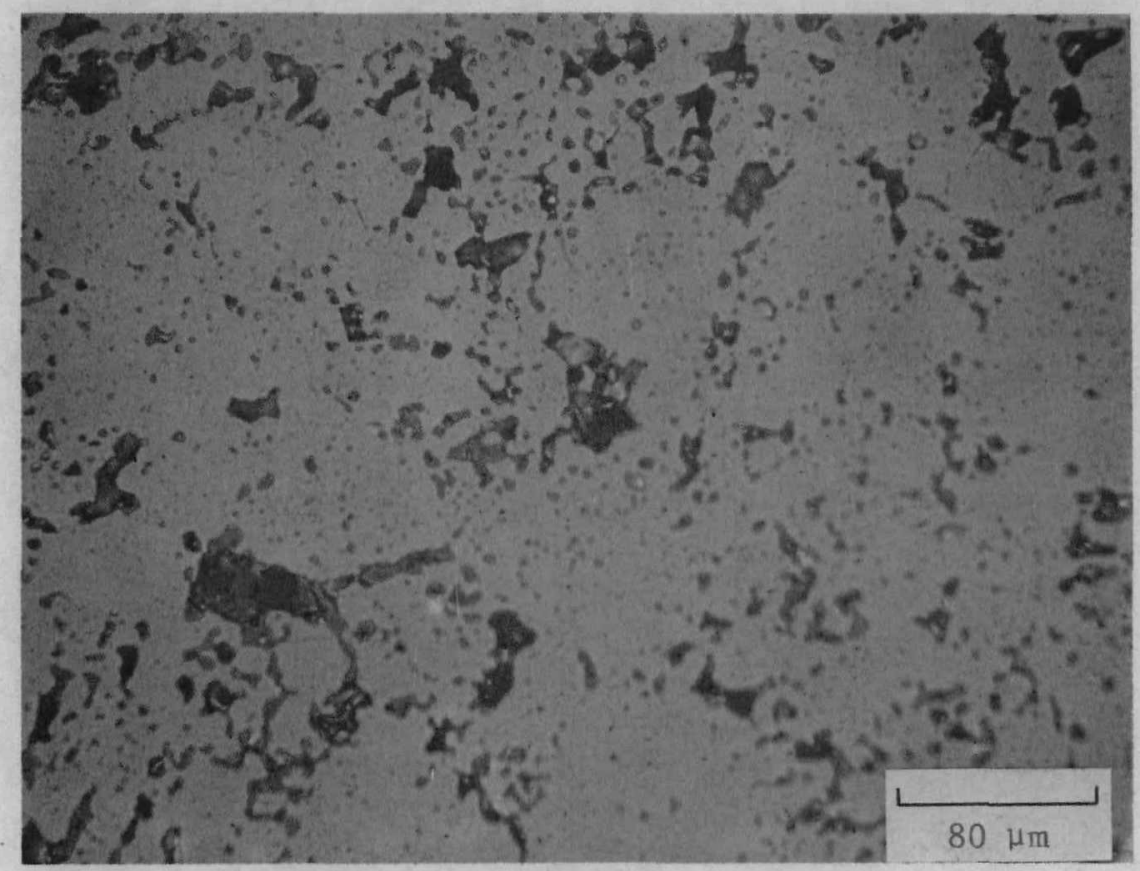

a. GPHS Pellet 30,5 -min Ramp (Centerline)

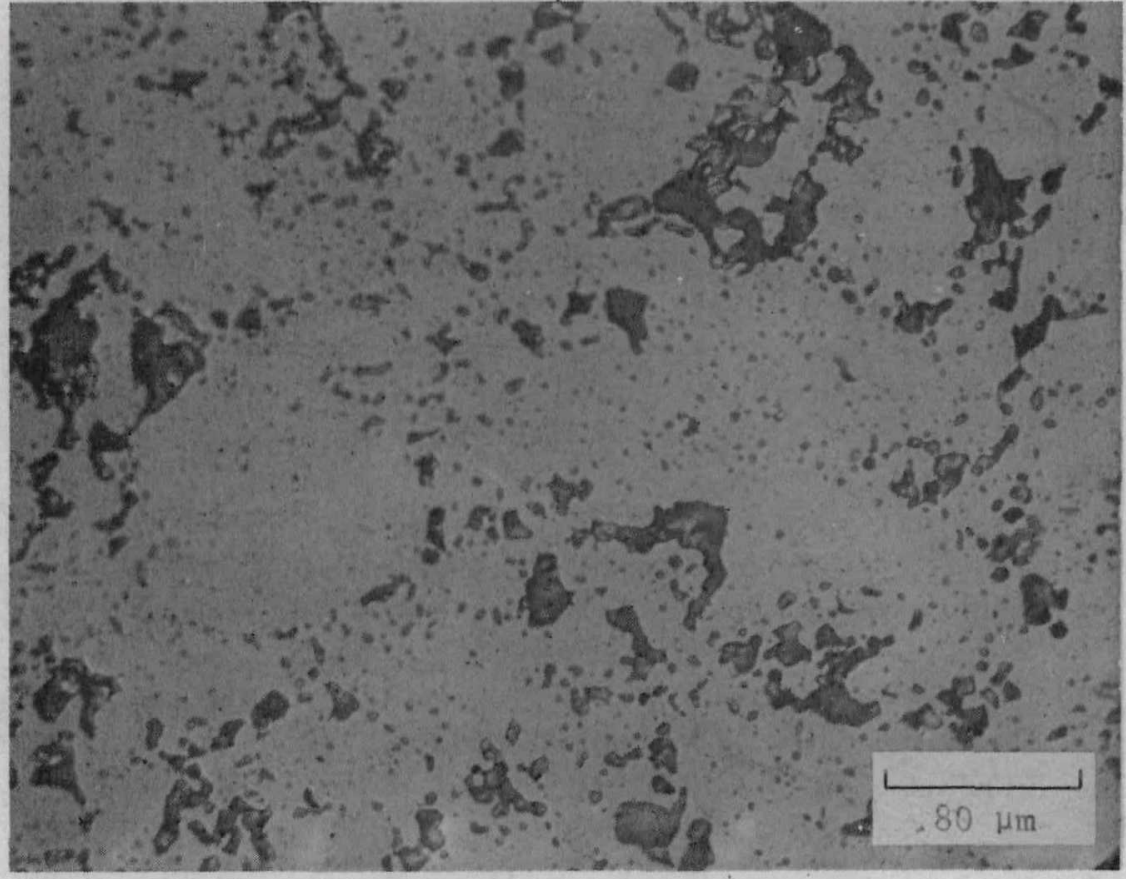

b. GPHS Pellet 33, 1-min Ramp

FIGURE 16. Effect of Pressure Ramp on Porosity in SRL GPHS Pellets 
MHW Permutation

Pellet of Variables

Run No. SST HPP RAMP HPT

Microstructure

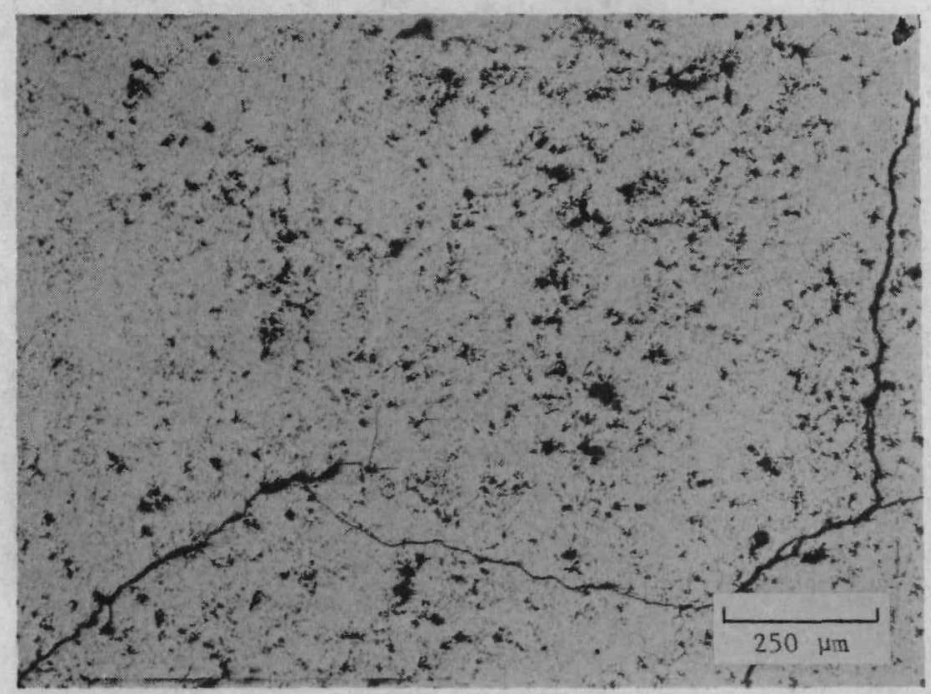

2

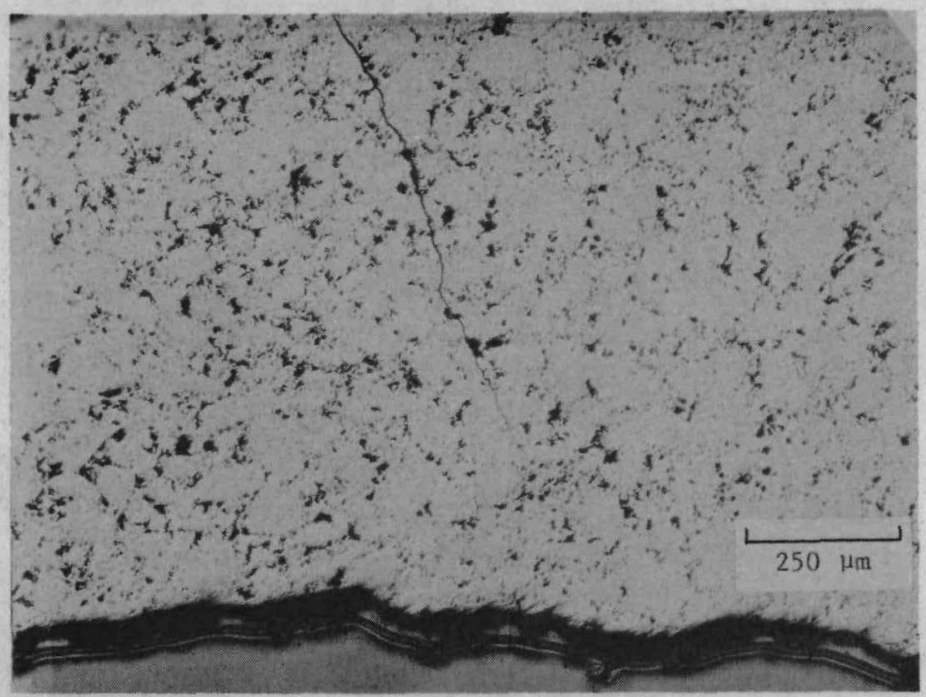

FIGURE 17. Effect of Pressure Ramp on Microstructure of MHW Pellets a. Low Shard Sintering Temperature, High Hot Press Pressure, High Hot Press Temperature 
MHW Permutation

Pellet of Variables

Run No. SST HPP RAMP HPT Microstructure

8

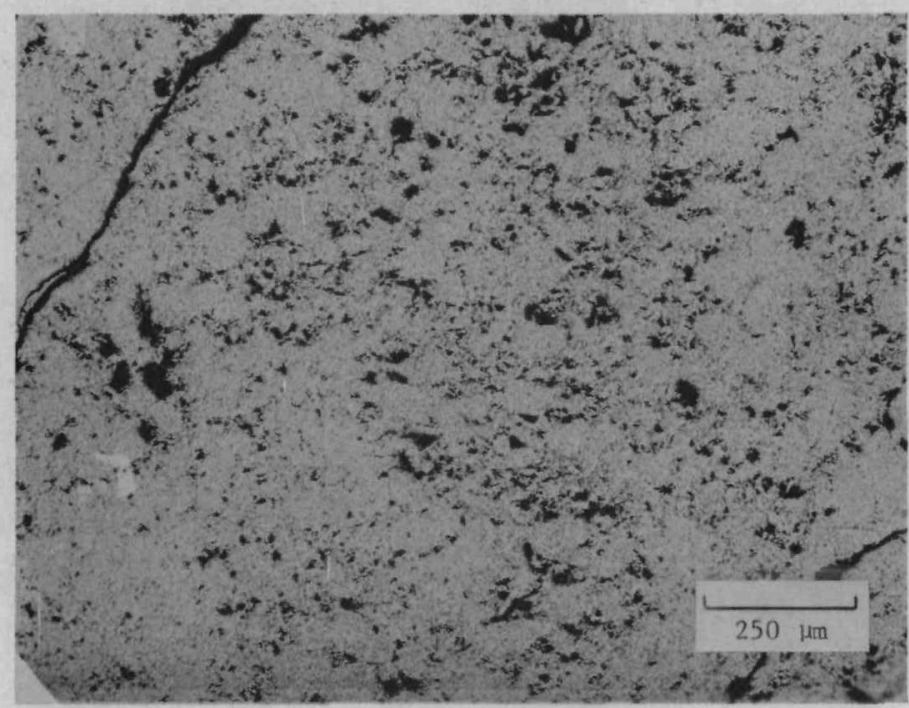

9

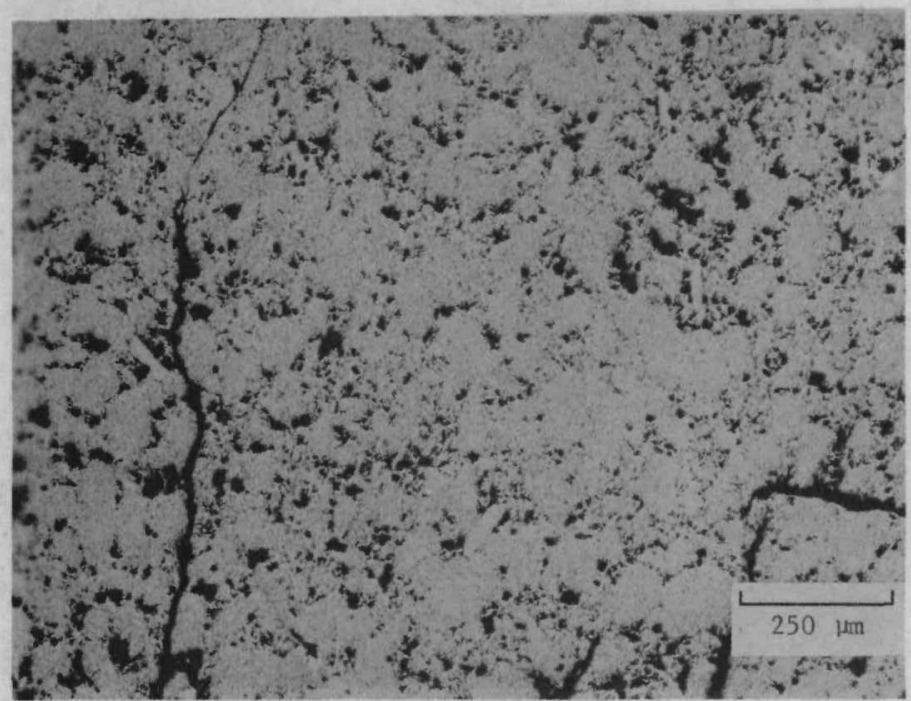

FIGURE 17. Continued. b. High Granule Sintering Temperature, High Hot Press Pressure, Low Hot Press Temperature. 

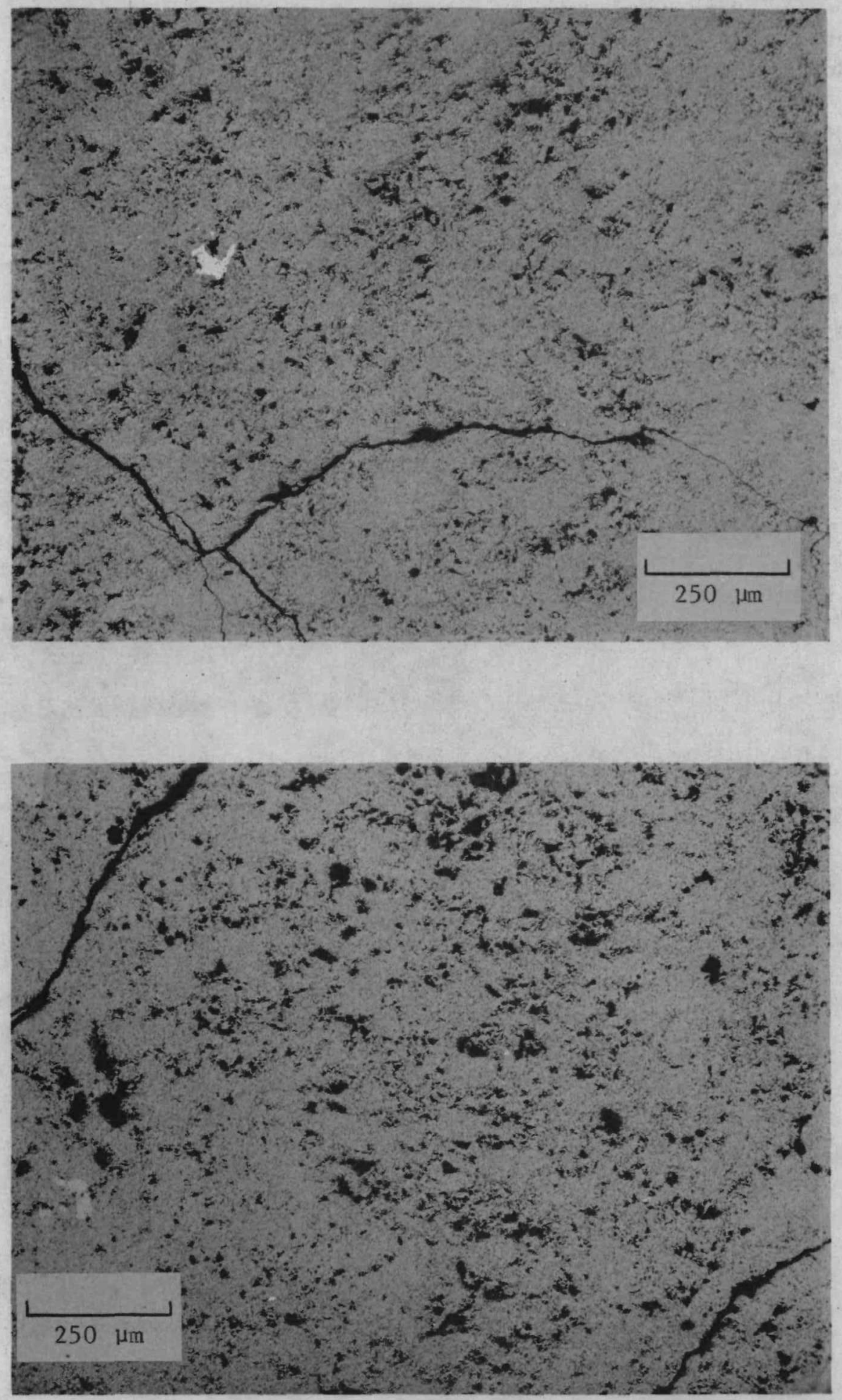

FIGURE 18. Variation in Porosity of MHW Pellet 8. 
MHW Permutation

Pellet of Variables

Run No. SST HPP RAMP HPT

8

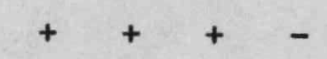

7

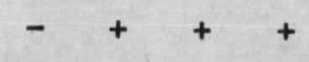

4

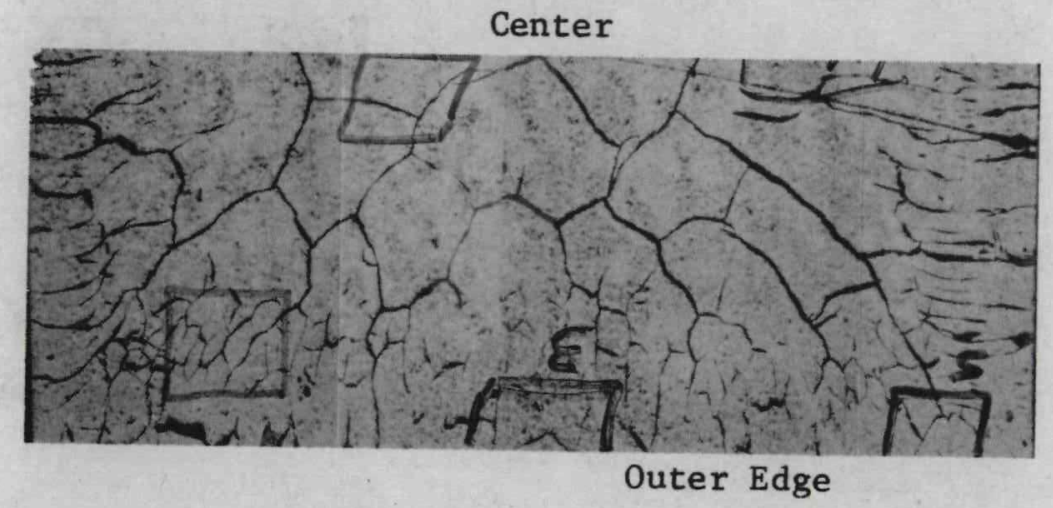

Microstructure

Center
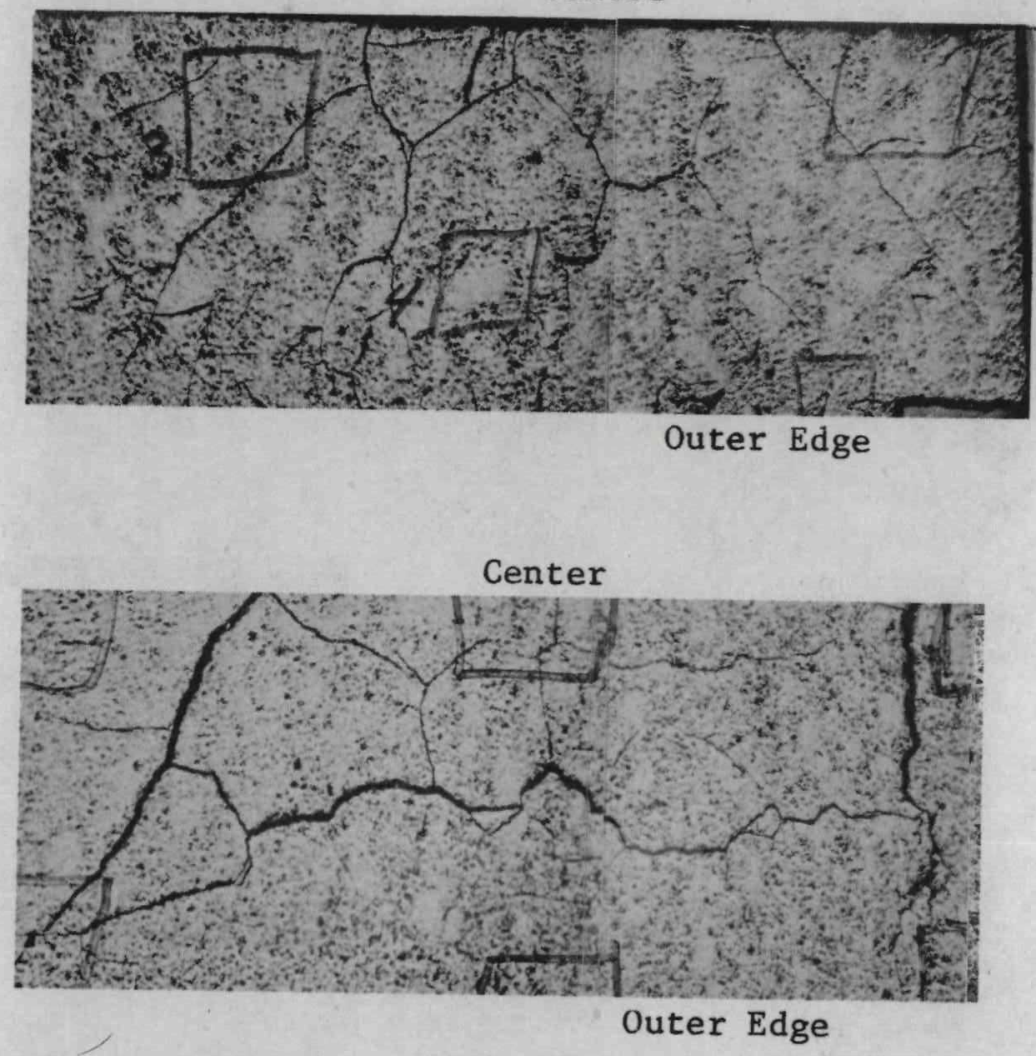

Outer Edge

FIGURE 19. Effect of Interaction of Hot-Press Pressure and Pressure Pressure, Fast Ramp.

\section{Ramp on Mlcrostructure of MH Pellets. a. High Hot-Press
P. H}

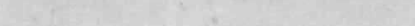


MHW Permutation

Pellet of Variables

Run No. SST HPP RAMP HPT

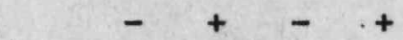

5

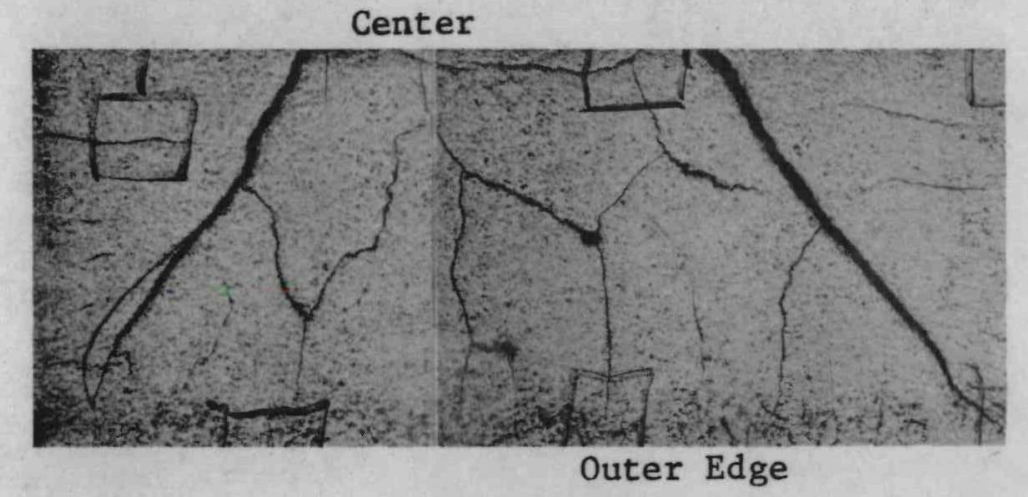

9
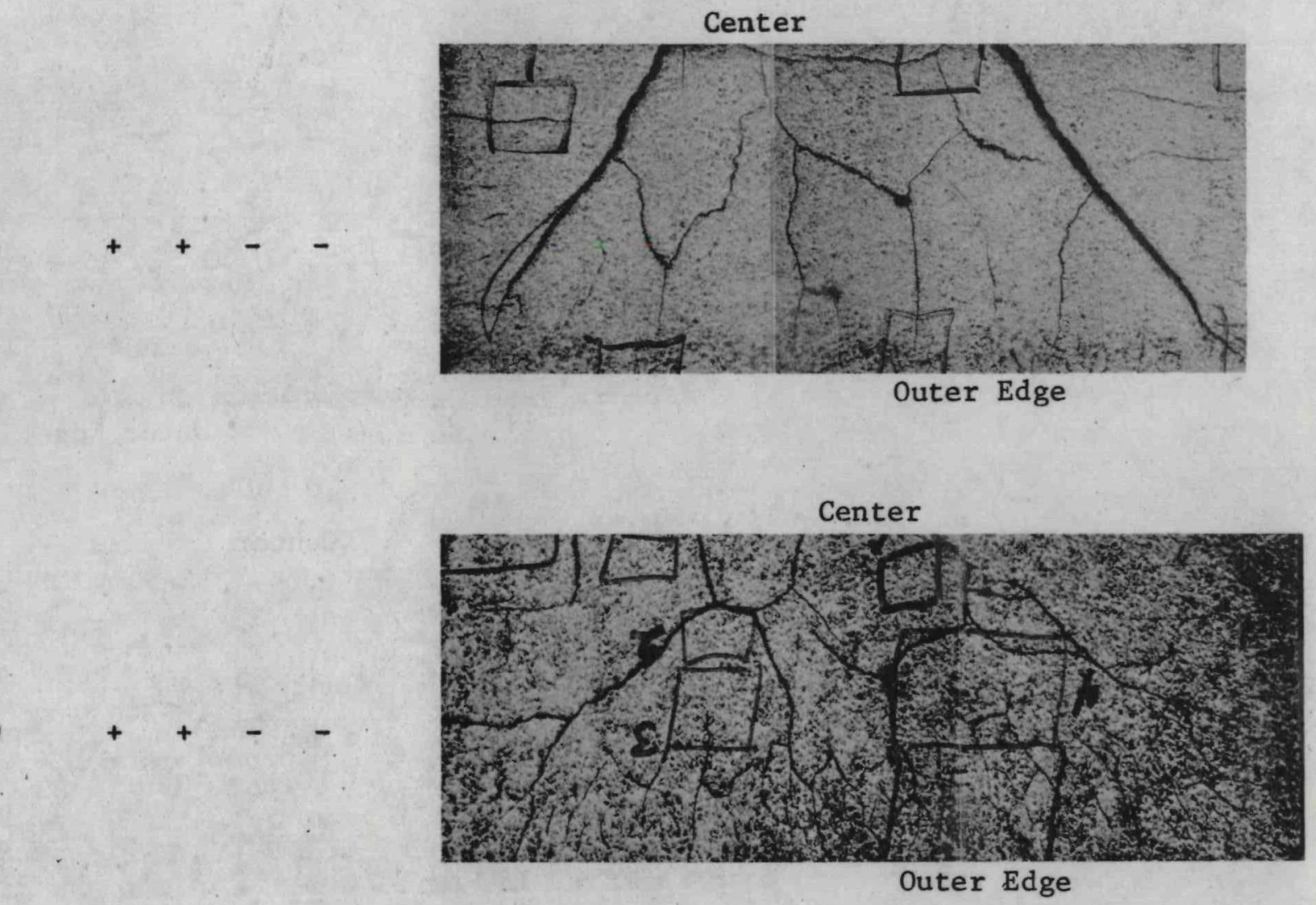

FIGURE 19. Continued. b. High Hot Pres Pressure, Slow Ramp 
MHW Permutation

Pellet of Variables

Run No. SST HPP RAMP HPT

$6+-++$

3
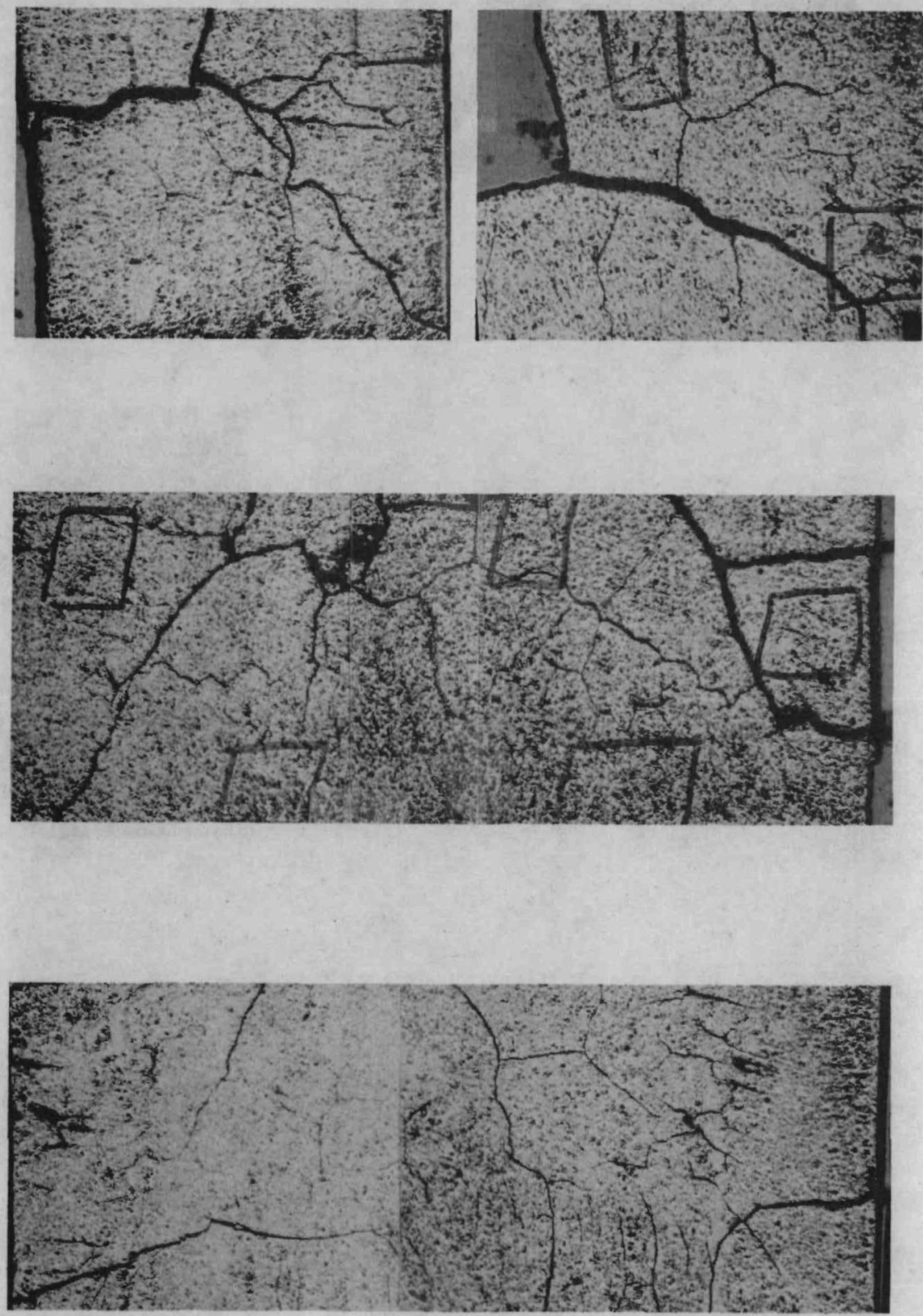

FIGURE 19. Continued. c. Low Hot Pres Pressure, Fast Ramp 

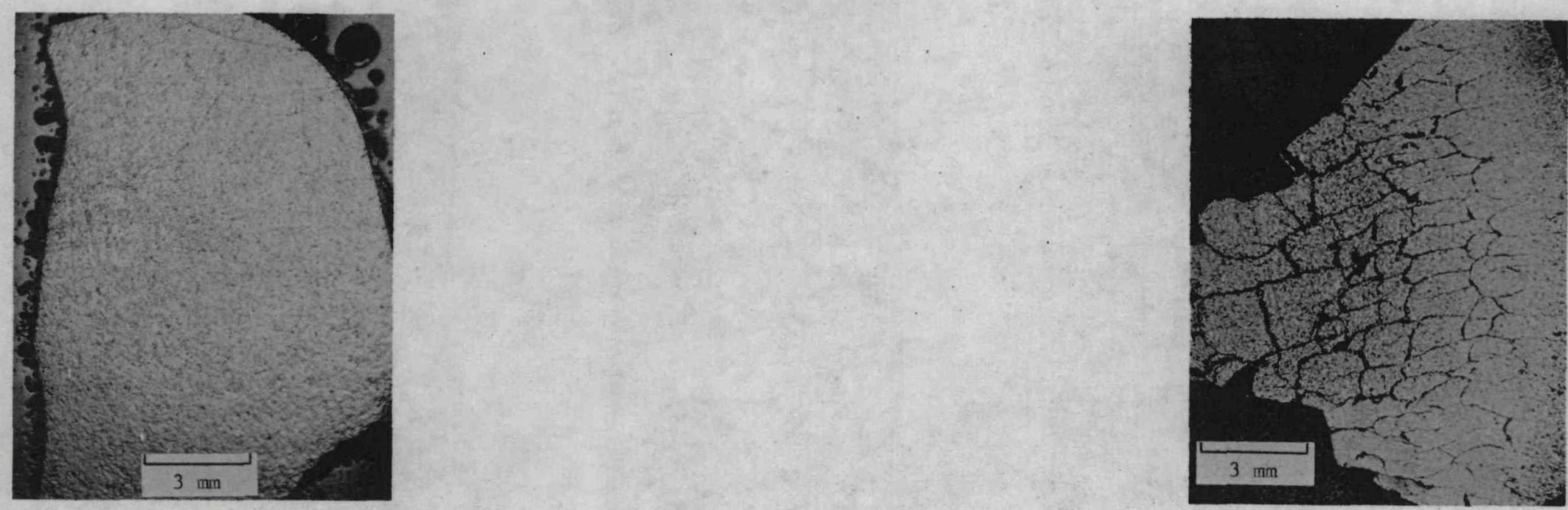

1
M
1

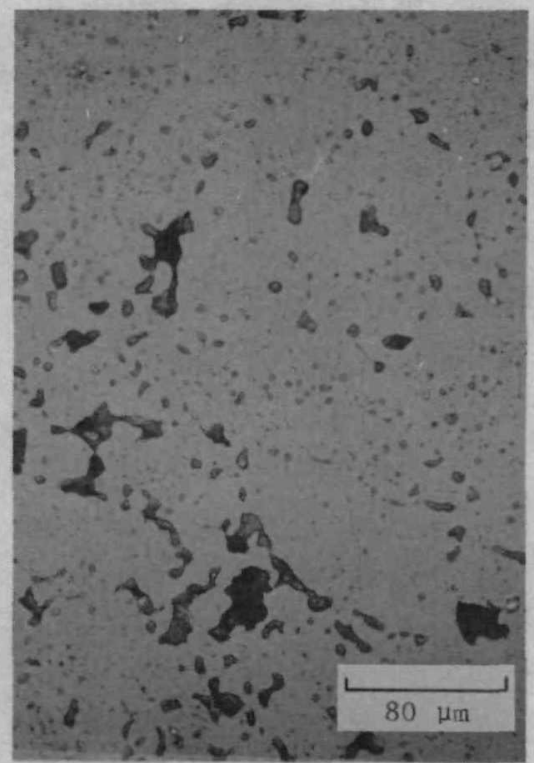

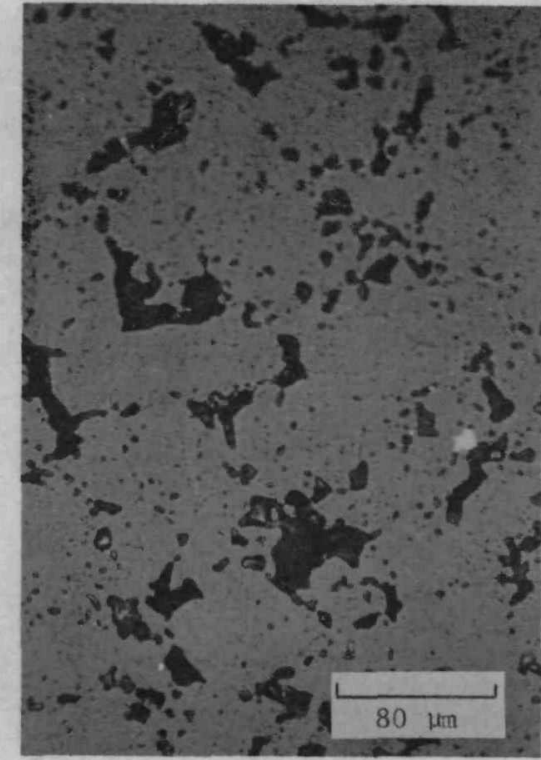

b. PEF GPHS 30 , Ideal Microstructure.

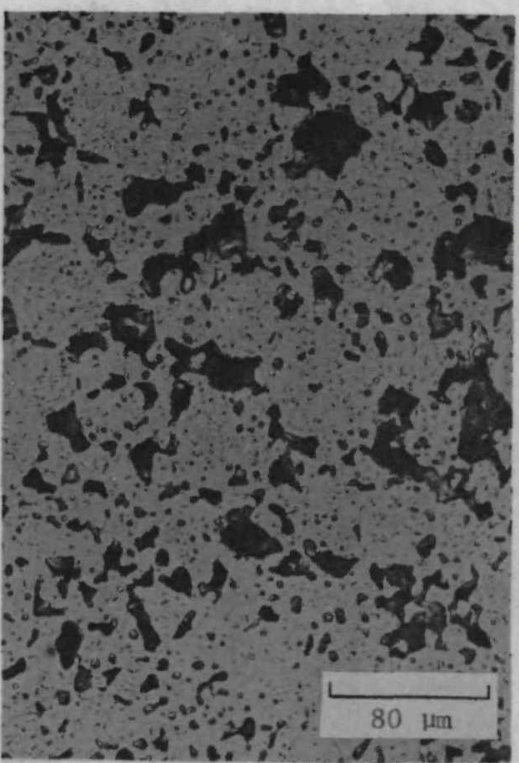

c. MHW Sphere 28. Many large intershard pores, but poor hot pressing conditions

but good hot pressing conditions
but large intershard pores,

FIGURE 20. Effects of Porosity and Hot Pressing Conditions on Pellet Cracking 


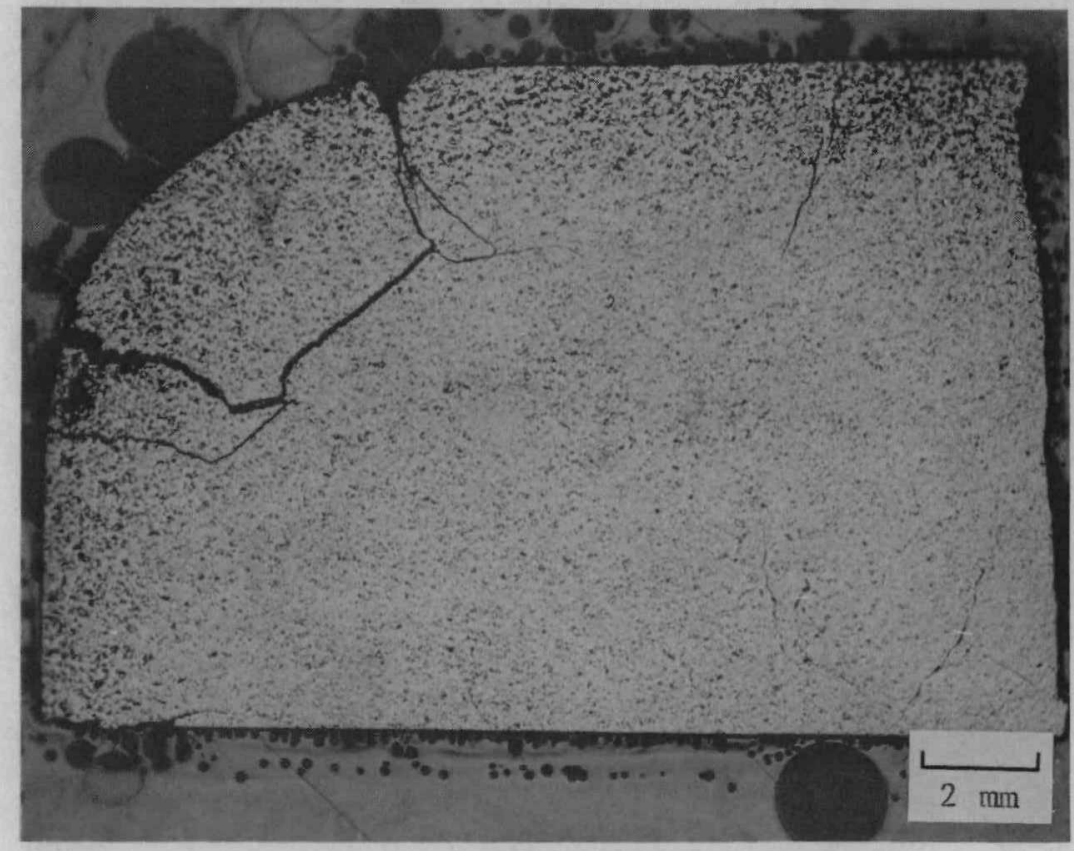

a. PEF GPHS Pellet 6

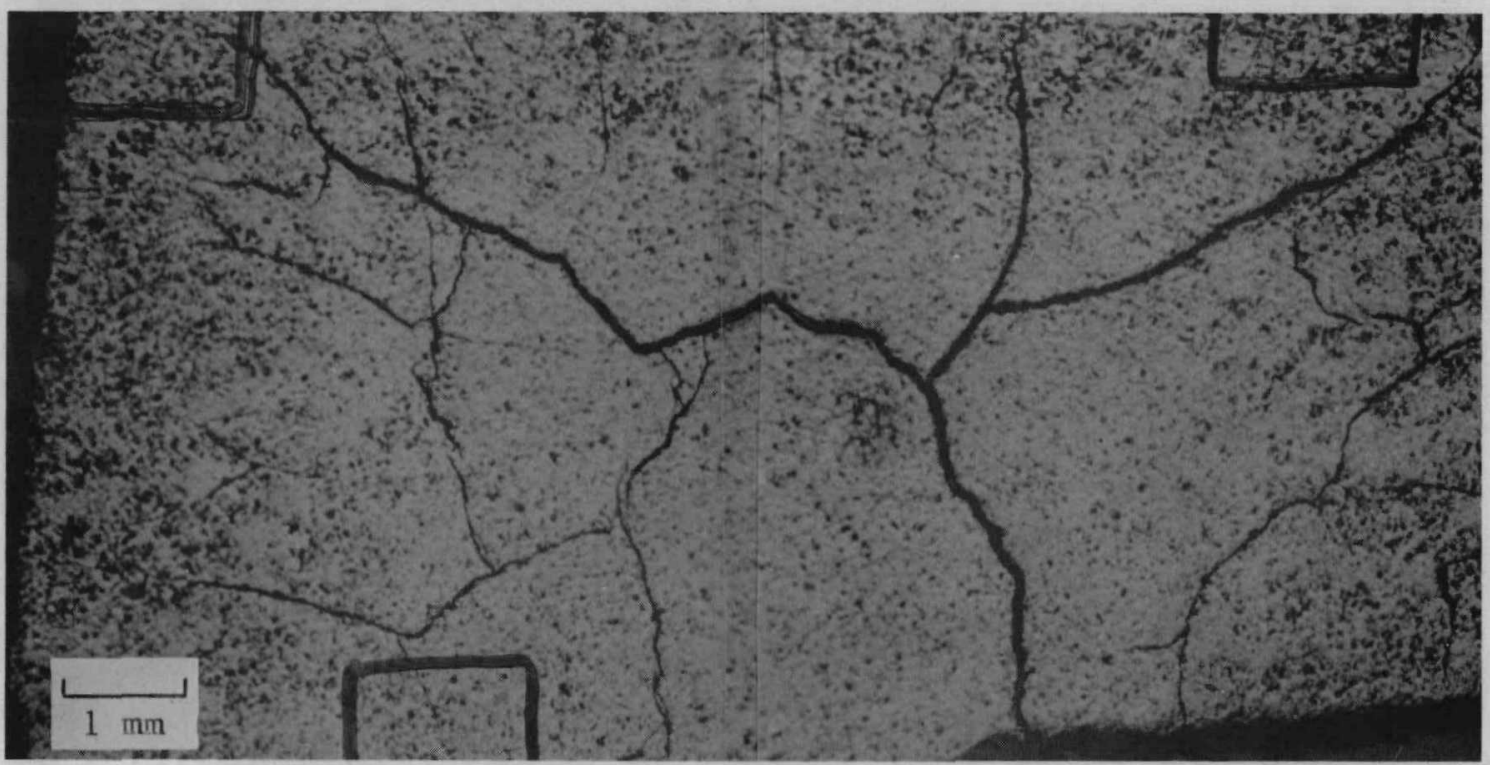

b. MHW Parametric Pellet 2

FIGURE 21. Low-Density Outer Band Caused by Combination of Low Shard Sintering Temperature and High Hot Pressing Temperature 


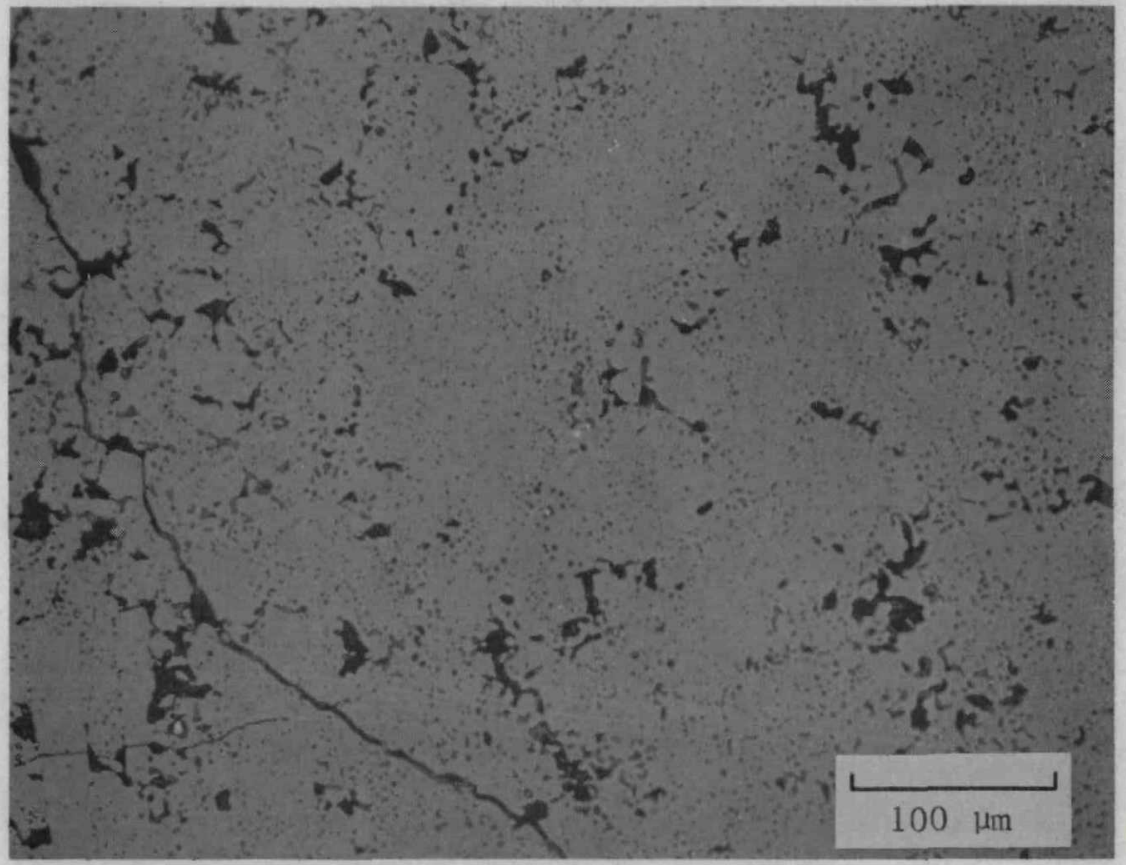

a. GPHS Pellet 16, Low Shard Sintering and Hot Pressing Temperature

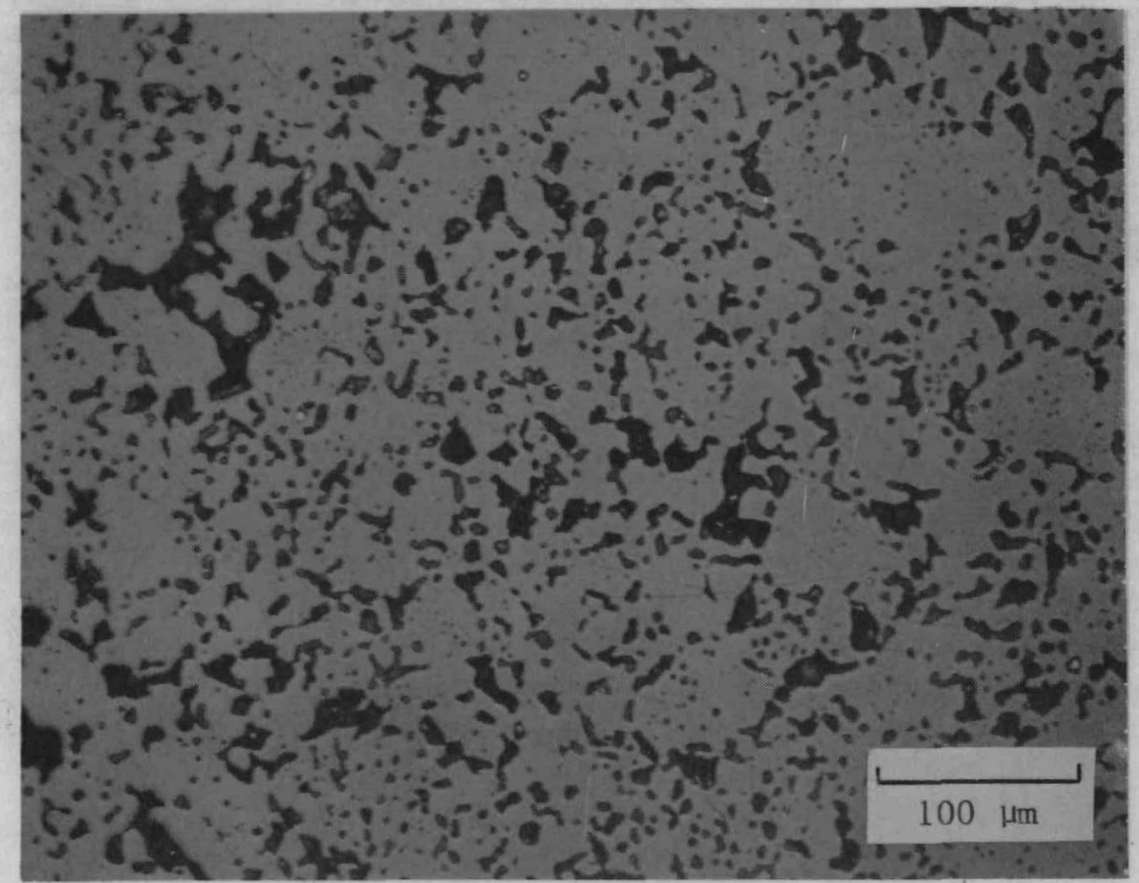

b. GPHS Pellet 17, Centerline Pellet

FIGURE 22. Effect of Low Shard Sintering Temperature and Low Hot Pressing Temperature on Pellet Porosity 


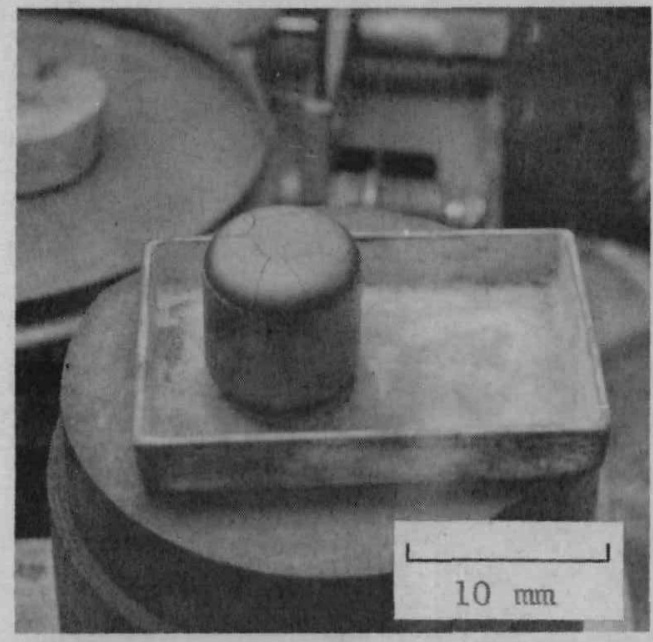
a. PEF GPHS Pellet 12, Load Initiated at $1100^{\circ} \mathrm{C}$

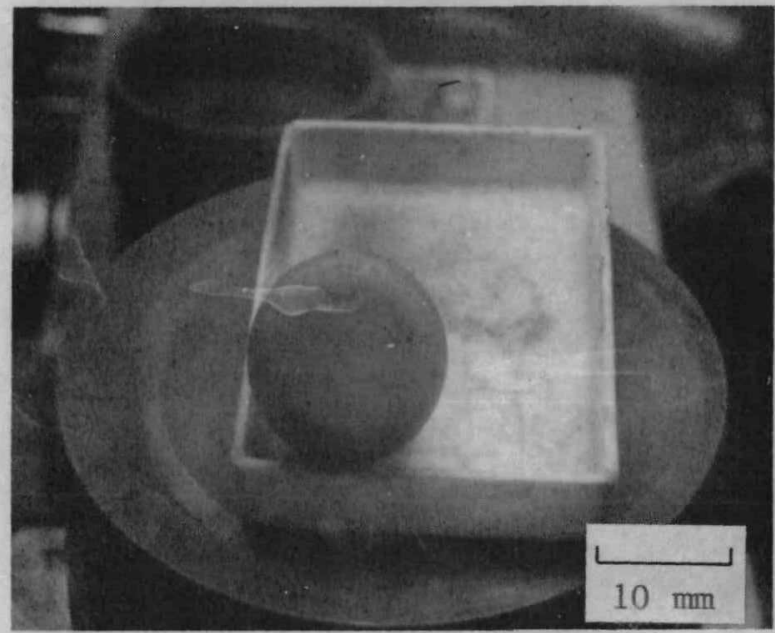

b. PEF GPHS 17 , Load Initiated at $1350^{\circ} \mathrm{C}$ (Centerline)

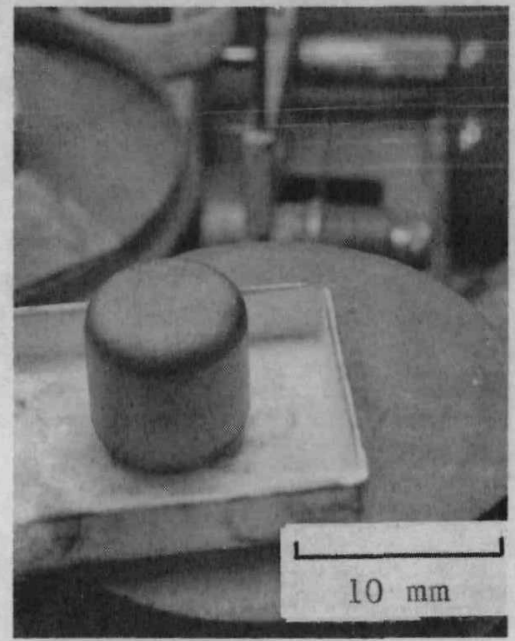

c. PEF GPHS 13, Load Initiated at $1500^{\circ} \mathrm{C}$

FIGURE 23. Effect of Load Initiation Temperature on Pellet Cracking 


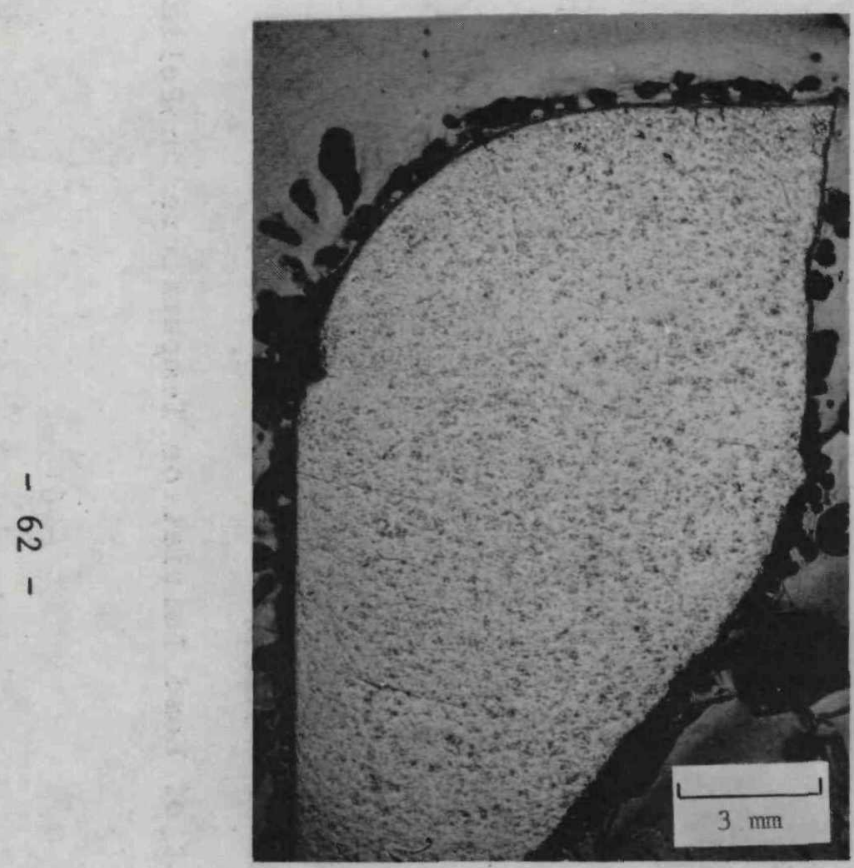

a. PEF GPHS Pellet 12, Load Initiated at $1100^{\circ} \mathrm{C}$

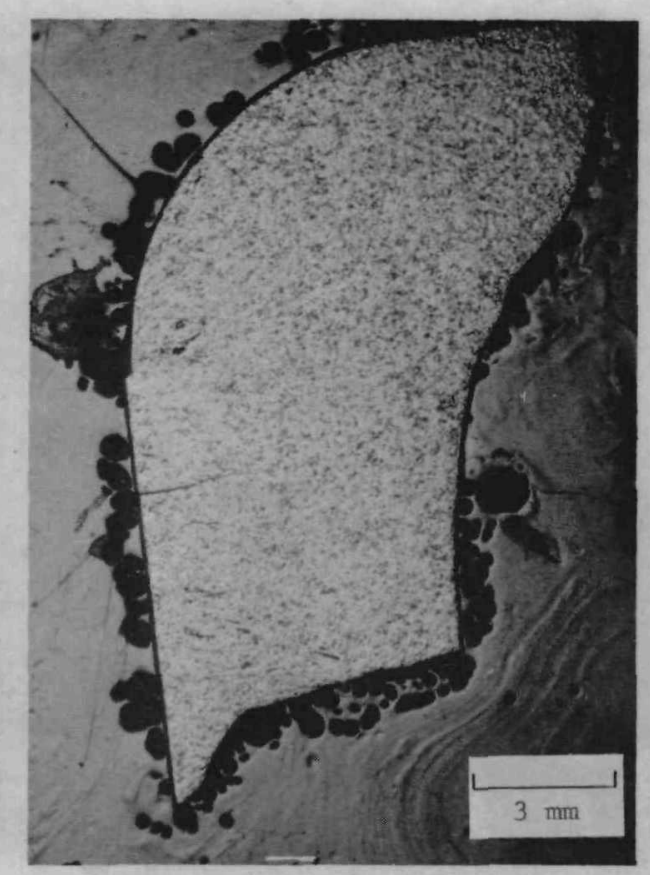

b. PEF GPHS Pellet 17, Load Initiated at $1350^{\circ} \mathrm{C}$

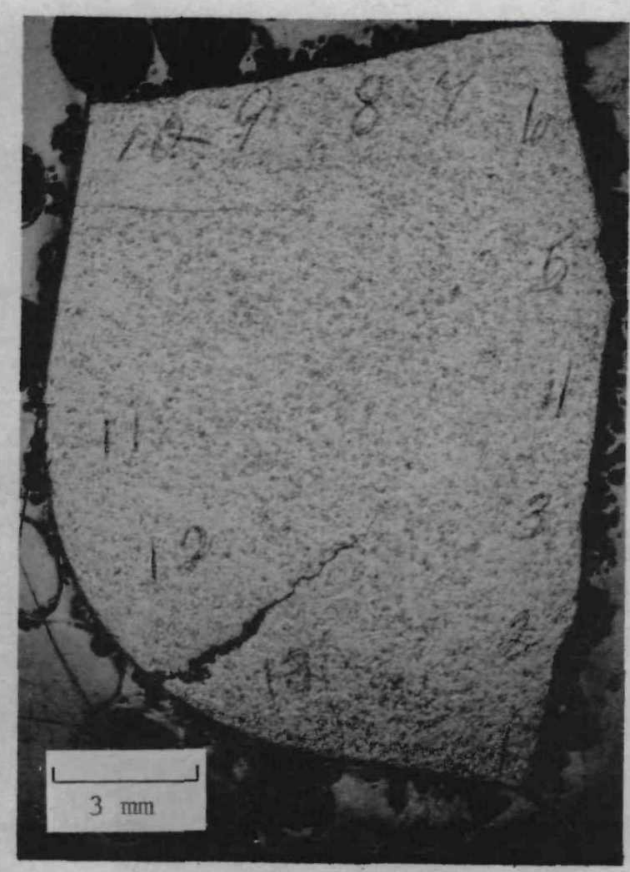

c. PEF GPHS Pellet 13, Load Initiated at $1500^{\circ} \mathrm{C}$

FIGURE 24. Effect of Load Initiation Temperature on Internal Cracking 


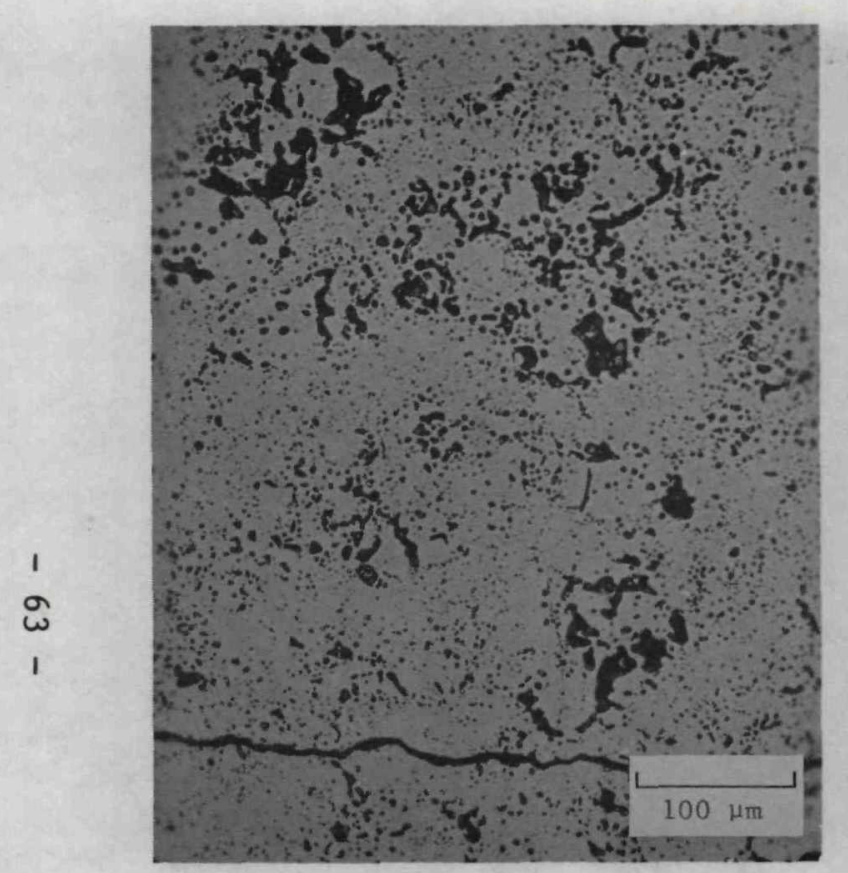

a. PEF GPHS Pellet 12, Load Initiated at $1100^{\circ} \mathrm{C}$

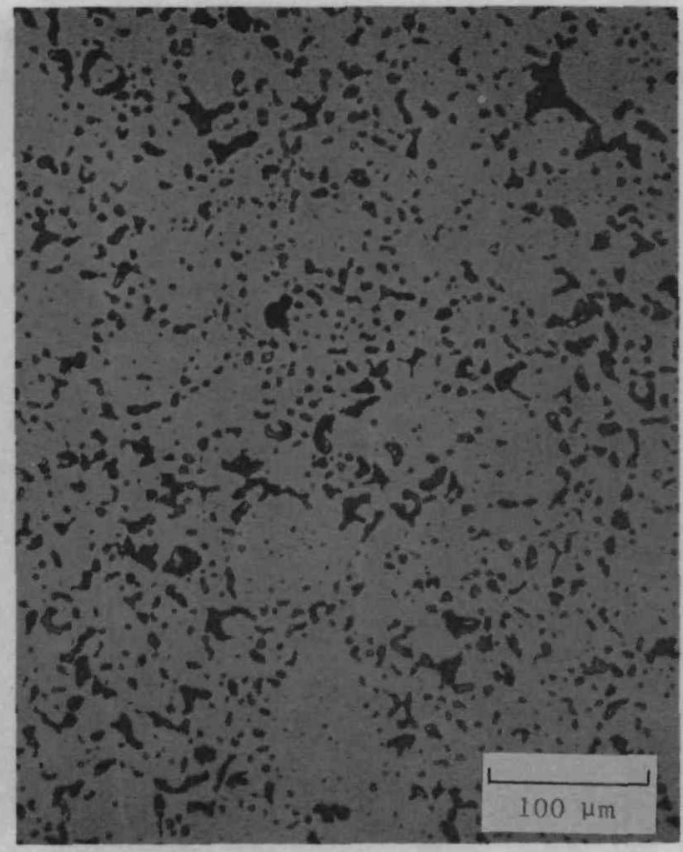

b. PEF GPHS Pellet 17, Load Initiated at $1350^{\circ} \mathrm{C}$ (Centerline)

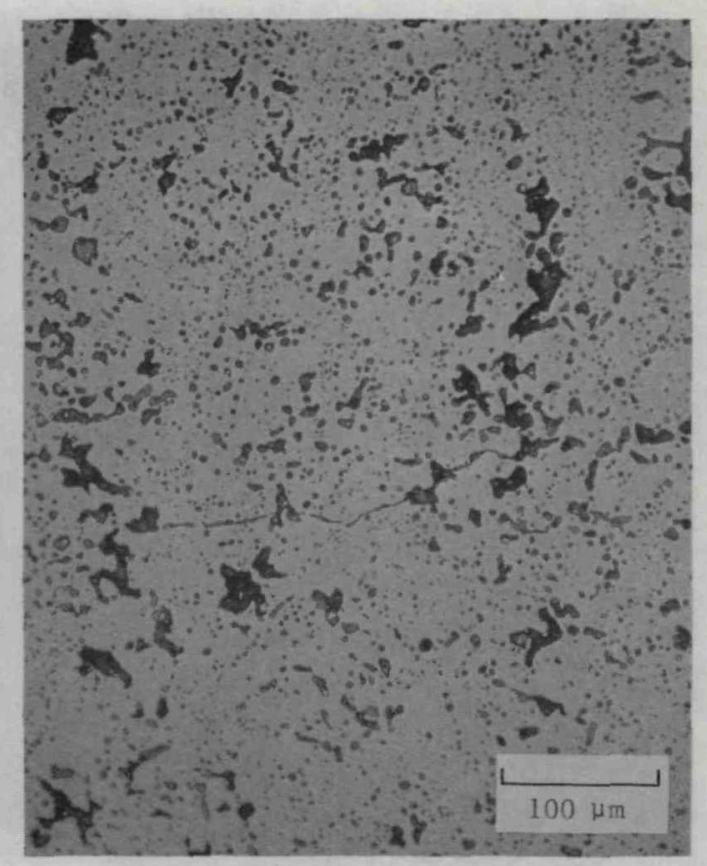

c. PEF GPHS Pellet 13, Load Initiated at $1500^{\circ} \mathrm{C}$

FIGURE 25. Effect of Load Initiation Temperature on Pellet Microstructure 


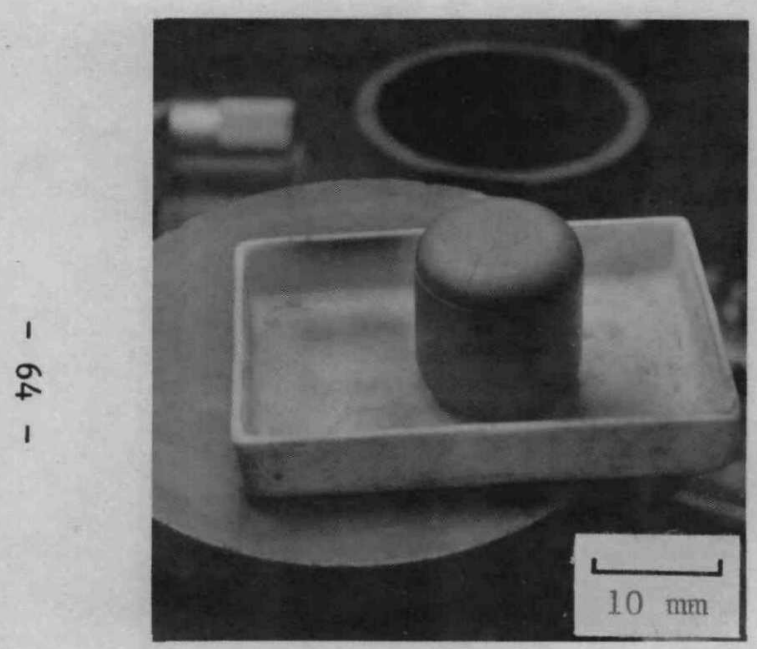

a. External Cracking

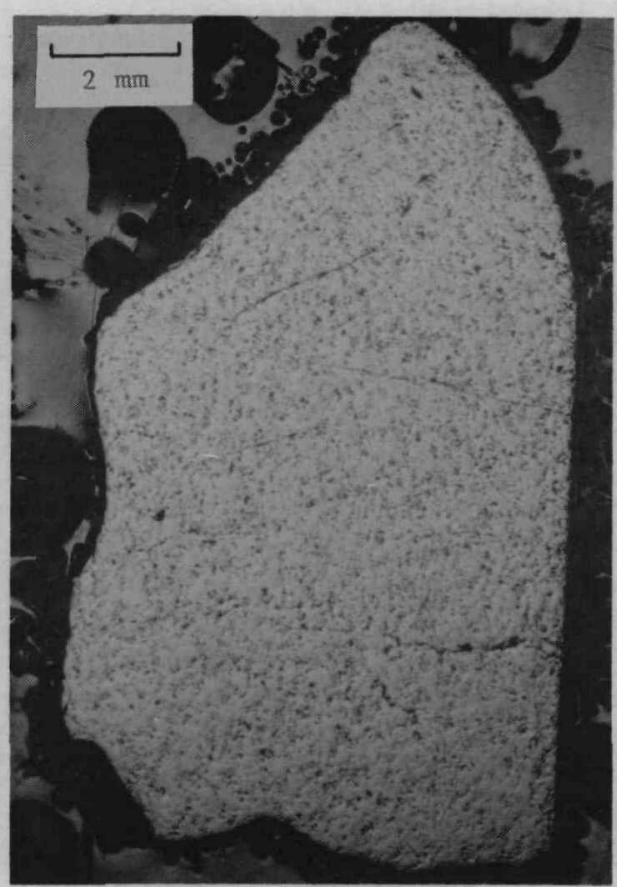

b. Internal Cracking

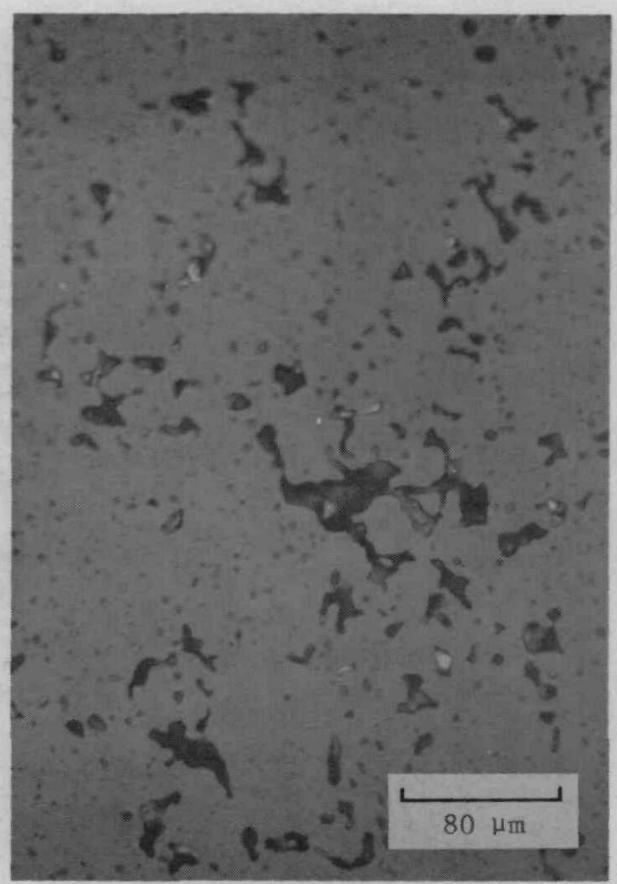

c. Microstructure

FIGURE 26. Effects of Two-Percent Increase in Die Charge on Pellet Cracking and Microstructure of PEF GPHS Pellet 20 


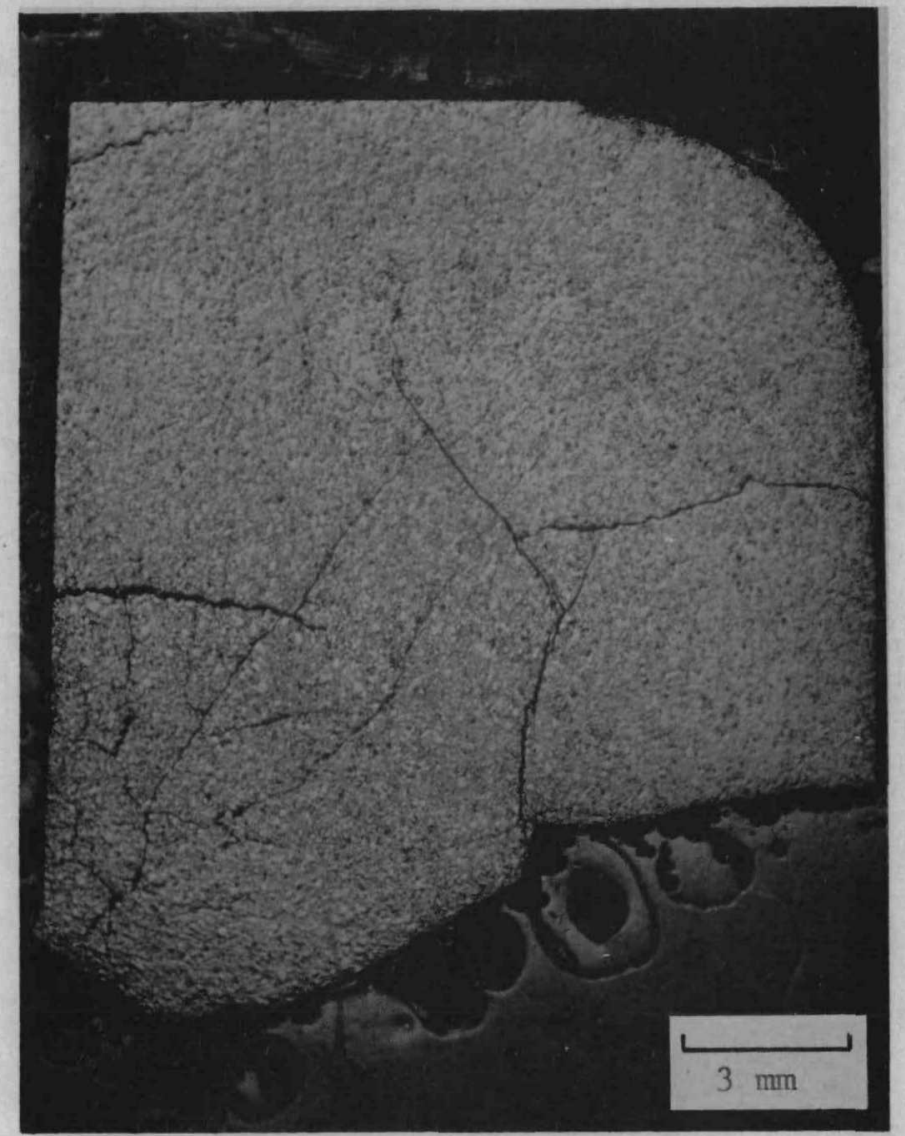

FIGURE 27. Internal Cracking Caused by Tight Die Punches (PEF GPHS Pellet 23) 


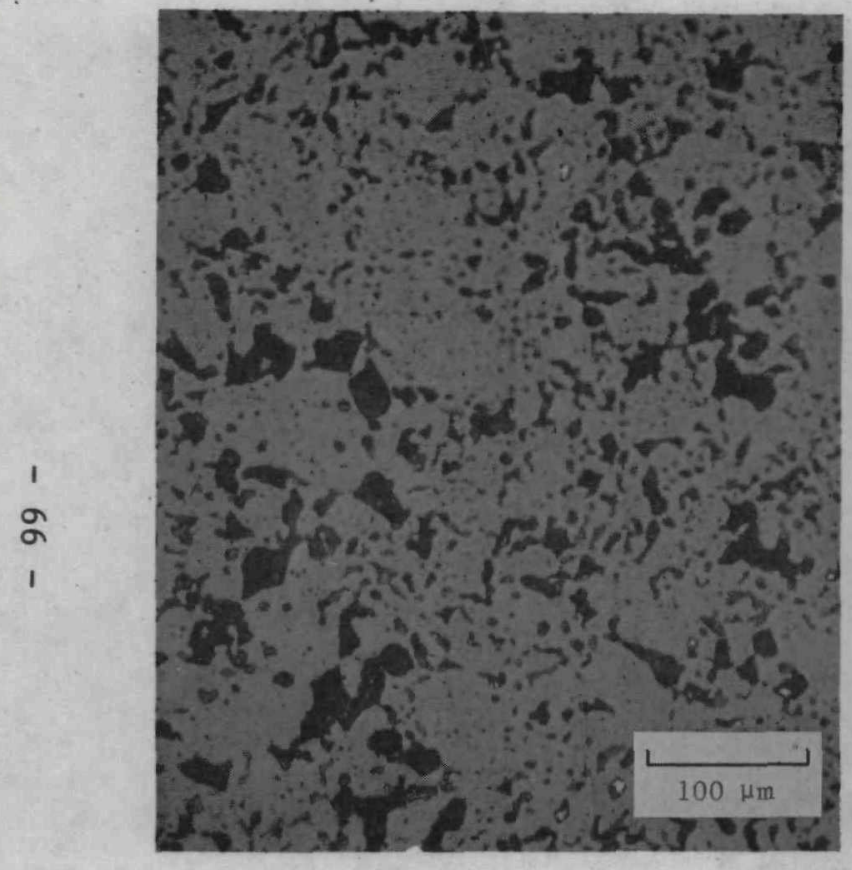

a. Coarsened Pores in PEF GPHS Pellet 23

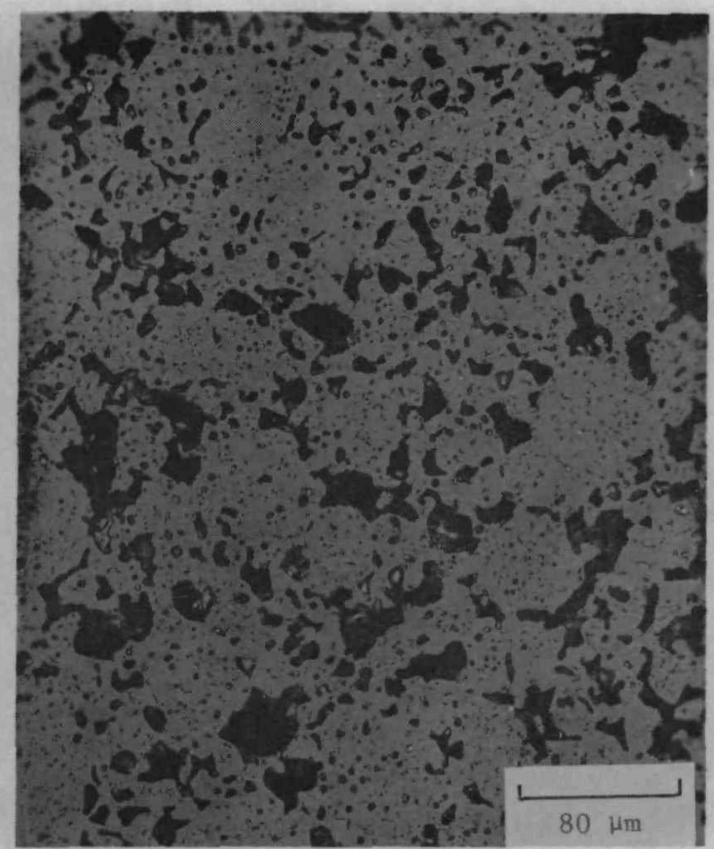

b. Coarsened Pores in MHW Sphere 28

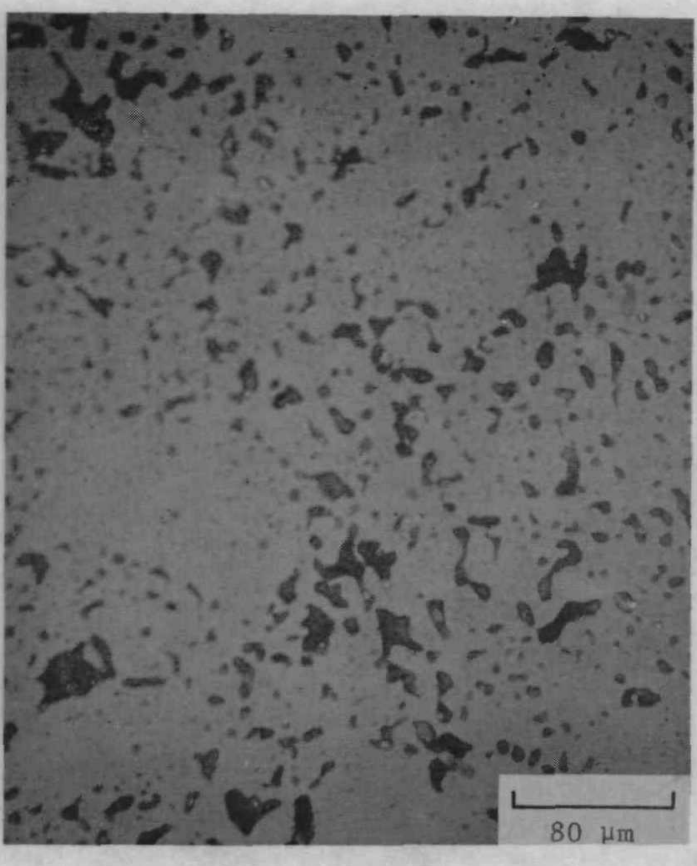

c. Uncoarsened Pores in PEF GPHS Pellet 23

FIGURE 28. Effect of Tight Die Punches on Pellet Microstructure 


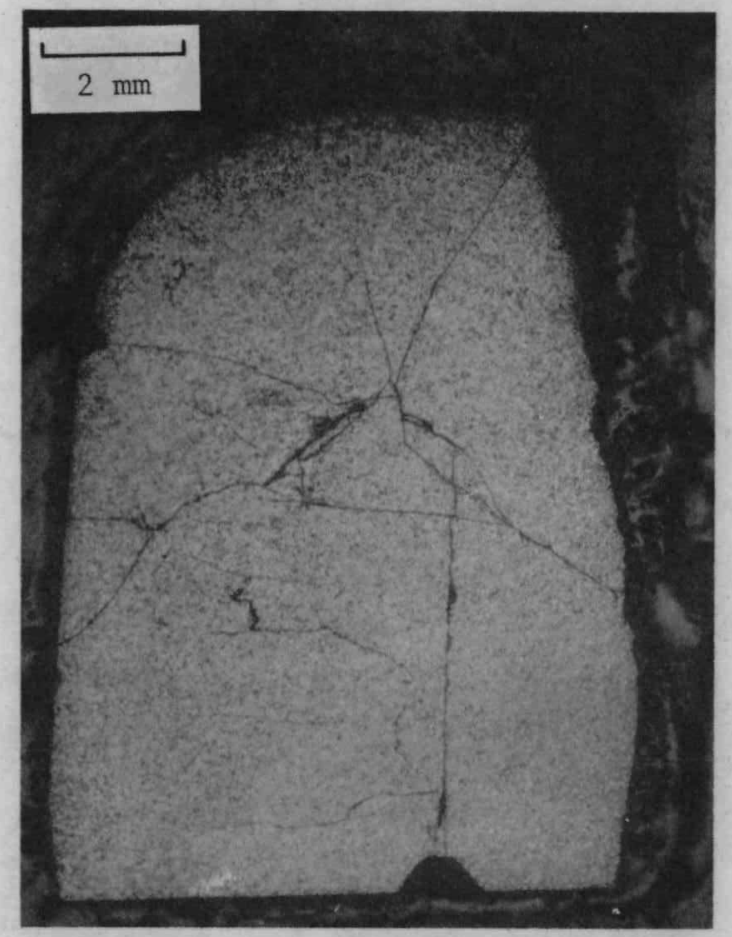

FIGURE 29. Cracking of PEF GPHS Pellet 39 Caused by Ar/5\% $\mathrm{O}_{2}$ Shard Sintering Atmosphere 


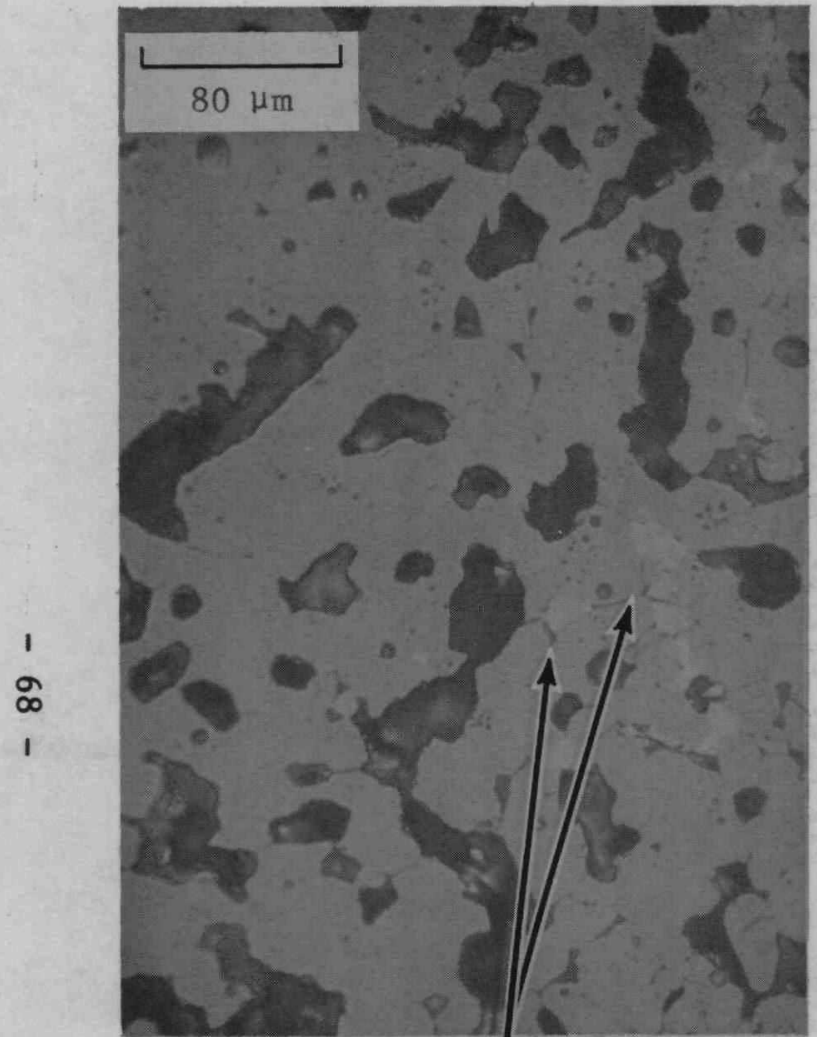

Grain-Boundary Separation

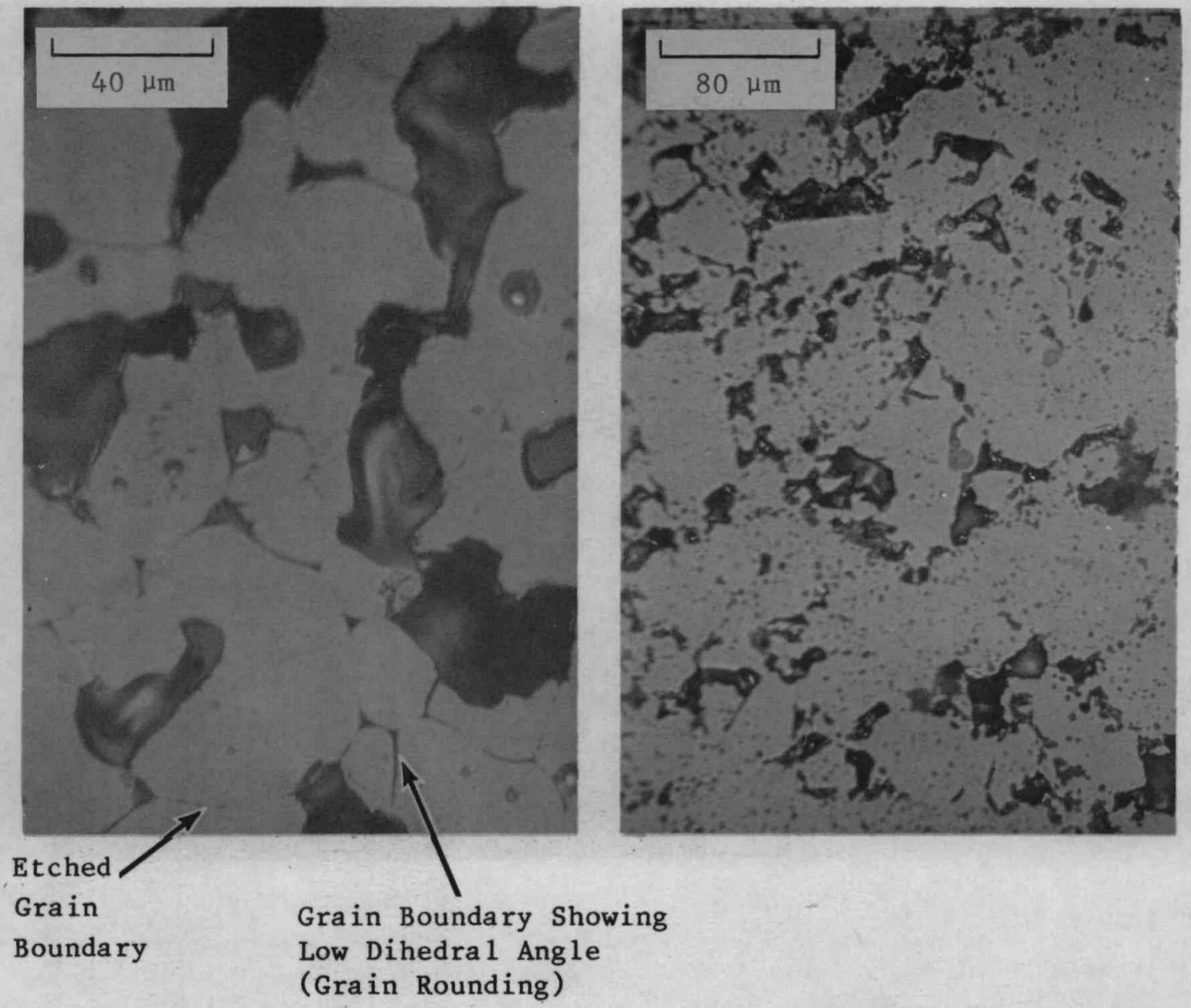

a. As Polished

c. PEF GPHS Pellet 30 , Centerline

FIGURE 30. Extensive Pore Coarsening Caused by High Gas Pressure 


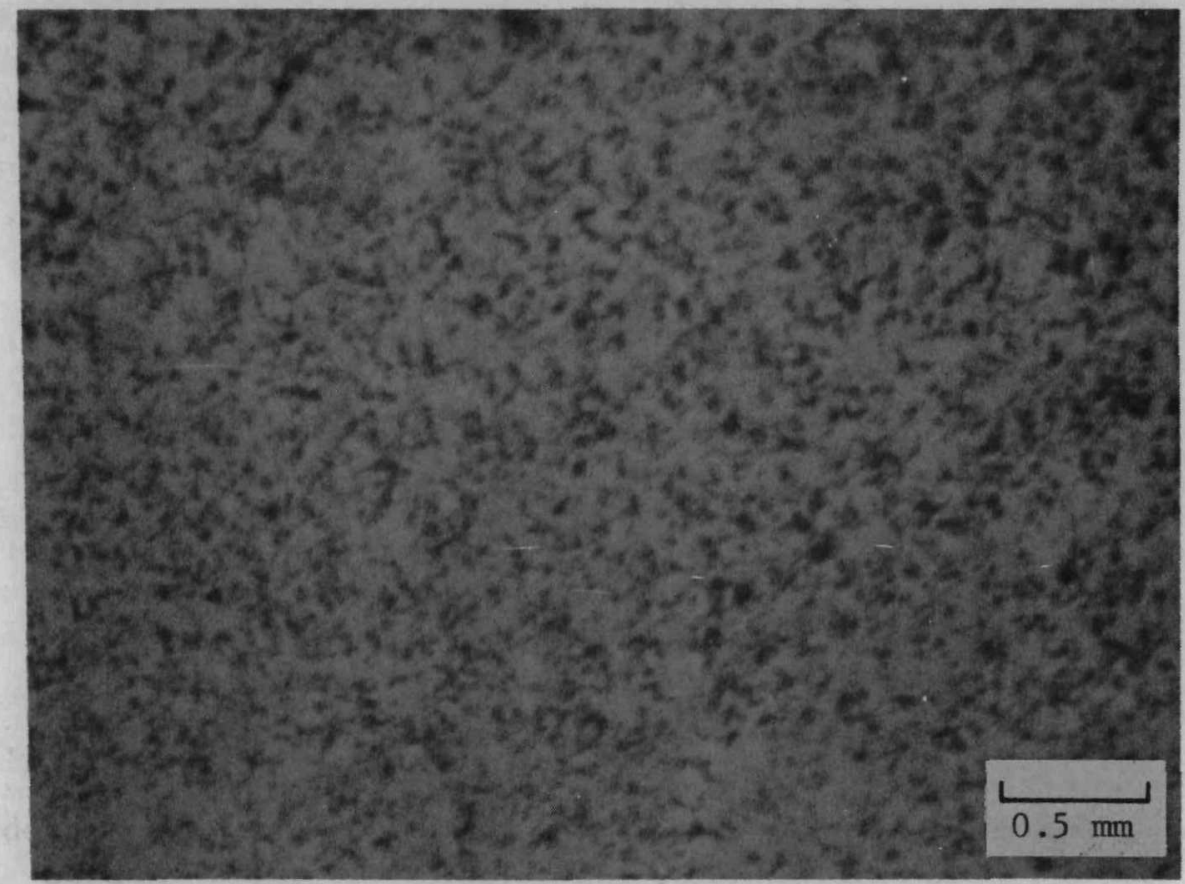

a. Normal Microstructure

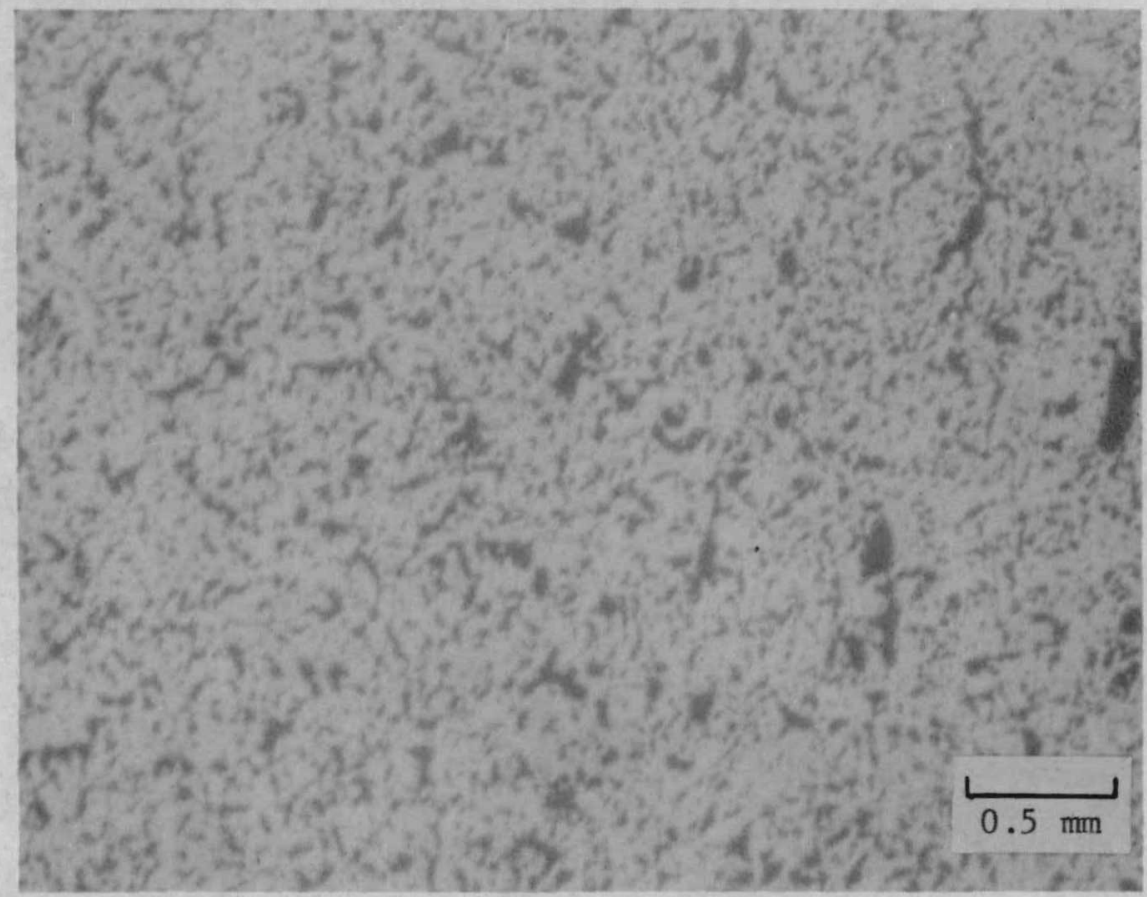

b. PEF GPHS Pellet 37. Enlarged pores can act as crack initiators

FIGURE 31. Comparison of Normal GPHS Microstructure with PEF GPHS Pellet 37 


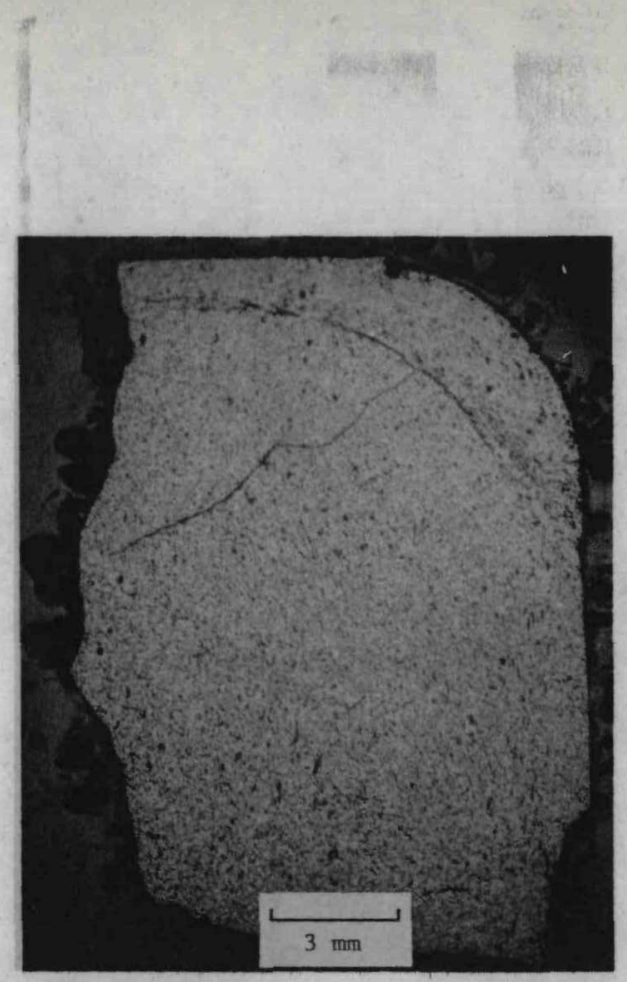

FIGURE 32. Paucity of cracking in PEF GPHS Pellet 37, Due Probably to Very High Hot Press Pressure and Slow Pressure Release.

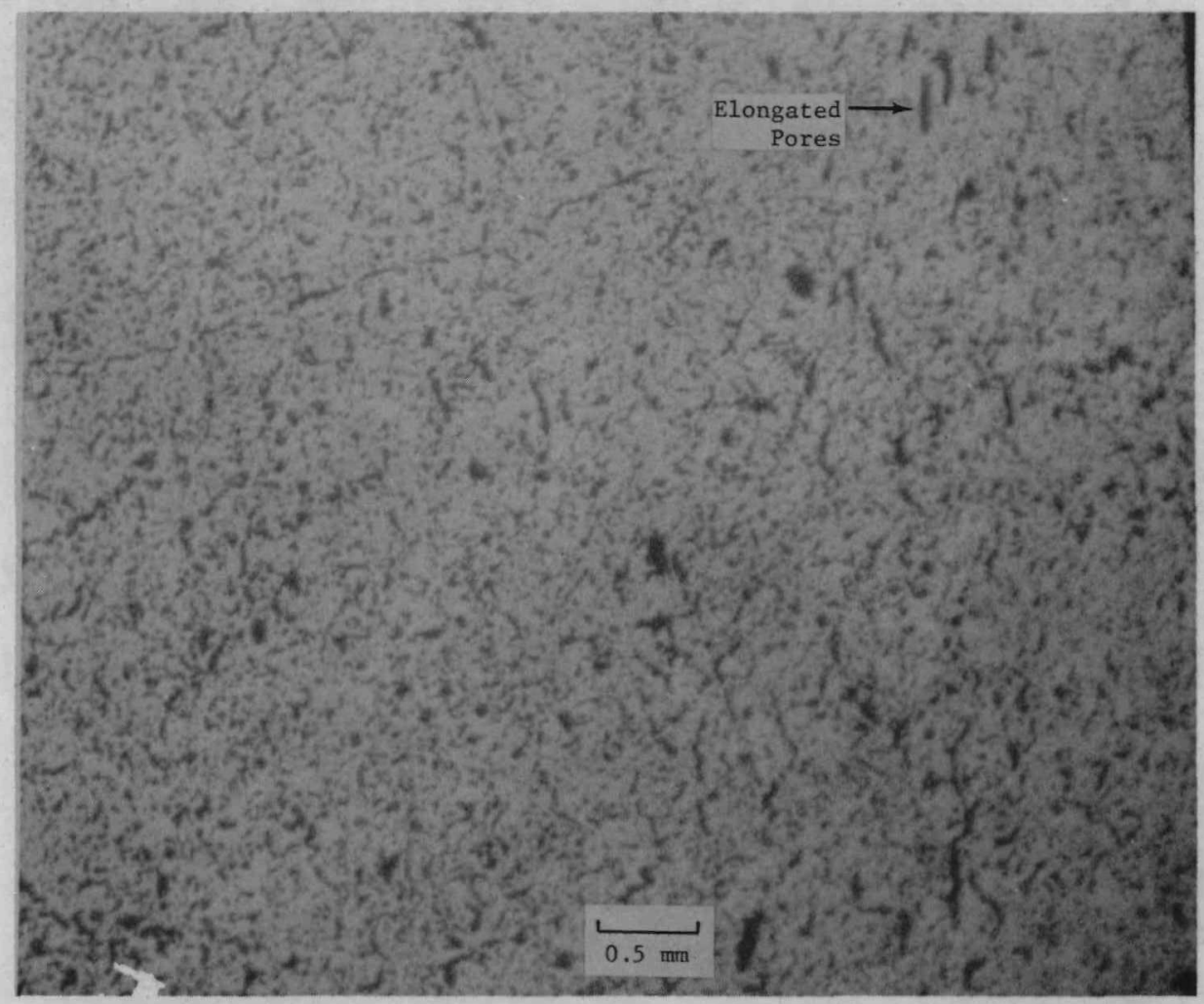

FIGURE 33. Elongated Pores Near Outside Edge of PEF GPHS Pellet 37 . 


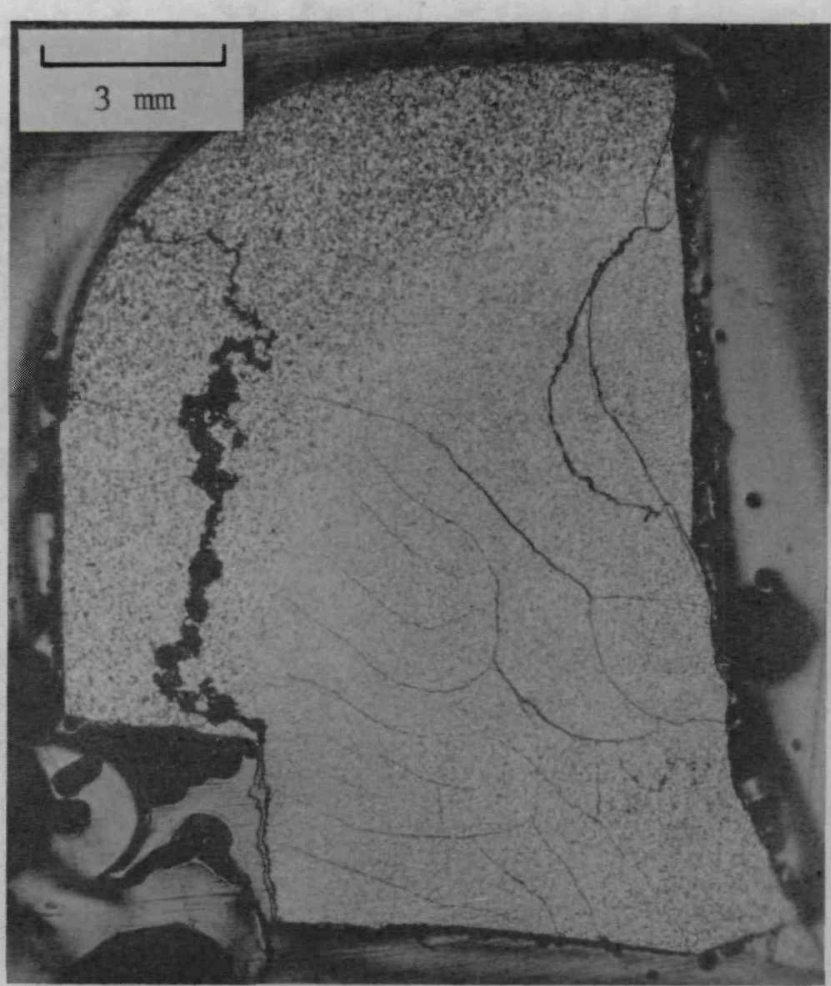

a. Fabricated at LANL

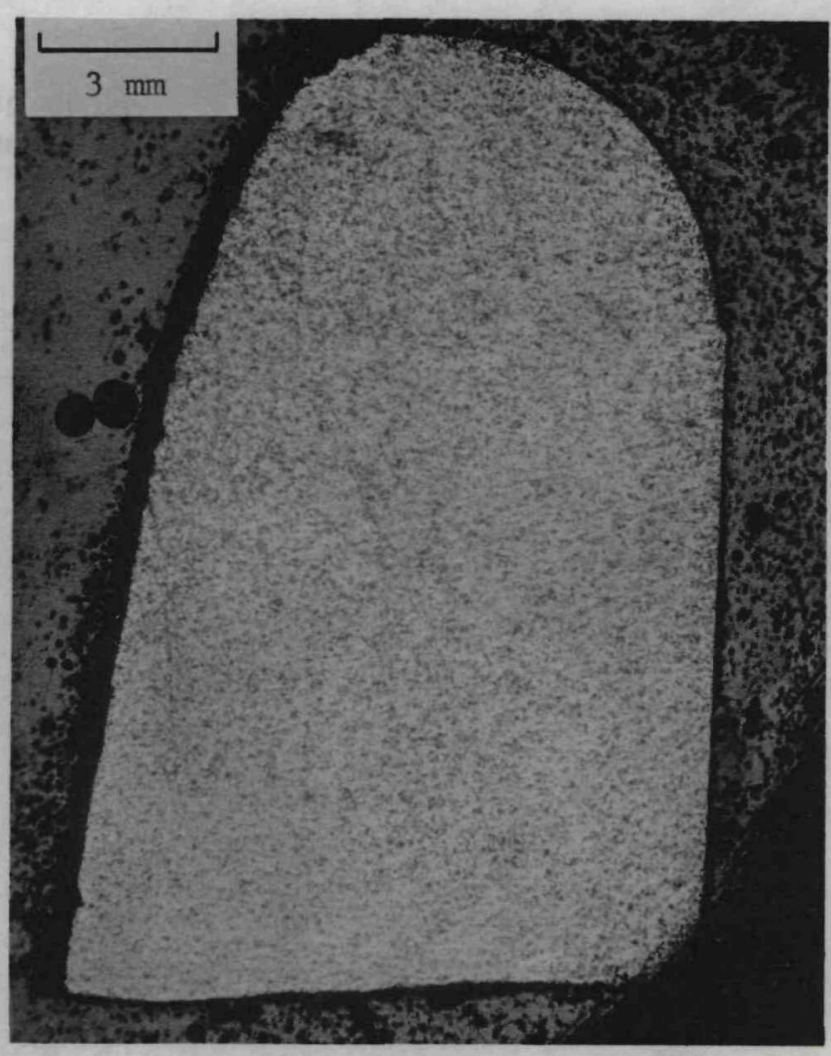

b. Fabricated in SRL PEF

FIGURE 34. Contrasting Microstructures of Typical GPHS Pellets 


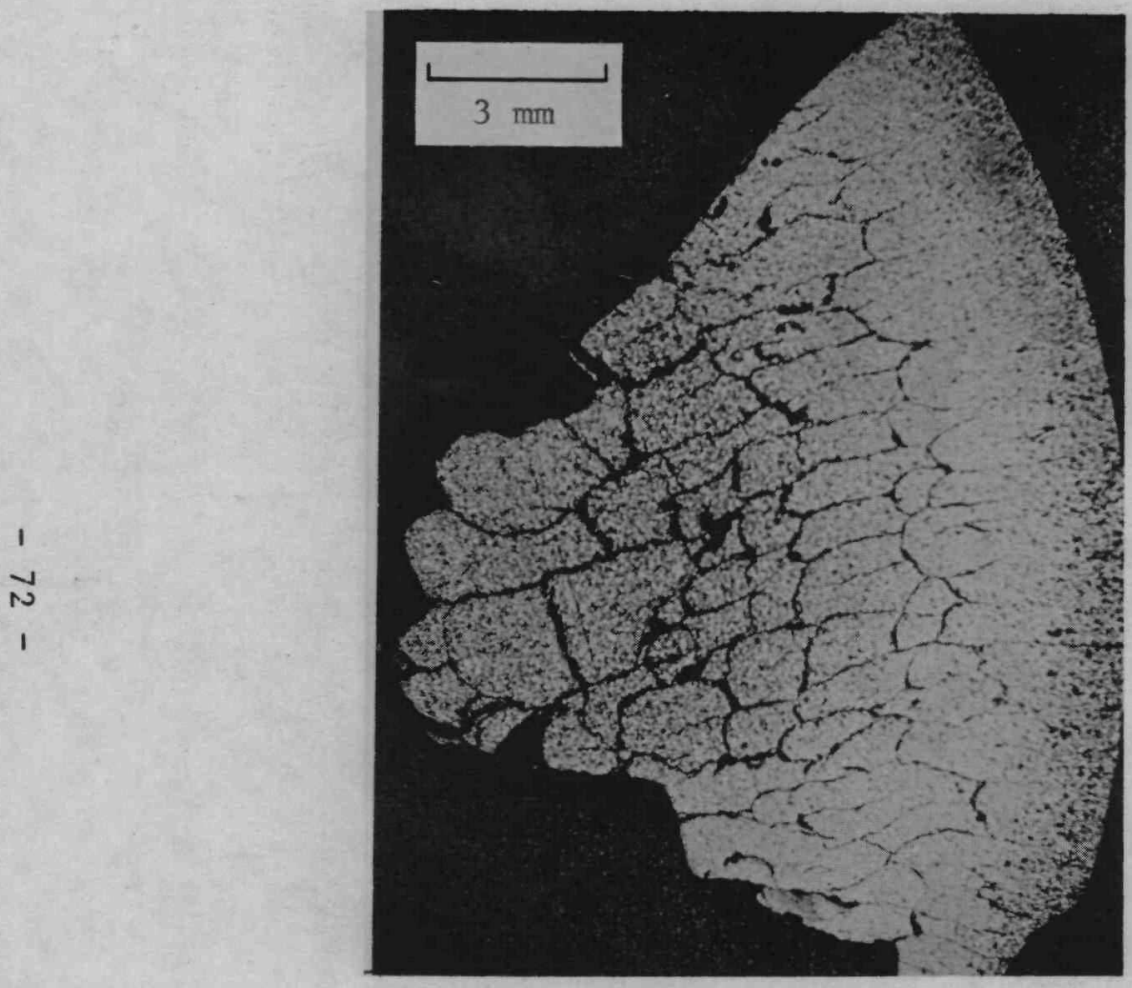

a.

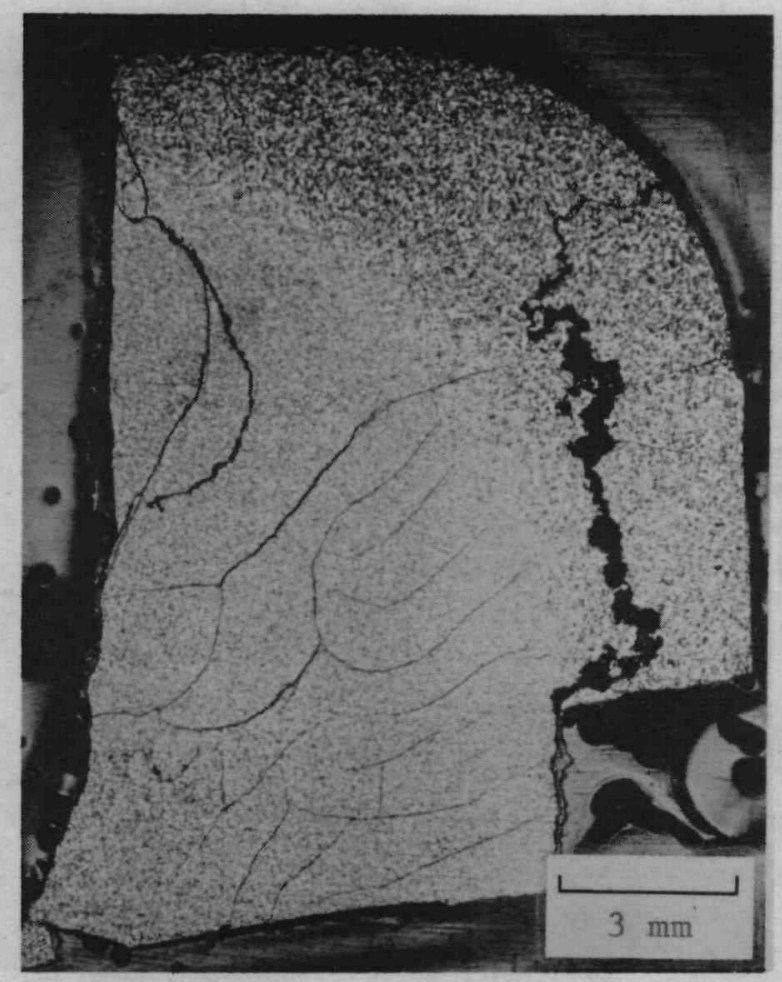

b.

FIGURE 35. Comparison of Microstructures of MHW Sphere 28 (a) and LANL GPHS Pellet (b) 


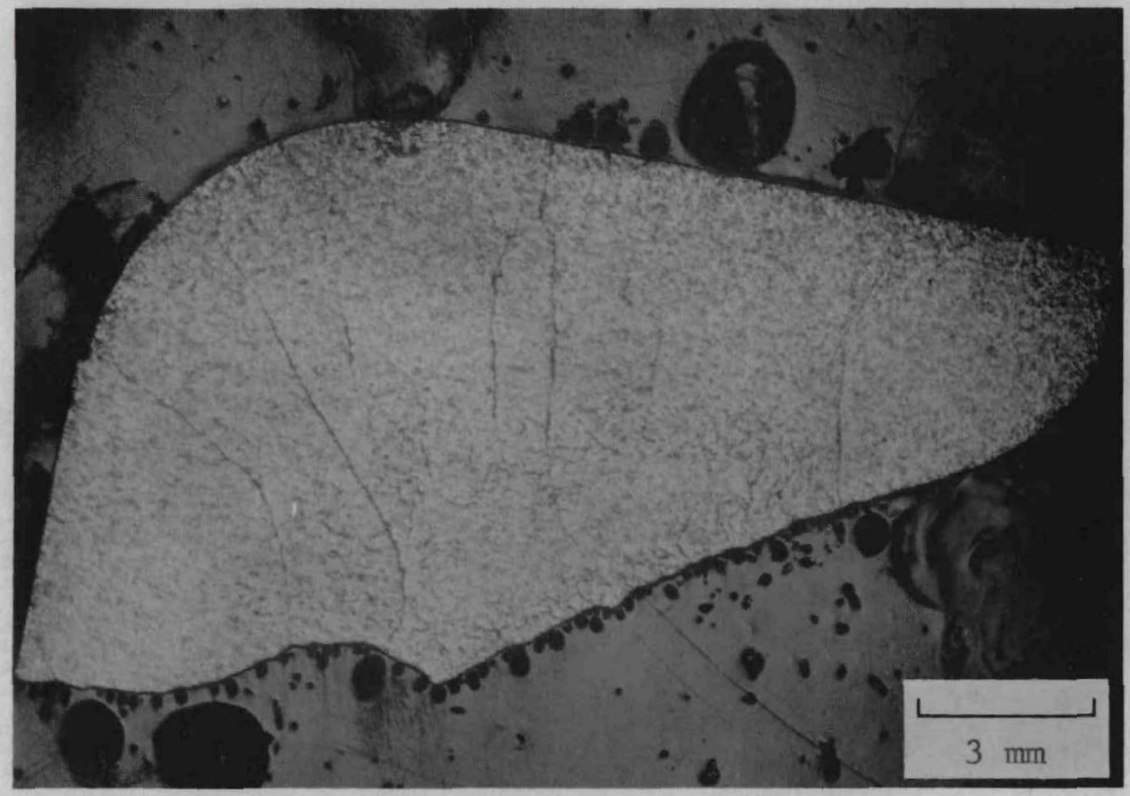

a. Network of Large Cracks

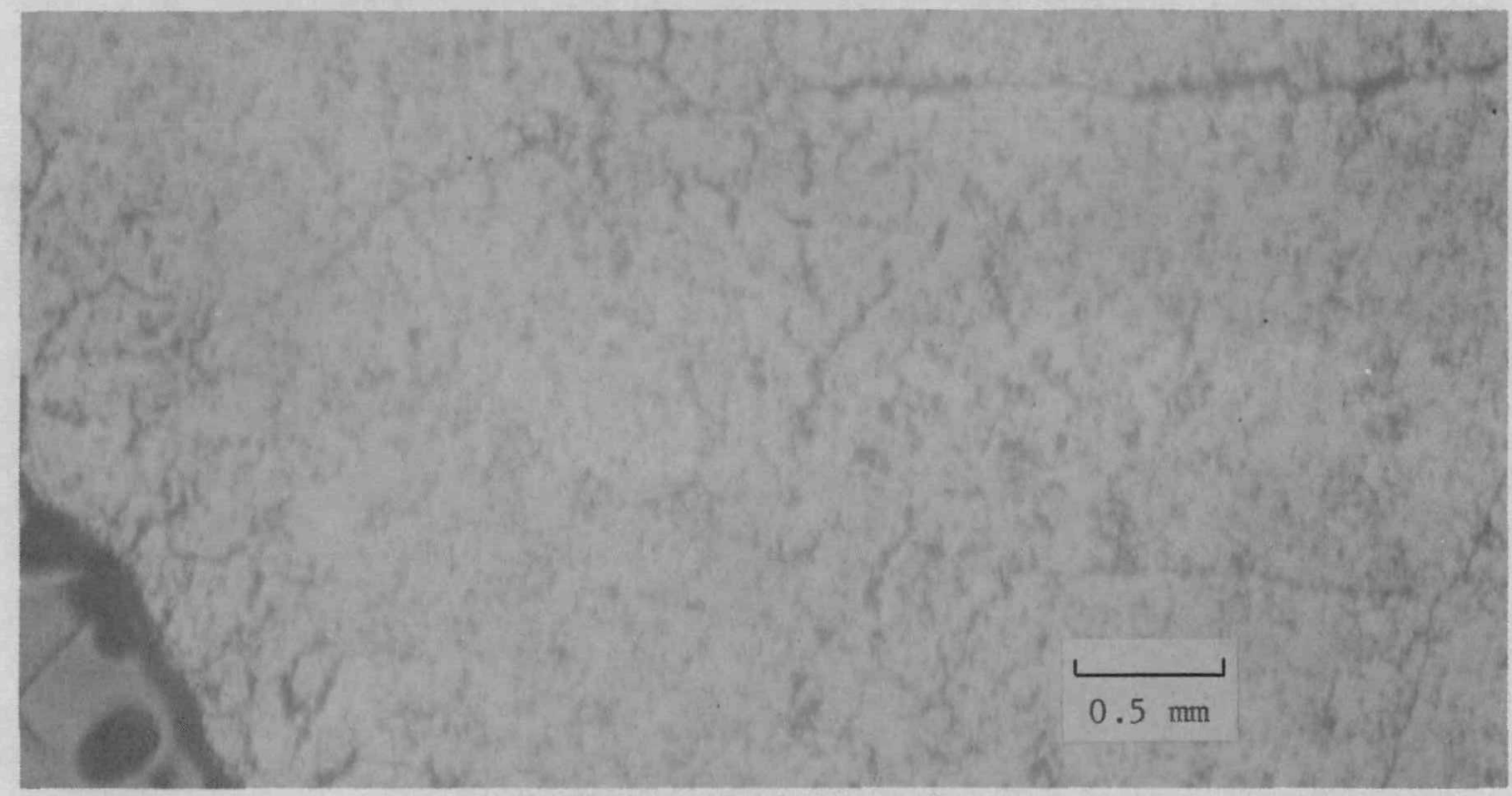

b. Numerous Fine Intershard Cracks

FIGURE 36. Cracking in GPHS Pellet 34, Fabricated in PEF, Using LANL Shards and LANL Hot Pressing Conditions 


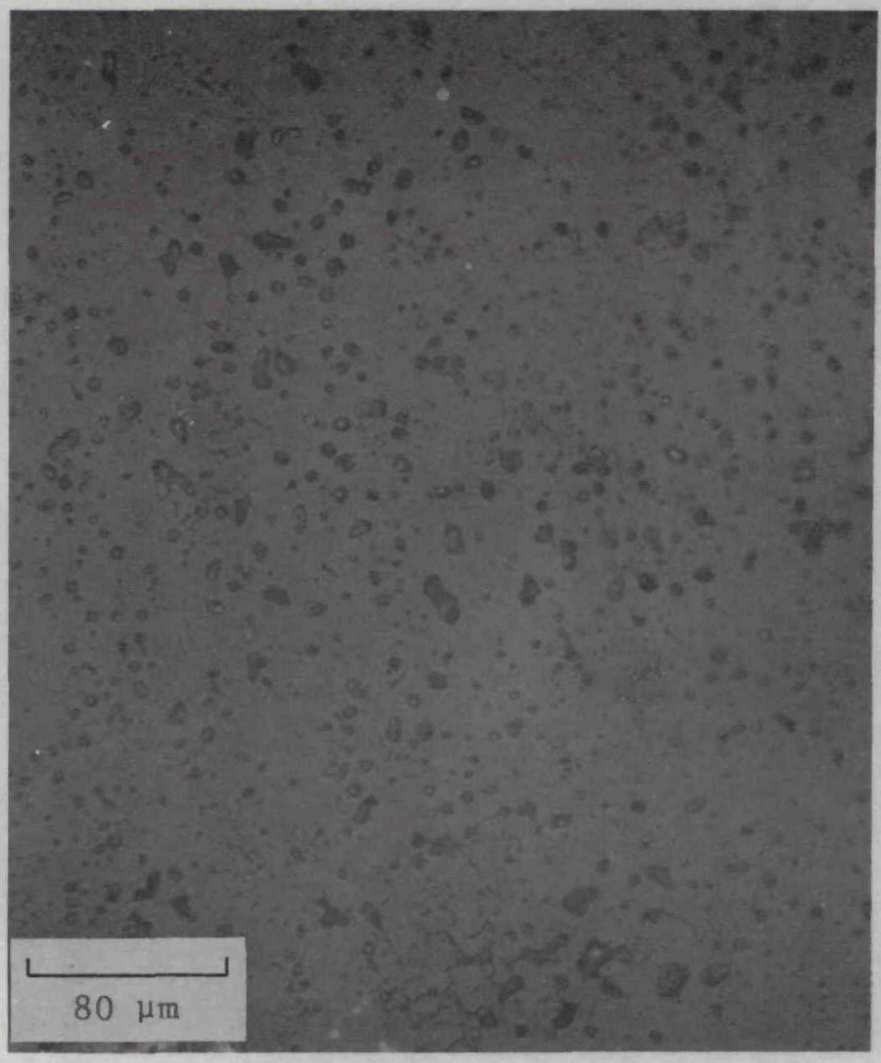

a.

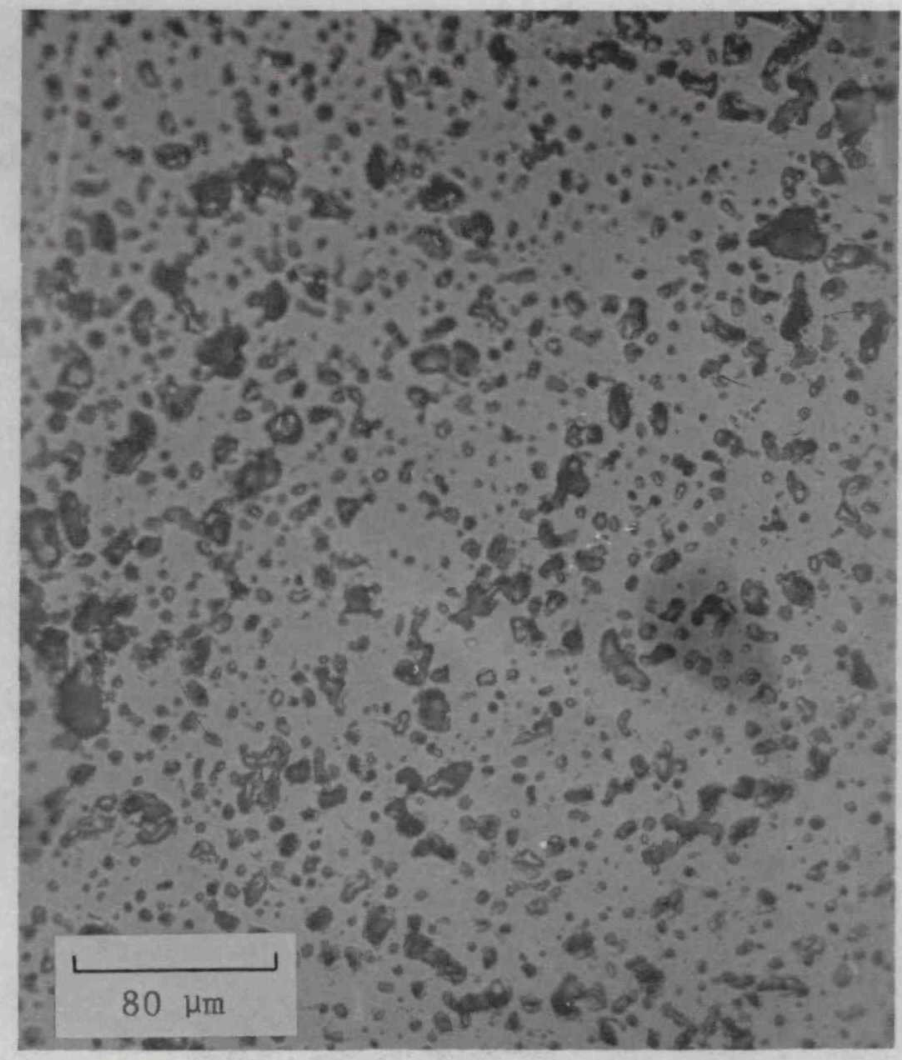

b.

FIGURE 37. Comparison of Porosities of (a) PEF GPHS Pellet 34 and (b) LANL GPHS Pellet 


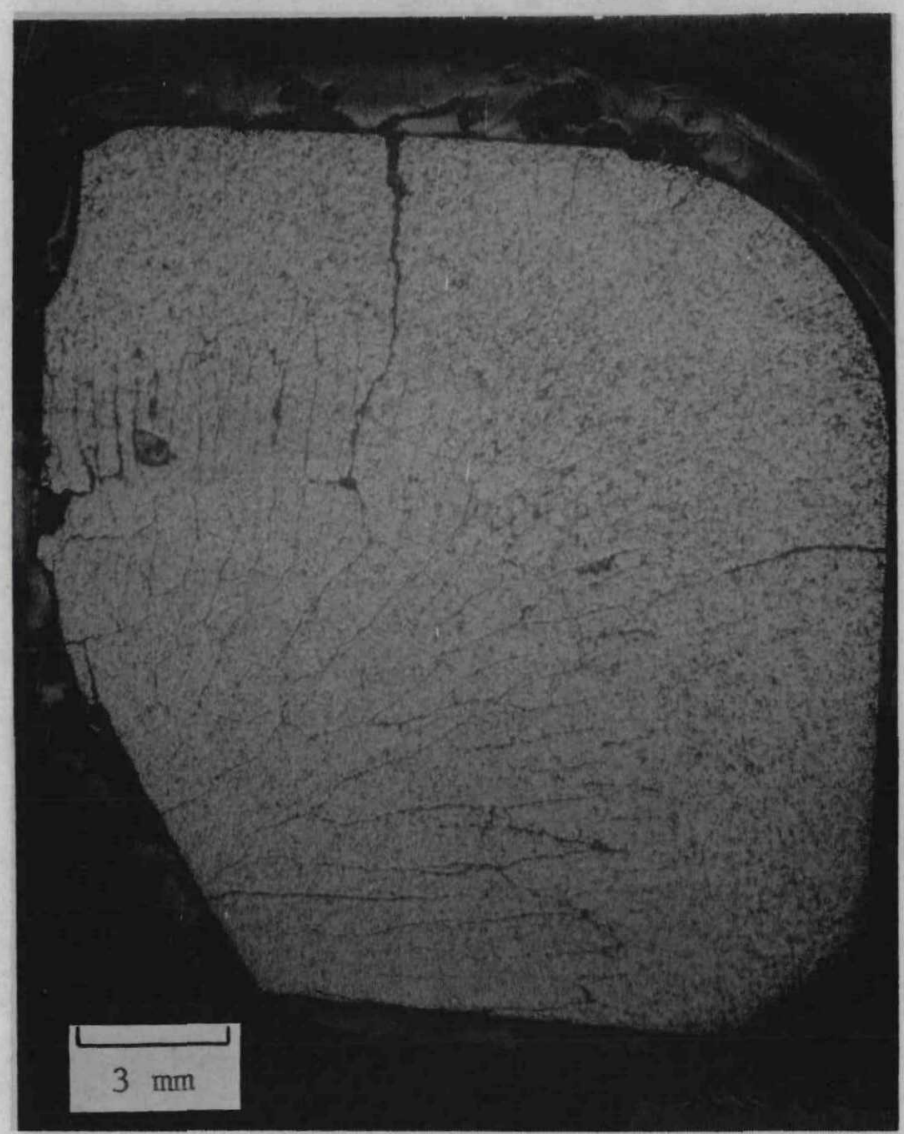

FIGURE 38. Microstructure of PEF Pellet GPHS 41. Fabricated Under Conditions That Represented a Combination of the Most Likely Process Deviations Expected in the PuFF Facility. 


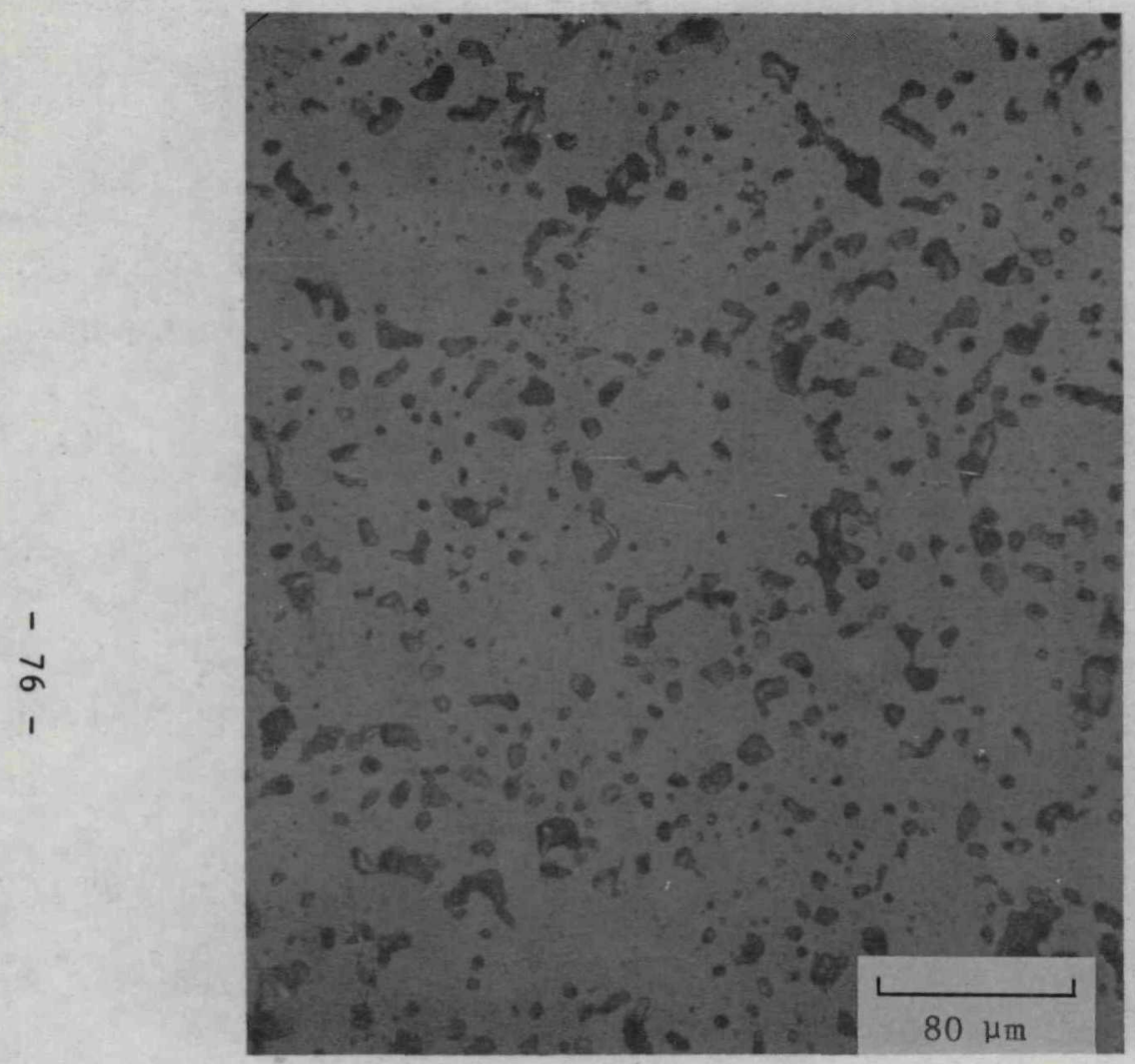

a.

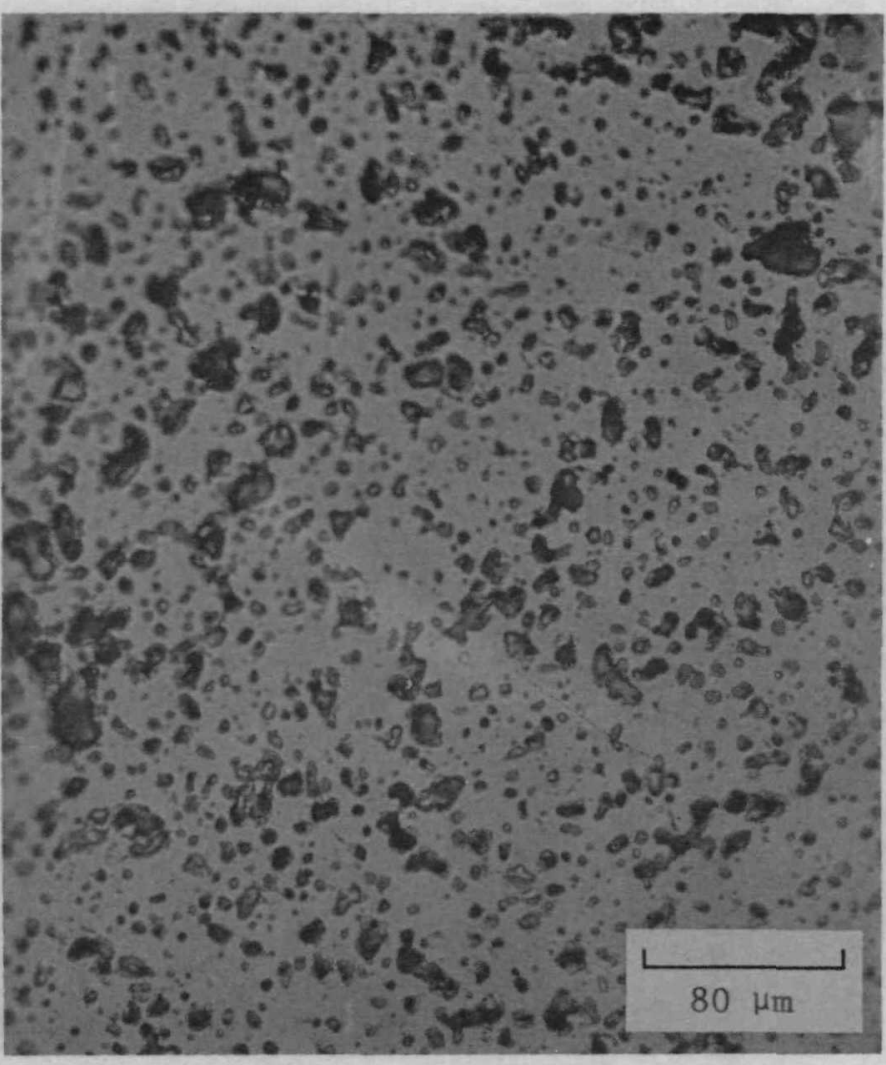

b.

FIGURE 39. Comparison of Porosities of GPHS Pellets (a) PEF GPHS Pellet 41 and (b) LANL Pellet 


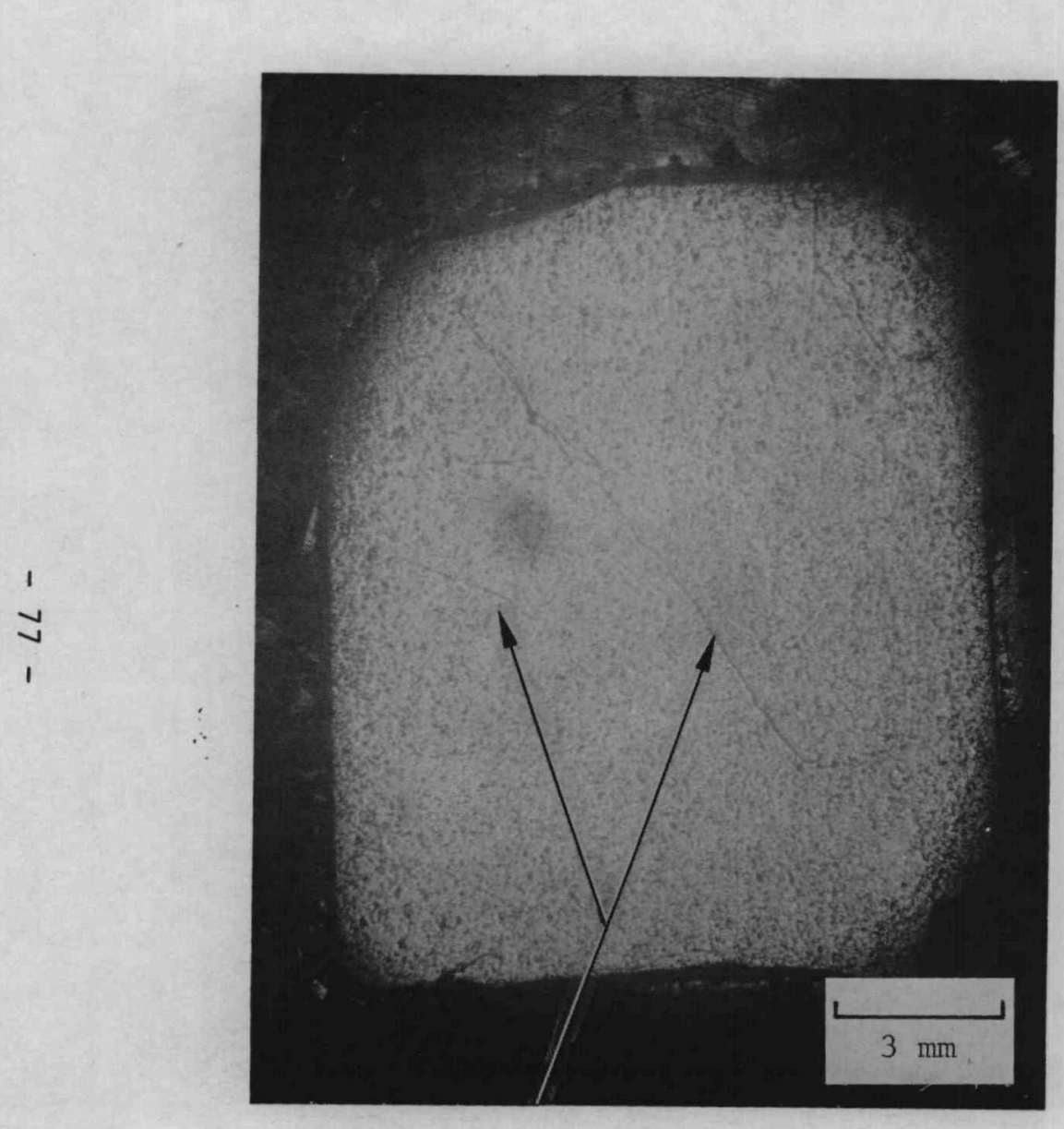

Macrocracks

a. Internal cracks
Microcracks

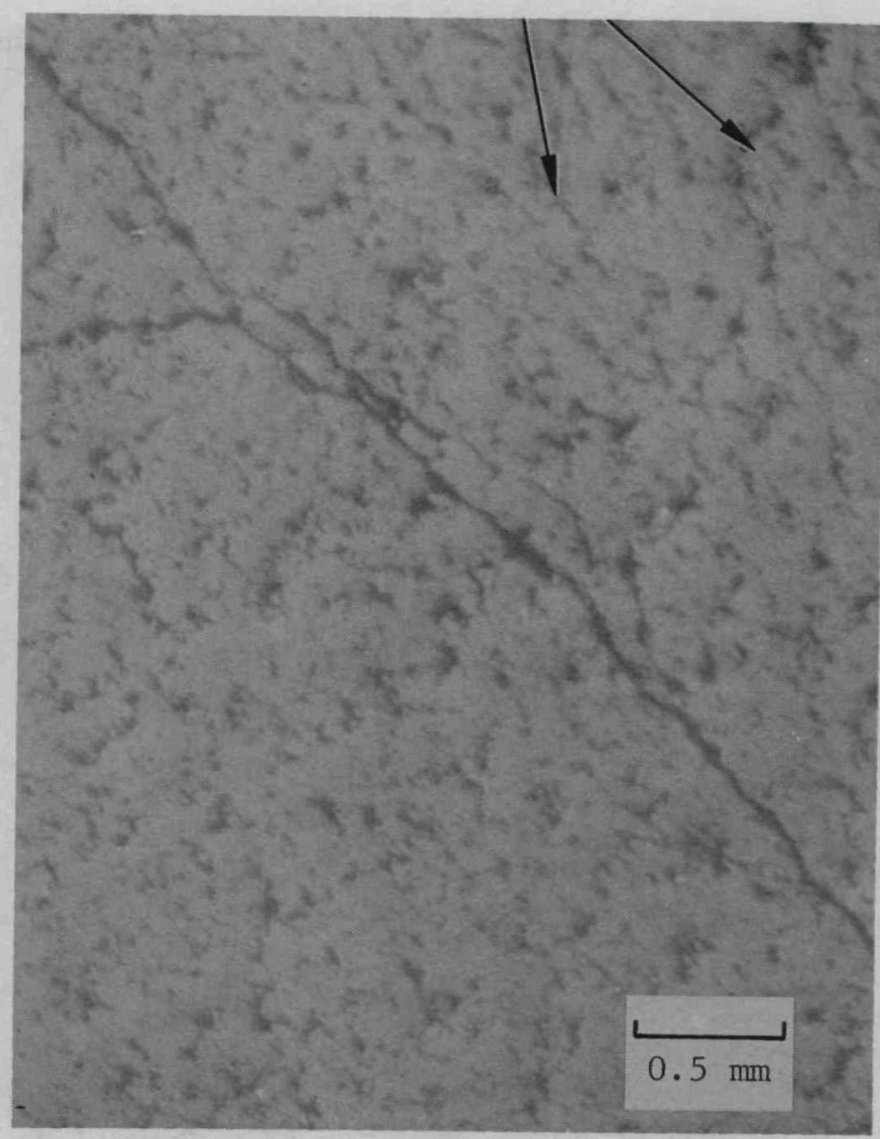

b. Microcracks. Porosity shows some large intershard pores

FIGURE 40. Macrocracks of PEF GPHS Pellet 35. Fabricated in PEF, Using PEF Shards and LANL Hot-Pressing Conditions. 


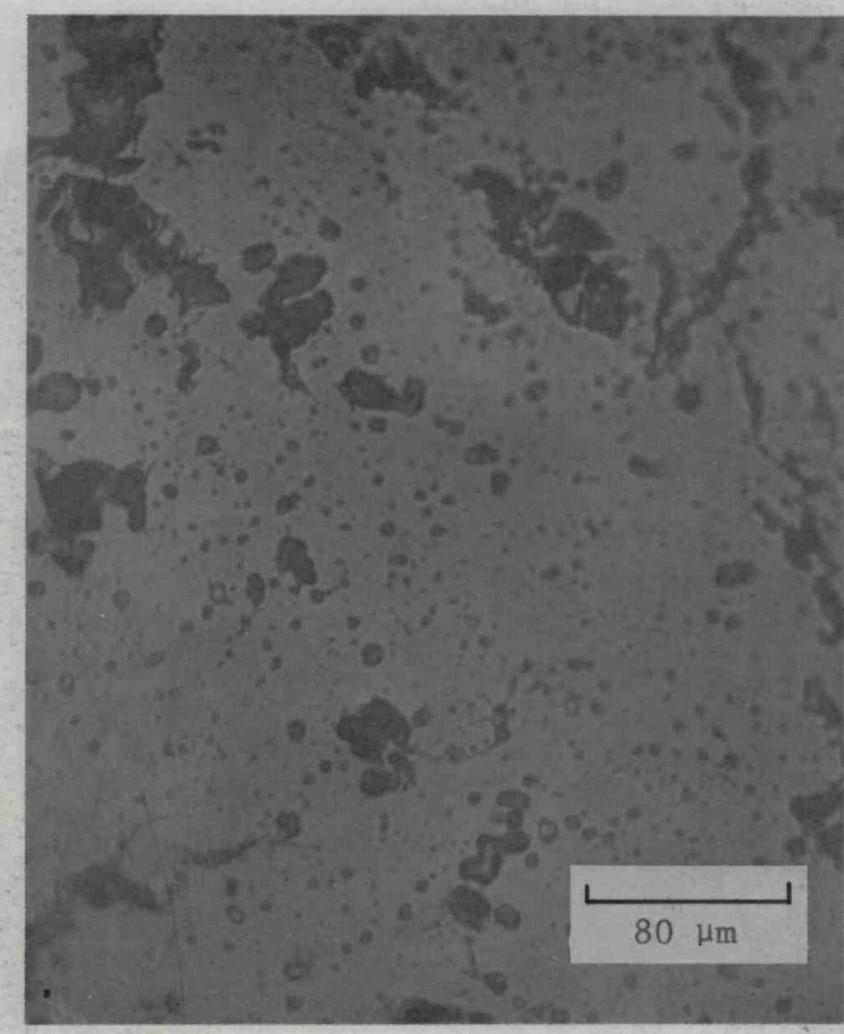

c. Microstructure of PEF GPHS Pellet 35

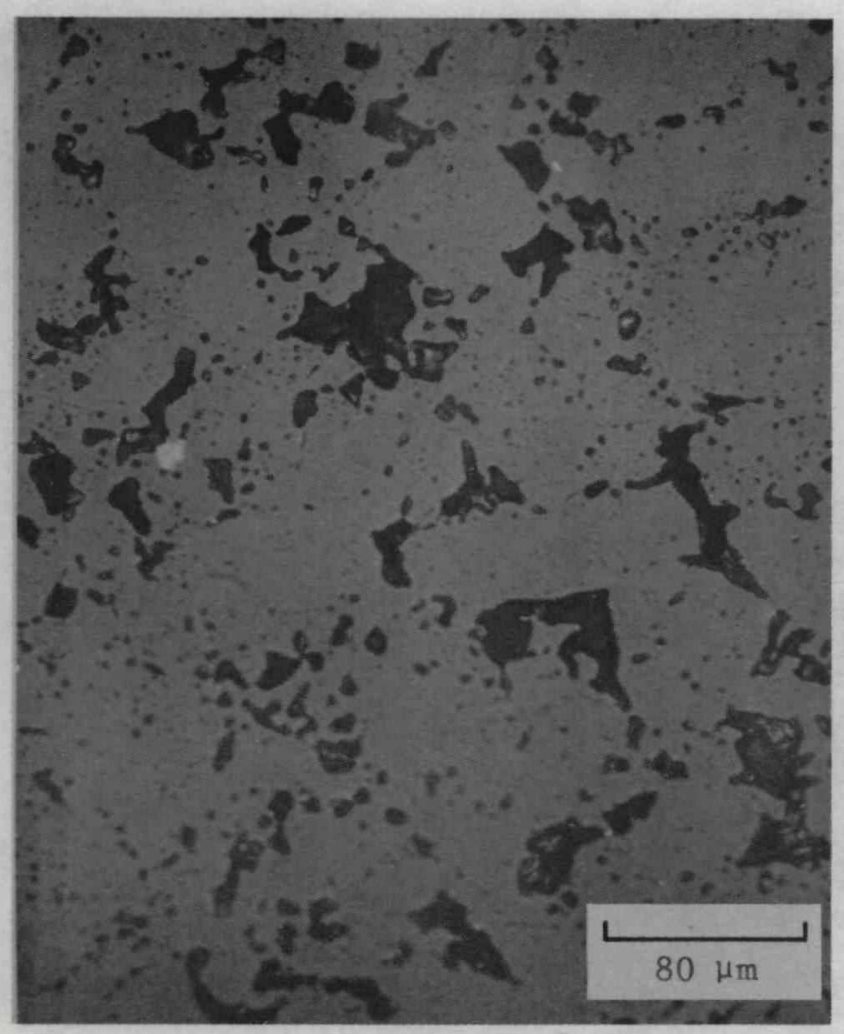

d. Microstructure of PEF GPHS Pellet 30, Centerline

FIGURE 40. Cont inued 


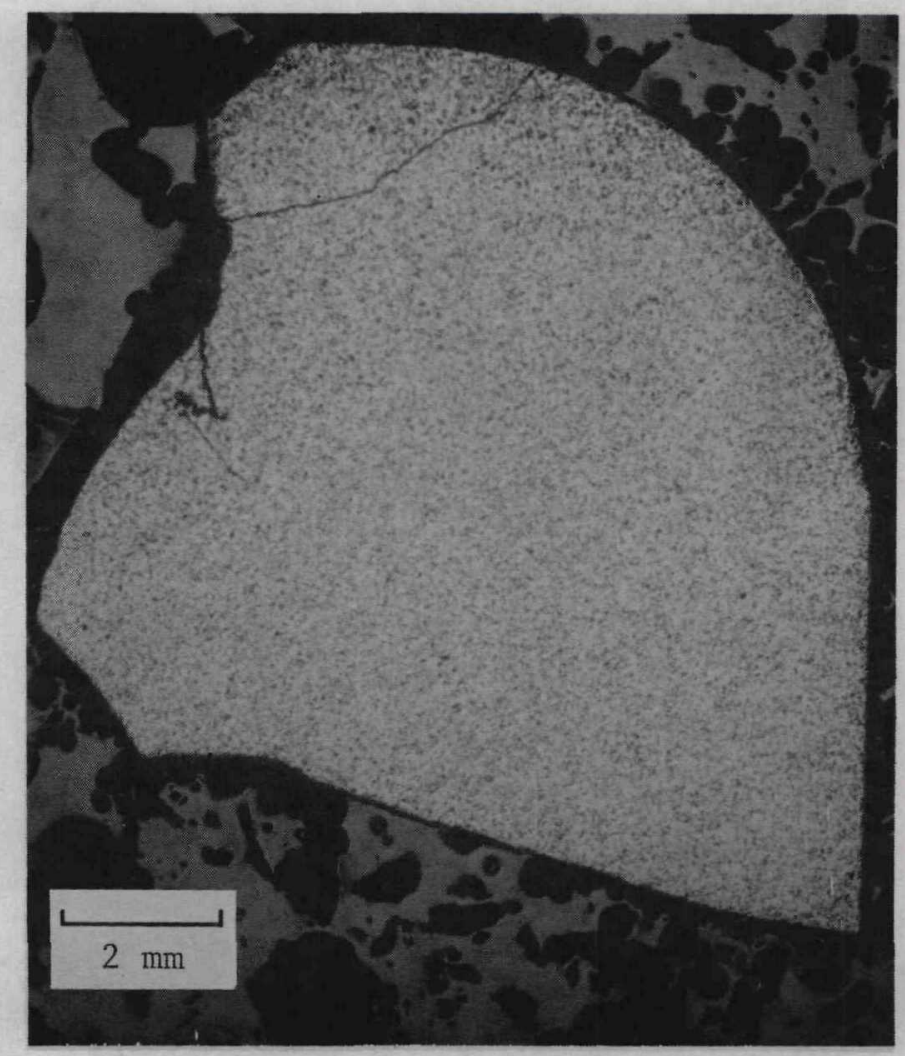

a. Paucity of Internal Cracking

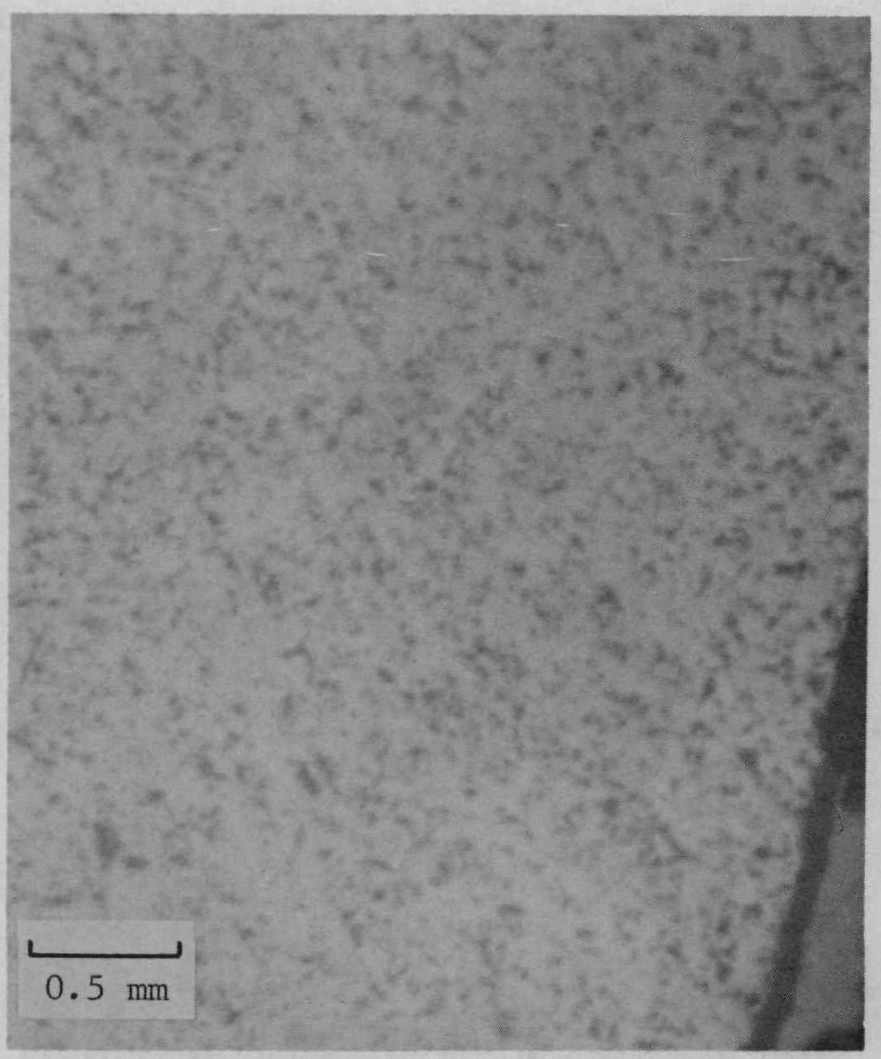

b. More Typical of PEF GPHS Pellet MIcrostructures. No microcracks

FIGURE 41. PEF GPHS Pellet 36 Fabricated in PEF using LANL Shards and SRL Hot Pressing Conditions 


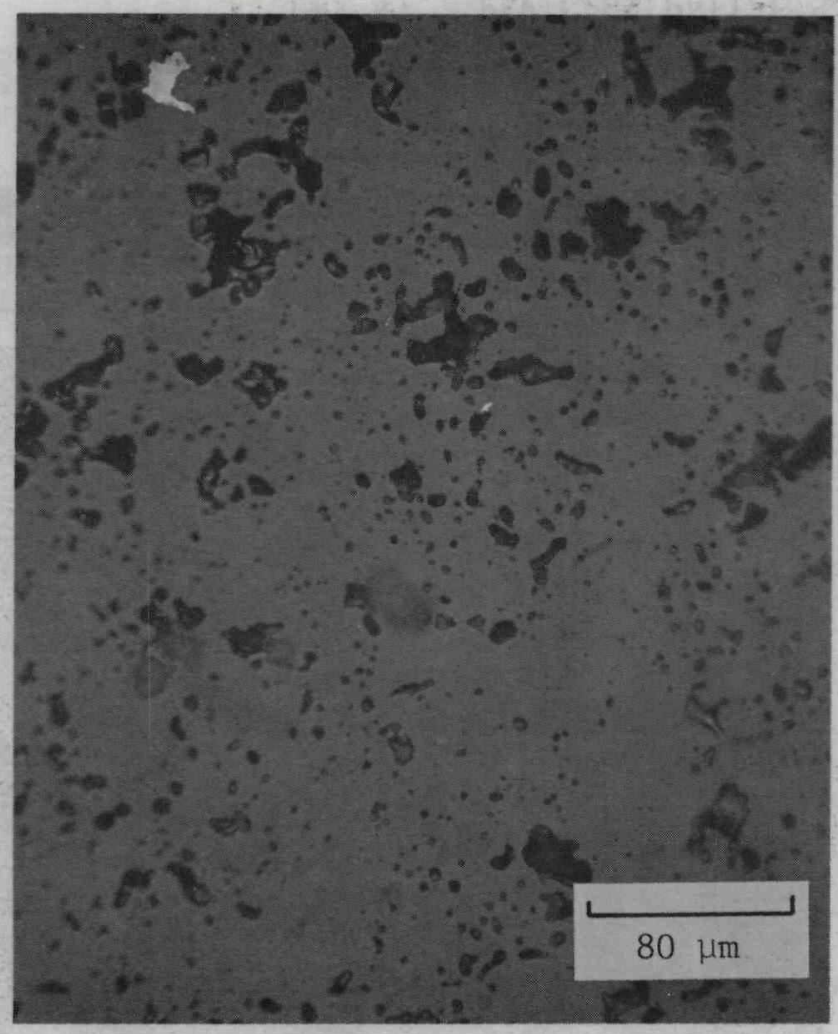

c. Porosity Approaching Typical Intershard Structure

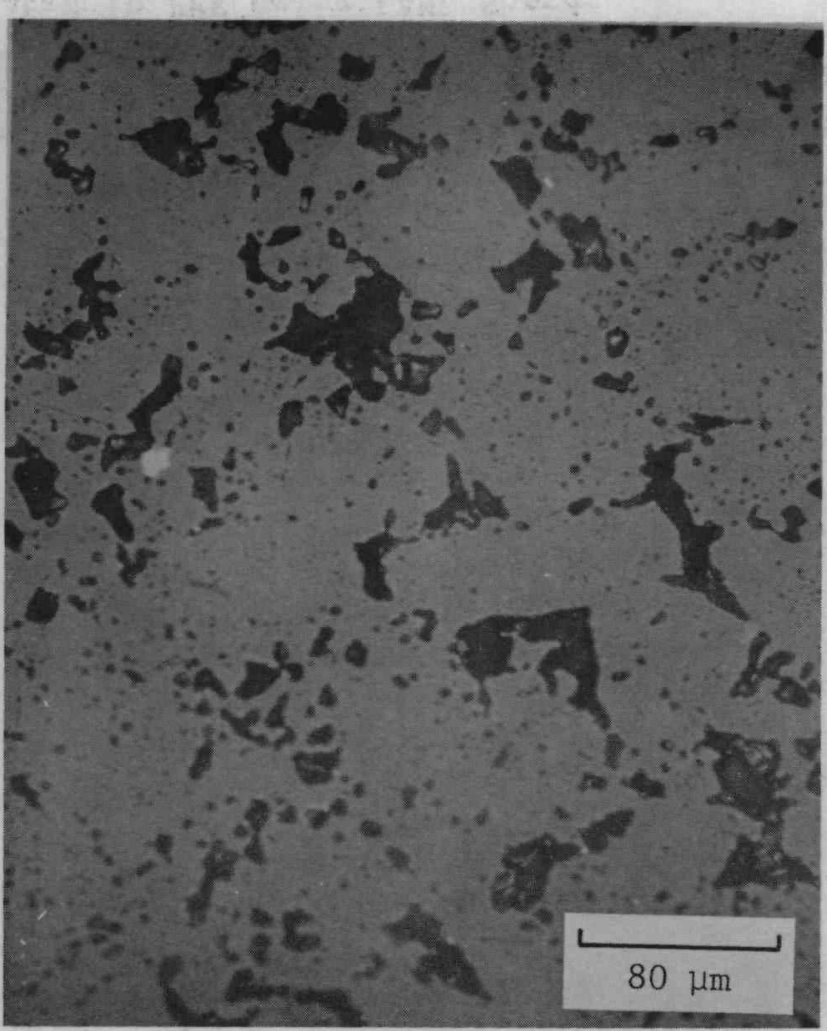

d. Microstructure of PEF GPHS Pellet 30 (Centerline)

FIGURE 41. Continued 


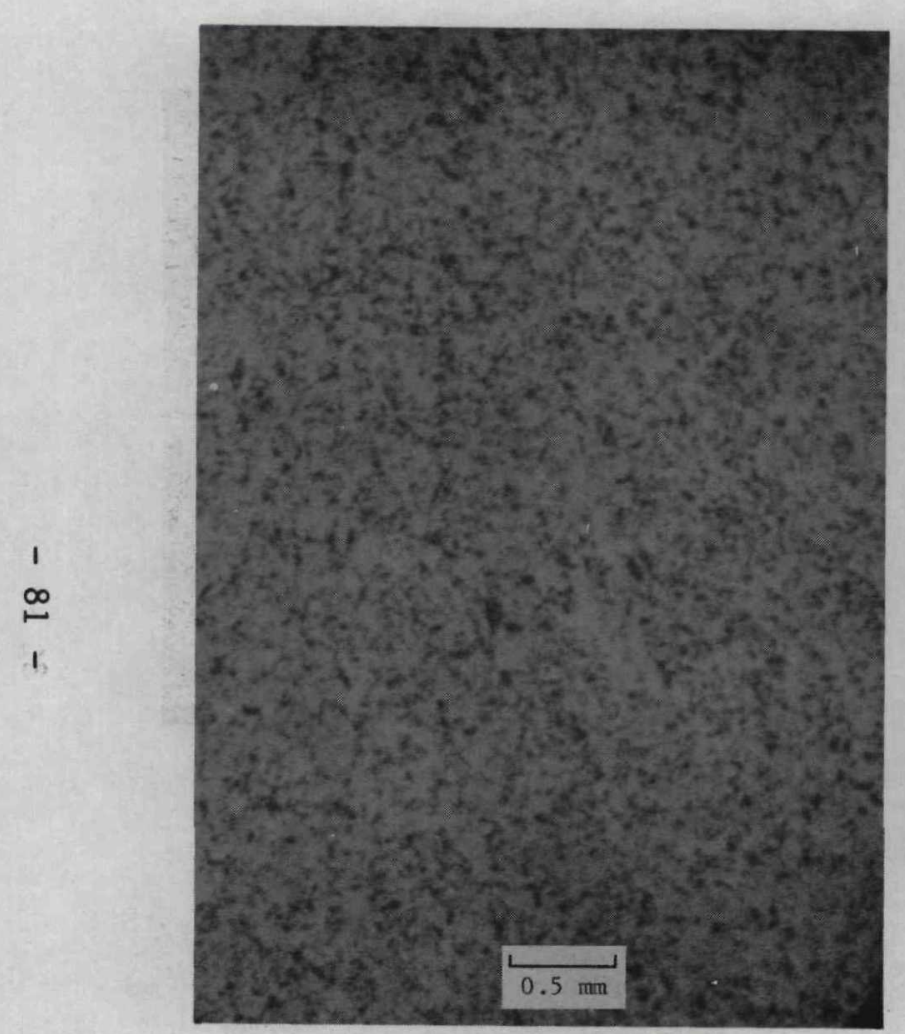

a. PEF GPHS Pellet 36; LANL Shards, PEF Hot Pressing Conditions
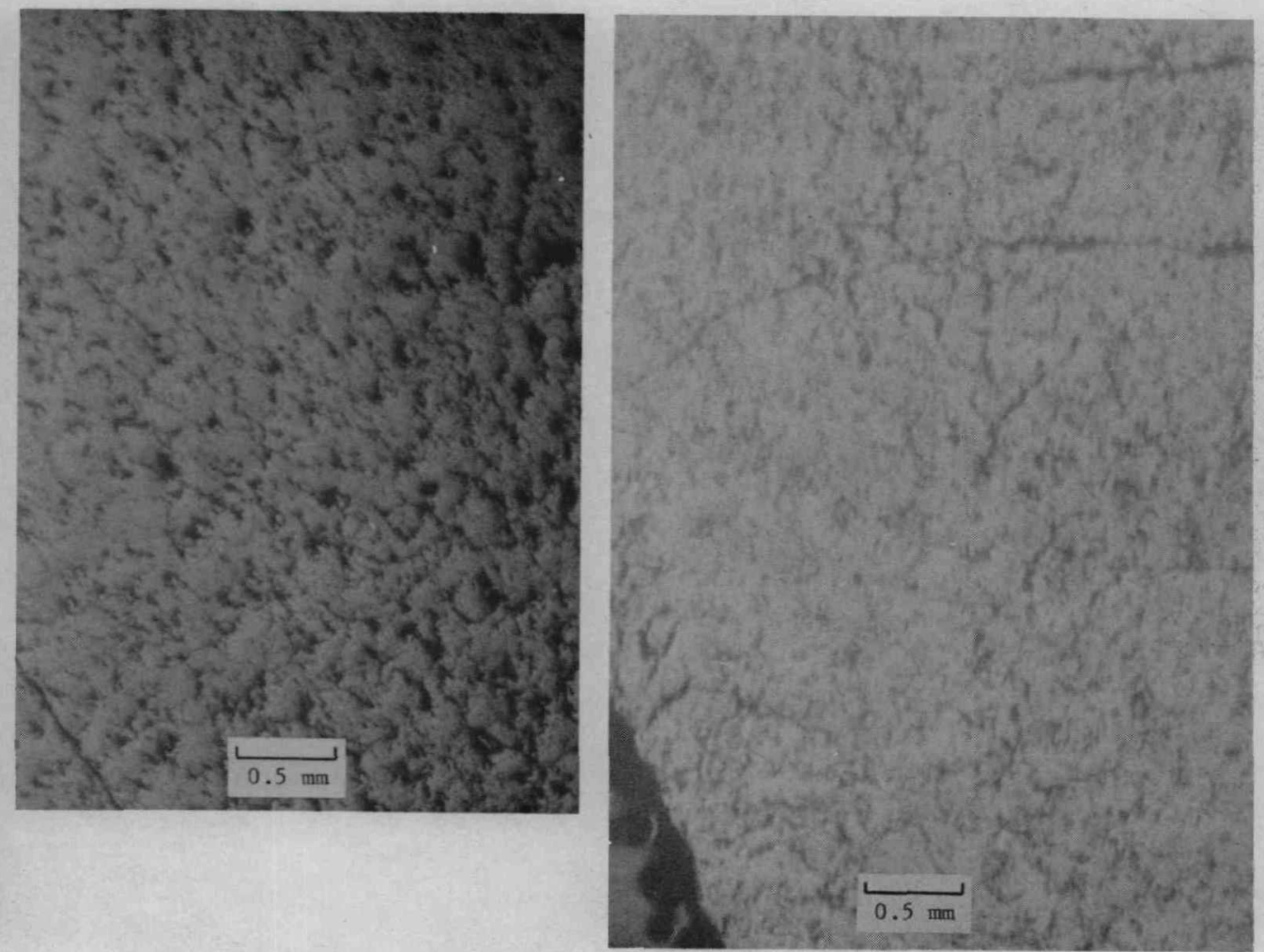

c. PEF GPHS Pellet 34;

LANL Shards and LANL Hot Pressing Conditions

FIGURE 42. Progressive Cracking Tendency Using Different

Combinations of PEF and LANL Shards and Hot Pressing

Conditions 

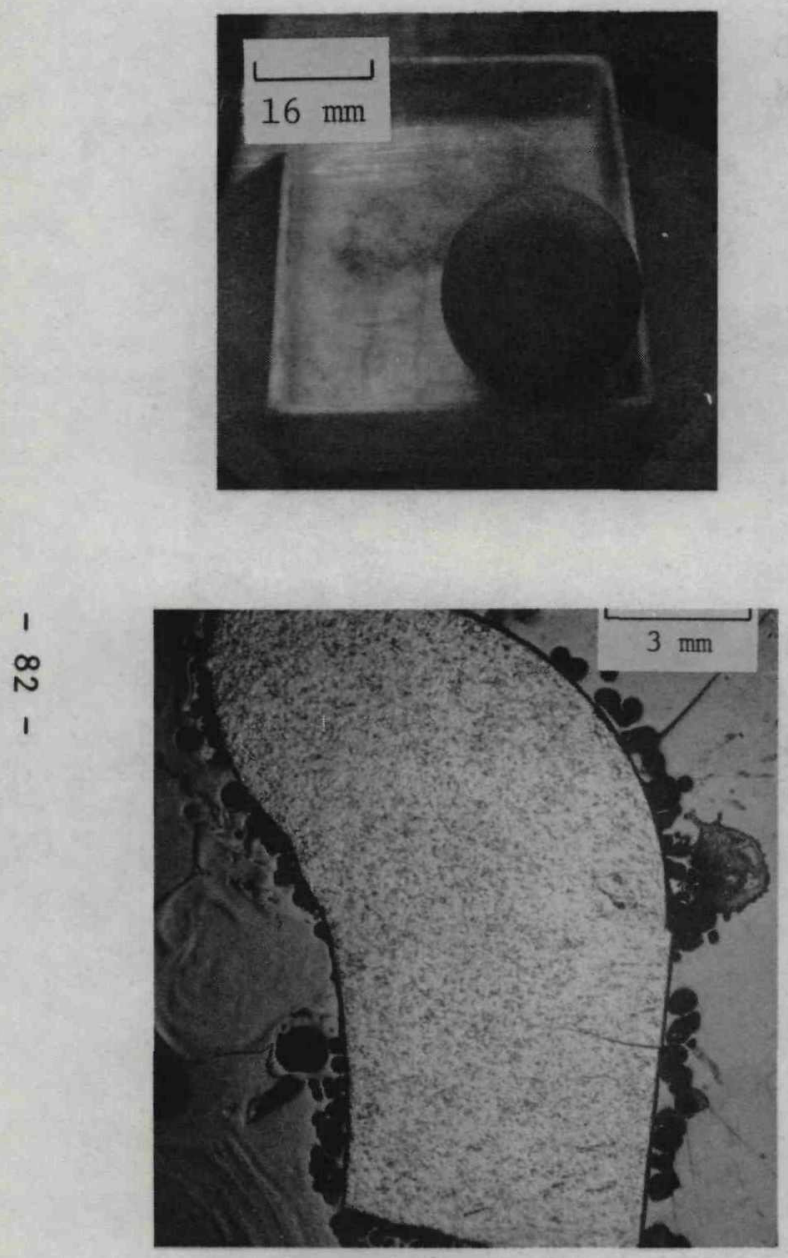

a. PEF GPHS Pellet 17

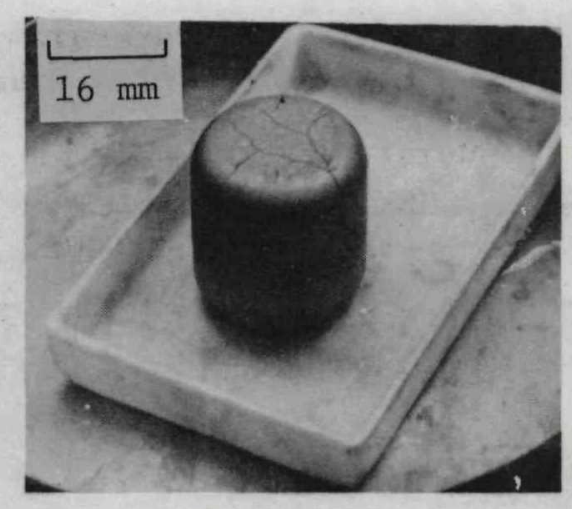

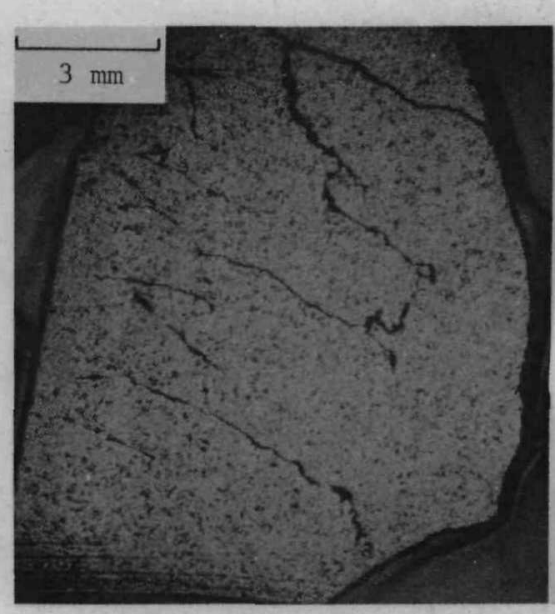

b. PuFF GPHS Pellet 22

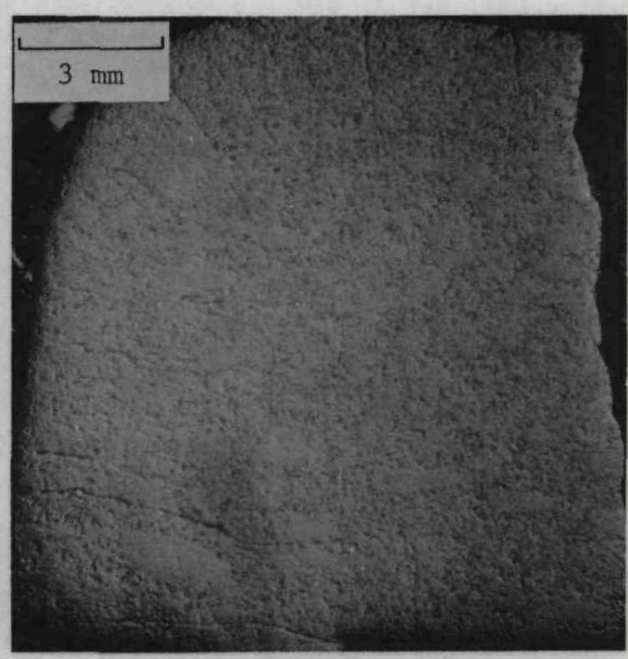

c. PuFF GPHS Pellet 54

FIGURE 43. Comparison of Macrocracking in (1) PEF Centerline Pellet, (b) Early PuFF GPHS Pellet, and (c) Later PuFF GPHS Pellet 

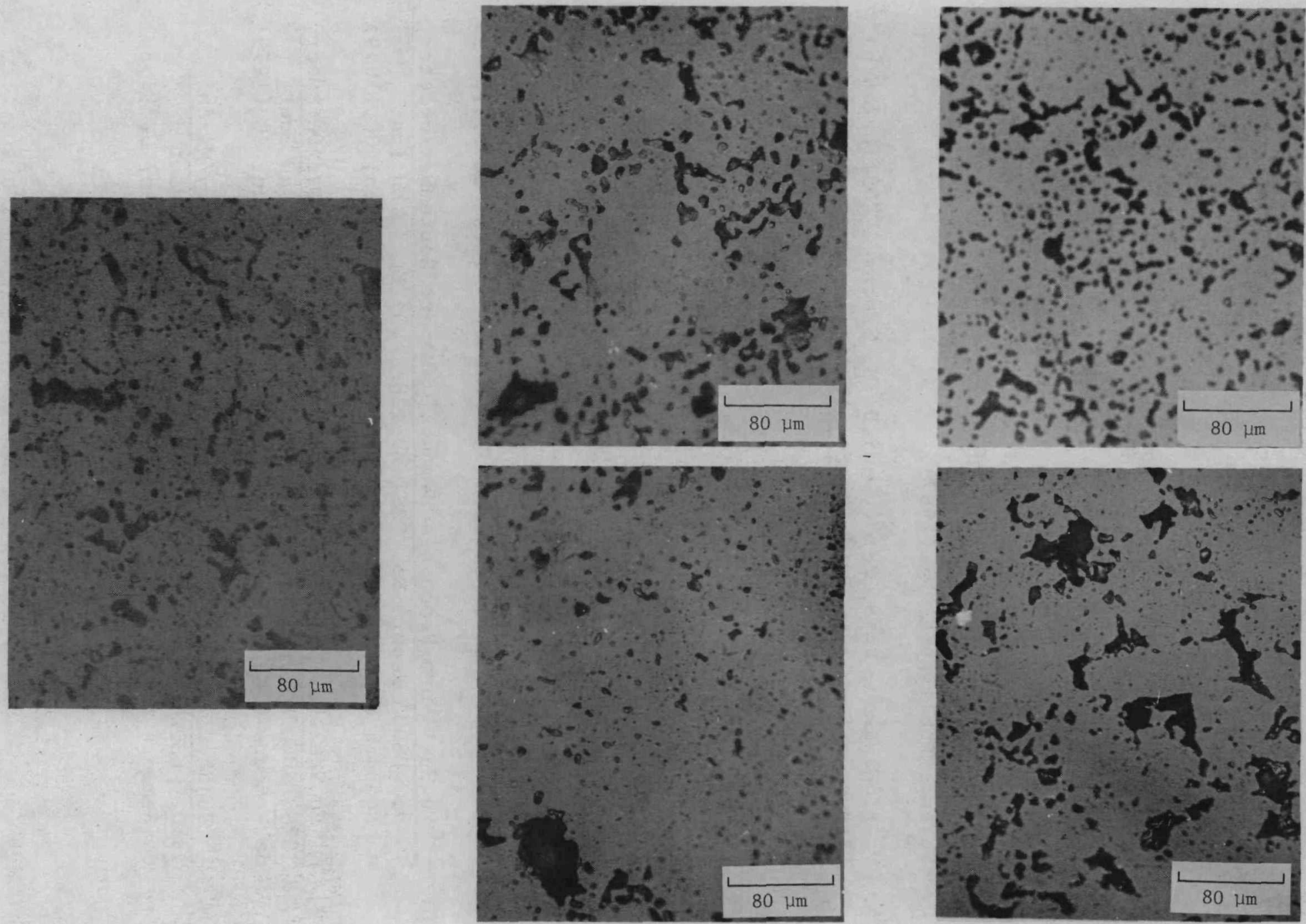

FIGURE 44. Comparison of Porosities of (a) PuFF GPHS Pellet 22, (b) PuFF GPHS Pellet 54, and (c) PEF Centerline GPHS Pellets 17 and 30. 


\section{REFERENCES}

1. Savannah River Laboratory Monthly Report, ${ }^{238}$ Pu Fuel Form Processes, September 1977. USDOE Report No. DPST-77-128-9, E. I. du Pont de Nemours \& Co., Savannah River Laboratory, Aiken, SC.

2. ${ }^{238} \mathrm{Pu}$ Fuel Form Processes Bimonthly Report July/August, 1979 . USDOE Report No. DPST-79-128-7/8, E. I. du Pont de Nemours \& Co., Savannah River Laboratory, Aiken, SC (1979).

3. B. Francois and W. D. Kingery. "The Sintering of Crystalline Oxides, II. Densification and Microstructure Development in $\mathrm{UO}_{2}$." pp. 499-526 in Sintering and Related Phenomenon, Kuczinski, Hooten, and Gibbons, Eds., Gordon and Breach, Science Publishers, NY (1967).

4. V. P. Gladkov, V. S. Zotov, and D. M. Skorov. "Diffusion of Carbon in Beryllium Oxide." Soviet Atomic Energy, 34(4), 360 (1973).

5. $238 \mathrm{Pu}$ Fuel Form Processes Bimonthly Report November/December, 1978. USDOE Report No. DPST-78-128-11/12. E. I. du Pont de Nemours \& Co., Savannah River Laboratory, Aiken, SC (1978).

6. ${ }^{238} \mathrm{Pu}$ Fuel Form Processes Bimonthly Report May/June, 1979. USDOE Report No. DPST-79-128-5/6, E. I. du Pont de Nemours \& Co., Savannah River Laboratory, Aiken, SC (1979).

7. ${ }^{238} \mathrm{Pu}$ Fuel Form Processes Bimonth1y Report September/October, 1978. USDOE Report No. DPST-78-128-9/10, E. I. du Pont de Nemours \& Co., Savannah River Laboratory, Aiken, SC (1978).

8. ${ }^{238} \mathrm{Pu}$ Fuel Form Processes Bimonthly Report September/October, 1979. USDOE Report No. DPST-79-128-9/10, E. I. du Pont de Nemours \& Co., Savannah River Laboratory, Aiken, SC (1979).

9. ${ }^{238} \mathrm{Pu}$ Fuel Form Processes Bimonthly Report November/December, 1979. USDOE Report No. DPST-79-128-11/12, E. I. du Pont

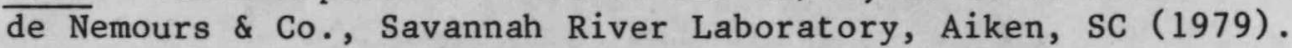

10. $238 \mathrm{Pu}$ Fuel Form Processes Quarterly Report January/March, 1980. USDOE Report No. DPST-80-128-1, E. I. du Pont de Nemours \& Co., Savannah River Laboratory, Aiken, SC (1980). 
REFERENCES Contd.

11. $238 \mathrm{Pu}$ Fuel Form Processes Quarterly Report April/June, 1980.

USDOE Report No. DPST-80-128-2, E. I. du Pont de Nemours \& Co., Savannah River Laboratory, Aiken, SC (1980).

12. $238 \mathrm{Pu}$ Fuel Form Processes Quarterly Report January/March, 1980. USDOE Report No. DPST-81-128-1, E. I. du Pont de.Nemours \& Co., Savannah River Laboratory, Aiken, SC (1981). 
DISTRIBUTION

Copy No.

1 F. E. Coffman, Acting Director, Office of Coordination and Special Projects, U. S. Department of Energy

2 B. J. Rock, Acting Director, Space Systems, U. S. Department of Energy

3 J. J. Lombardo, Space Systems, U. S. Department of Energy

4 G. Bennett, Space Systems, U. S. Department of Energy

5 H. Rover, Asst. Secretary for Defense Programs, U. S. Department of Energy

6 A. W. Whiteman, Albuquerque Operations Office

7 D. L. Krenz, Albuquerque Operations office

8 H. N. Hill, Manager, Dayton Area Office

9 R. D. Baker, CMB, DO, Los Alamo National Laboratory

10 S. E. Bronisz, CMB-5, MS -730, Los Alamo National Laboratory

11 W. Stark, Los Alamo National Laboratory

12 R. Behrens, Los Alamo National Laboratory

13 W. T. Cave, Monsanto Research Corporation

14 B. R. Kogenge, Monsanto Research Corporation

15 Technical Library, Sandra National Laboratories, Albuquerque

16 T. J. Young, Sandra National Laboratories, Albuquerque

17 W. Whitmore, General Electric Company, Philadelphia

18 R. H. Cooper, Oak Ridge National Laboratory

19 W. Pardue, Battelle Memorial Institute, Columbus, Ohio

20-25 Savannah River Operations Office, DOE

26-63 Savannah River Laboratory, TIS Files

64-65 Technical Information Center, Oak Ridge, TN

66 G. Linkous, Teledyne Energy Systems, Timonium, MD 